\title{
Do winds control the confluence of subtropical and subantarctic surface waters east of New Zealand?
}

by

Denise Fernandez

\author{
Submitted in fulfilment \\ of the requirements \\ for the degree of \\ Master of Science \\ in Geophysics
}

School of Geography, Environment and Earth Sciences

Victoria University of Wellington, New Zealand

April 2012 



\begin{abstract}
The confluence region east of New Zealand is one of only a few places in the world where the Antarctic Circumpolar Current meets the strong southwardflowing boundary current of a subtropical gyre. The convergence of subtropical and subantarctic water creates strong fronts. The fronts have clear signatures in height and temperature that make them appropriate places to investigate ocean/climate variability. The location and extent of the New Zealand confluence should respond to changes in large-scale wind patterns, as changes in South Pacific currents have been linked to wind shifts. However, recent studies have shown that highly energetic eddies, local winds, and the bathymetry may be significant controls of currents and associated fronts. This thesis investigates the temporal and spatial variability of the confluence and evaluates its response to variability in South Pacific winds.

Analysis of the 18-year time series, from January 1993 to December 2010, of sea surface height mapped from satellite altimetry was used to investigate the location and extent of fronts and the eddy activity and relate these to the wind forcing. Wind stress data were used with the Island Rule to estimate the winddriven transport of the western boundary currents that feed the confluence. In addition, the climate modes Southern Annular Mode (SAM) and Southern Oscillation Index (SOI) were used to examine the influence of the principal modes of atmospheric variability. Time series of the local wind stress curl and local climate indices were calculated and compared to the intensity of the confluence to test any influence of local forcing. In addition, bathymetric effects were investigated by evaluating evidence for preferred front locations near topographic features.
\end{abstract}

Sea level anomalies in the confluence region are increasing at $3.4 \mathrm{~cm}$ decade ${ }^{-1}$. The sea surface height gradients and the eddy kinetic energy are also increasing at a rate of $0.01 \mathrm{~cm} \mathrm{~km}^{-1}$ and $23 \mathrm{~cm}^{2} \mathrm{~s}^{-2}$ per decade respectively, indicating 
an intensification of the fronts and eddy activity in the confluence. There is a high and significant correlation $(r=0.84)$ between the front and eddy signals reflecting baroclinic instabilities inherent in the fronts. Difference in transport anomalies across the confluence derived from the Island Rule are also increasing at $8.8 \mathrm{~Sv}$ decade $^{-1}$. SAM and SOI indices showed little or no correspondence with variability in the confluence intensity and eddy kinetic energy, and the same lack of correspondence was observed in local winds and local indices. While these results suggest a connection between the variability in the confluence and South Pacific winds, there is a preferential location of the strongest fronts and eddy activity northeast of Bounty Plateau and Bollons Seamount, indicating some bathymetric control.

The correspondence between basin-scale winds and sea surface height gradients in the confluence region indicates that if wind stress continues to increase, as current trends predict, front intensity and eddy activity will also increase, enhancing the transfer of heat and nutrients that, respectively, influence energy transfer and biological productivity. 


\section{Acknowledgements}

First of all, I would like to thank my supervisors Melissa Bowen and Lionel Carter, for giving me the opportunity to do my master thesis in such an interesting topic in physical oceanography, I could not ask for better guidance and support. I want to thank Melissa for being so generous with her time, her knowledge, and for keeping me excited about this project from day one until the end. A big thanks to Lionel for his contagious enthusiasm for the ocean sciences, for challenging me and helping me see the big picture beyond numbers, time series and trends. Both have been an inspiration to me, and I feel privileged to have studied under their supervision.

Thanks to Victoria University of Wellington for the financial support through the scholarships I received during the last two years. I am also very grateful to the Geosciences Society of New Zealand for selecting me as a recipient of the S.J. Hastie Scholarship 2010.

It has been a pleasure to be part of the Antarctic Research Centre family, I am going to miss lunch time conversations where topics included science, baking, travel stories and Argentinian football.

A special thanks to Andrew Mellanby for computer and software support, and to Euan Smith, Carolin Boese and Daniel Mortara for helping me to climb the first and steep steps of software coding. I would like to thank Paulo Calil, Mike Williams, and Helen Bostock for comments that helped to improve this research. I gratefully acknowledge Brett Mullan from the National Institute of Water and Atmospheric Research for providing wind data used in this work.

I am indebted to Martha Savage who gave me the opportunity to develop my skills as a research assistant being an undergraduate student and for getting me involved in the New Zealand Ocean Bottom Seismic Project cruise on the RV Roger Revelle in 2010. A huge thanks must also go to Helen Bostock for taking me onboard of the Solander Through Voyage to the Southern Ocean on 
the RV Tangaroa in 2011. I thoroughly enjoyed working at sea with amazing and professional crews and I feel very proud to have had contributed to these projects.

It has been a pleasure to spend time with such a great group of people who provided laughs, cookies, ice-cream afternoons and an ear when one most needed it, so I thank Aitana, Brook, Carolin, Karen, Kathi, Katrina, Laura, Lloyd, Richard, Sanne, Sapi, and Susi for their friendship.

Finally, I would like to thank my husband Daniel, for his love, endless encouragement, and support in all my pursuits. 


\section{Contents}

Abstract

Acknowledgements $\quad$ v

List of Figures $\quad$ xi

List of Acronyms $\quad$ XV

1 Introduction 1

1.1 Motivation . . . . . . . . . . . . . . . . 1

1.2 Confluence region east of New Zealand . . . . . . . . . . . . . 3

1.3 Wind forcing of the South Pacific Ocean . . . . . . . . . 7

1.4 Role of mesoscale eddies in oceanic frontal regions . . . . . . . . 10

1.5 Additional potential controls on the confluence region . . . . . . 12

1.6 Thesis goals and outline . . . . . . . . . . . . . . . . 14

2 Data and Methods $\quad 17$

2.1 Sea Surface Height $(\mathrm{SSH})$ data . . . . . . . . . . . . . . 17

2.2 Sea Surface Temperature $(\mathrm{SST})$ data . . . . . . . . . . 18

2.3 Wind stress data . . . . . . . . . . . . . . . . . 18

2.4 Climate indices . . . . . . . . . . . . . . . . . . 19

2.4.1 Global indices . . . . . . . . . . . . . . . . . . 19

2.4 .2 Local indices . . . . . . . . . . . . . . . 22 
2.5 Methods and analysis . . . . . . . . . . . . . . . . . . 23

2.5.1 Spectra of Sea Level Anomalies . . . . . . . . . . . 23

2.5.2 Calculating gradients of SSH . . . . . . . . 25

2.5.3 Eddy Kinetic Energy (EKE) . . . . . . . . . . . . . . 27

2.5.4 SST variability across the confluence . . . . . . . 28

2.5.5 South Pacific wind forcing of the confluence . . . . . . 30

$\begin{array}{llr}3 & \text { Results } & 37\end{array}$

3.1 Sea surface height anomaly . . . . . . . . . . . . . . . . 37

3.2 Variability of the Confluence . . . . . . . . . . . . . 39

3.2.1 Intensity of fronts . . . . . . . . . . . . 39

3.2 .2 EKE variability . . . . . . . . . . . . . . . . 46

3.3 Area average of fronts and EKE time series . . . . . . . . . 50

3.4 Sensitivity tests: changing the shape of the confluence . . . . . . 53

3.5 Temperature difference across the confluence . . . . . . . . . . 55

3.6 Response of the confluence to wind forcing . . . . . . . . . . 57

3.6.1 South Pacific winds and the meridional transport of confluent Western Boundary Currents . . . . . . . . 57

3.6.2 Southern Hemisphere climate indices and variability of the confluence ................. . . 60

3.6.3 Regional wind control on the confluence . . . . . . . . 61

3.6.3.1 Local indices . . . . . . . . . . . . 62

$\begin{array}{lll}4 & \text { Discussion } & 65\end{array}$

4.1 Sea level anomalies . . . . . . . . . . . . . . . . . 65

4.2 Temporal and spatial variability of the confluence . . . . . . 66

4.3 Confluence response to wind forcing . . . . . . . . . . . . 71

$\begin{array}{llr}5 & \text { Conclusions } & 75\end{array}$

5.1 Summary of results . . . . . . . . . . . . . . . . 75 
5.2 Implications for the past and future oceanography of the region 77

5.3 Future work . . . . . . . . . . . . . . . . . 78

5.4 Concluding thoughts . . . . . . . . . . . . . . 79

$\begin{array}{ll}\text { Bibliography } & 81\end{array}$ 


\section{List of Figures}

1.1 Bathymetry of the Southwest Pacific Ocean around New Zealand. 3

1.2 A schematic of the confluence region off eastern New Zealand. . 4

1.3 SST and SSS maps indicating the confluence region. . . . . . . 5

1.4 Mean SSH fronts from January 1993 to December 2010. . . . . . 6

1.5 Schematic of subtropical and subantarctic inflows in the South Pacific Ocean. . . . . . . . . . . . . . . . 8

1.6 Time series of the area average wind stress curl of South Pacific region, between East of New Zealand and Chile. . . . . . . . . . 9

1.7 Mean EKE from January 1993 to December 2010. . . . . . . . . 13

2.1 Time series of climate indices SAM and SOI. . . . . . . . . 21

2.2 Degrees of Freedom for SLA spectra. . . . . . . . . . . . 24

2.3 Map of the mean SST for 1993-2010 (OI.v2 data) to compute temperature differences across the confluence. . . . . . . . . . 29

2.4 Schematic of integration contours for the Island Rule. . . . . . . 32

2.5 Island Rule integration contour. . . . . . . . . . . . . . . . 34

3.1 Time series of area average of the Sea Level Anomaly (SLA). . . 37

3.2 Power spectrum of area average SLA . . . . . . . . . . . . . 39

3.3 Variance preserved spectrum of area average SLA. . . . . . . . . 40

3.4 Mean $|\nabla S S H|$ in confluence. . . . . . . . . . . . . . . . . . 41

3.5 Yearly mean $|\nabla S S H|\left(\mathrm{cm} \mathrm{km}^{-1}\right)$ in the confluence region. . . . 42 
3.6 Maximum intensity of $|\nabla S S H|$ at the confluence plotted as function of longitude. . . . . . . . . . . . . . . . . . . 43

3.7 Latitude of maximum intensity of the confluence plotted as a function of time. . . . . . . . . . . . . . 43

3.8 Yearly means of maximum $|\nabla S S H|\left(\mathrm{cm} \mathrm{km}^{-1}\right)$ plotted as function of latitude and longitude. . . . . . . . . . . . . . 45

3.9 Mean EKE from January 1993 to December 2010. . . . . . . . . 46

3.10 Yearly mean EKE in confluence region. . . . . . . . . . . . . . . 48

3.11 Maximum EKE levels plotted as function of longitude. . . . . . 49

3.12 Area average of $|\nabla S S H|$ and EKE time series. . . . . . . . . 51

3.13 Eddy activity south of the confluence. . . . . . . . . . . . . 51

3.14 Time series of area area weighted EKE in the confluence compared to time series of EKE immediate south of the confluence. 52

3.15 Sensitivity test 1: confluence domain determined by EKE levels associated with geostrophic velocities $\geq 23 \mathrm{~cm} \mathrm{~s}^{-1}$. . . . . 54

3.16 Sensitivity test 2: confluence domain determined by EKE levels associated with geostrophic velocities $\geq 25 \mathrm{~cm} \mathrm{~s}^{-1}$. . . . . . 54

3.17 SST changes across the confluence compared to area average $|\nabla S S H|$

3.18 SST variability along southwest - northeast transect at the western edge of confluence. . . . . . . . . . . . . . . . 56

3.19 Meridional transport of WBCs east of New Zealand. . . . . . . . 58

3.20 Time series of $\Delta T A$ and area average $|\nabla S S H| . \quad \ldots \ldots 60$

3.21 Global climate indices SAM and SOI compared with confluence front intensity. . . . . . . . . . . . . . . . 61

3.22 Time series of the area average local wind stress curl and $|\nabla S S H| .62$

3.23 Time series of the area average local wind stress curl anomaly and EKE. . . . . . . . . . . . . . . . . 62 
3.24 Local Z2 climate index and area average of local wind stress curl time series. . . . . . . . . . . . . . . 63

3.25 Local Z2 climate index and area average of $|\nabla S S H|$ time series. 64 


\section{List of Acronyms}

ACC Antarctic Circumpolar Current

DOF Degrees of Freedom

EKE Eddy Kinetic Energy

EUAC East Auckland Current

ACC Antarctic Circumpolar Current

DOF Degrees of Freedom

EAC East Australian Current

ENSO El Niño Southern Oscillation

G-I Glacial-Interglacial

MSLA Mapped Sea Level Anomaly

MDT Mean Dynamic Topography

MSLP Mean Sea Level Pressure

SLA Sea Level Anomaly

SSH Sea Surface Height

SSS Sea Surface Salinity

SST Sea Surface Temperature

SPSG South Pacific Subtropical Gyre

SAM Southern Annular Mode

SOI Southern Oscillation Index 
SAF Subantarctic Front

SAW Subantarctic Water

STF Subtropical Front

STW Subtropical Water

WBCs Western Boundary Currents 


\section{Chapter 1}

\section{Introduction}

\subsection{Motivation}

Winds are the major driver of the upper ocean circulation (Pond and Pickard, 1983), therefore changes in large-scale wind patterns should influence the location of ocean fronts and boundary currents. Observational and model studies show changes in wind strength and location over modern times (Thompson and Solomon, 2002; Toggweiler et al., 2006; Cai, 2006) and on glacial-interglacial (G-I) time scales (Hesse, 1994; Lamy et al., 1999). However, the response of fronts and currents to winds is only now emerging (Qiu and Chen, 2006; Böning et al., 2008; Sallée et al., 2008b). Nearly two decades of high quality satellite data of the sea surface height ( $\mathrm{SSH}$ ) are now available and many decades of wind and sea surface temperature data, providing an opportunity to investigate the link between wind forcing and ocean dynamics.

Oceanic fronts are regions where water mass properties and SSH show strong horizontal gradients. An oceanic front forms when the convergence of water with different properties creates a region with rapid spatial changes in temperature, salts and nutrients (Heath, 1985). While ocean currents transport heat, momen- 
tum, and water masses from one region to another, mixing of water properties occurs across frontal boundaries (Murphy et al., 2001). Fronts form the boundaries between ocean currents and are often associated with energetic flows or jets (Deacon, 1937; Orsi et al., 1995; Belkin and Gordon, 1996; Sokolov and Rintoul, 2007).

East of New Zealand, warm Suptropical flows meet cold Subantarctic flows creating a strong front which I refer as "the confluence" hereinafter. Fronts in the confluence region east of New Zealand have been found to have surface geostrophic velocities between $12 \mathrm{~cm} \mathrm{~s}^{-1}$ and $20 \mathrm{~cm} \mathrm{~s}^{-1}$ relative to $1000 \mathrm{~m}$ and show intense temperature and salinity gradients (Bryden and Heath, 1985). Strong gradients generate bigger signals in observations. Thus, the response of the ocean to wind changes should be most apparent in these frontal regions. They are therefore sensitive places where the impact of climate variability can be assessed.

Factors other than large-scale winds may also influence the location and strength of these fronts, such as local winds, seabed topography (Fig. 1.1) and eddy adjustment (Sallée et al., 2008b; Morrow et al., 2010; Qiu and Chen, 2010). Eddies are the "weather systems" of the ocean, formed by instabilities that grow on the strong density and velocity changes at fronts. Responses to local forcings need to be investigated to discern their influence on variability in the confluence region versus that of larger-scale winds.

In this study the spatial and temporal variability of the confluence region will be examined. The results will be used to address a fundamental question:

Are the winds over the South Pacific Ocean the main control of the confluence region east of New Zealand?

Assessing the connection between winds and ocean fronts is essential for interpreting past climate signals and anticipating future changes. 


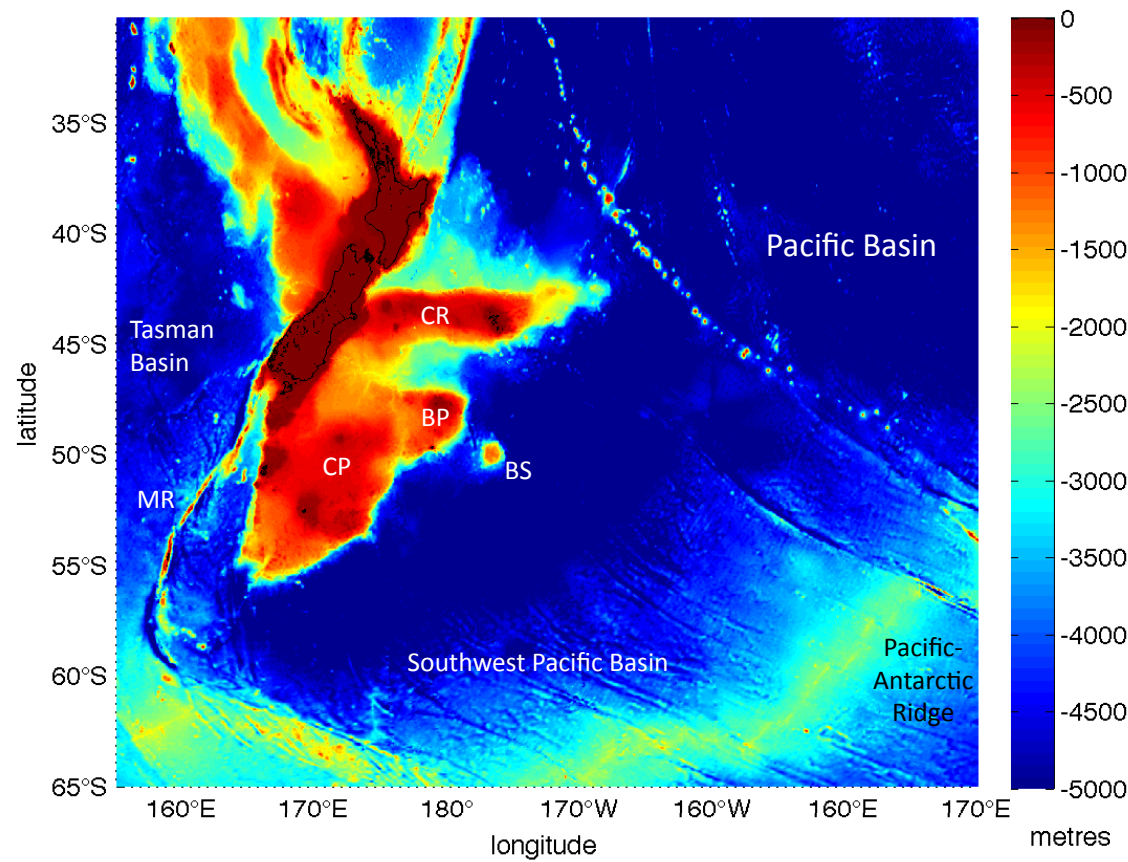

Figure 1.1: Bathymetry of the Southwest Pacific Ocean around New Zealand. Colours represent bathymetry up to 5000 metres. Includes names of topographic features relevant to this study: $\mathrm{CP}=$ Campbell Plateau, $\mathrm{BP}=$ Bounty Plateau, $\mathrm{CR}=$ Chatham Rise, $\mathrm{BS}=$ Bollons Seamount and $\mathrm{MR}=$ Macquarie Ridge.

\subsection{Confluence region east of New Zealand}

The Antarctic Circumpolar Current (ACC), the largest-scale current system in the world, connects the three southern basins of the Atlantic, Indian and Pacific oceans. The main ACC flow travels clockwise around Antarctica and is concentrated into several fronts, of varying intensity (Orsi et al., 1995).

The northern part of the ACC is defined by the Subantarctic Front (SAF). South of New Zealand, the SAF follows the steep eastern flank of Campbell Plateau (Morris et al., 2001) to around $49^{\circ} \mathrm{S}$ where it meets the strong southward and eastward flow of the South Pacific Subtropical Gyre (SPSG). East of Bollons Seamount the SAF is found between $53^{\circ} \mathrm{S}$ and $54^{\circ} \mathrm{S}$ (Uddstrom and Oien, 1999) 
(Fig. 1.2).

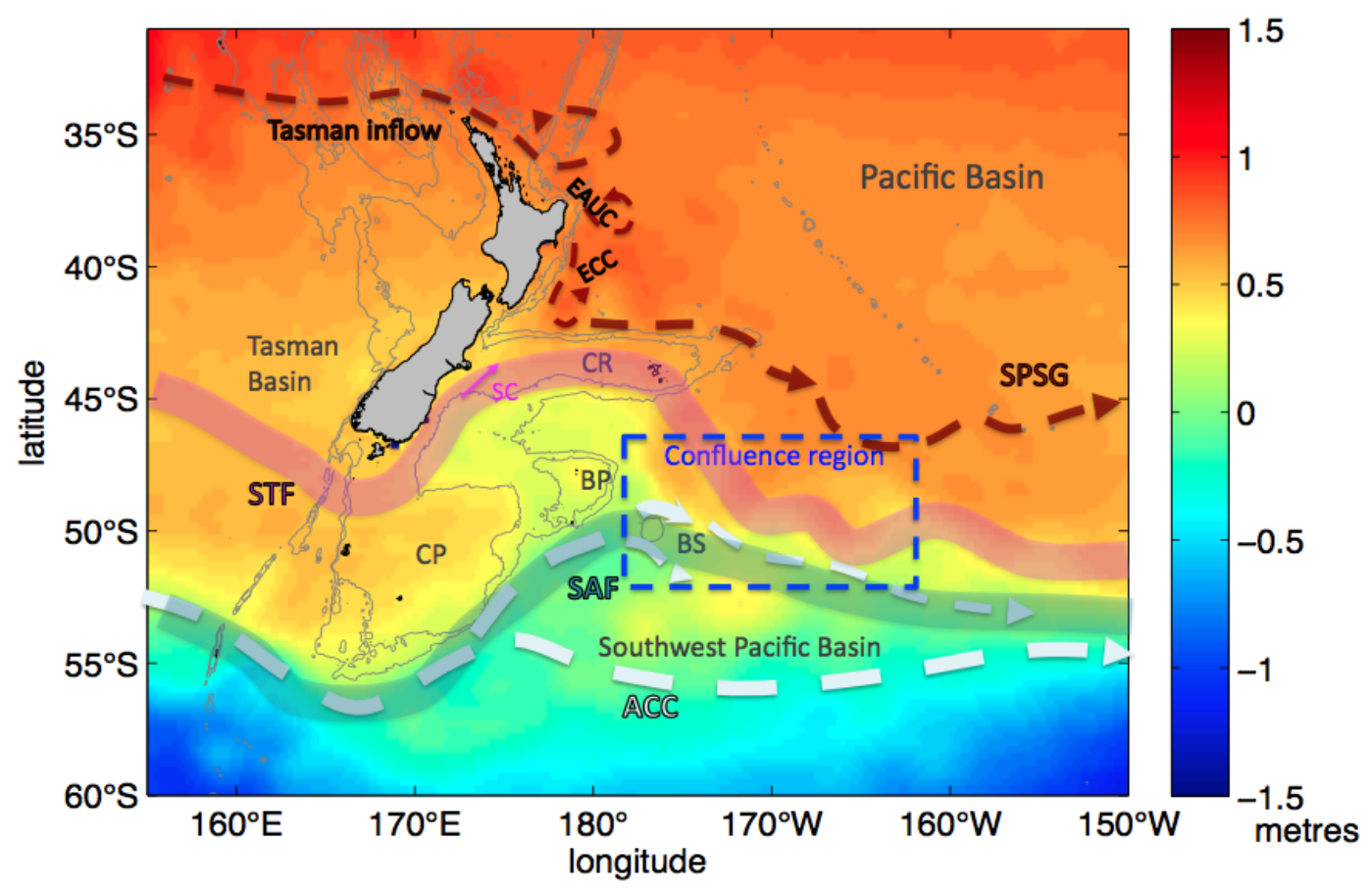

Figure 1.2: A schematic of the confluence region off eastern New Zealand on top of the mean sea surface height in metres (derived from the CNES-CLS09 Mean Dynamic Topography (MDT) and Archiving, Validation, and Interpretation of Satellite Oceanographic Data (AVISO)). Includes boundary currents, approximate location of main fronts and topographic features: $\mathrm{ACC}=$ Antarctic Circumpolar Current bounded by the $\mathrm{SAF}=$ Subantarctic Front; to the north is the $\mathrm{STF}=$ Subtropical Front bounded by the SPSG=South Pacific Subtropical Gyre. Boundary currents are the $\mathrm{SC}=$ Southland Current, the ECC=East Cape Current, and to the north the EAUC=East Auckland Current. Topographic features on map are the $\mathrm{CP}=$ Campbell Plateau, $\mathrm{BP}=$ Bounty Plateau, $\mathrm{CR}=$ Chatham Rise, and $\mathrm{BS}=$ Bollons Seamount.

North of the SAF, the Subtropical Front (STF) passes south of New Zealand. Near the Southland coast the STF is also called the Southland Front (Heath, 1985). East of the South Island, the STF lies along the southern edge of the Chatham Rise. Two subtropical currents flow on either side of the Rise; the continuation of the East Cape Current (ECC) along the northern rise and the Southland Current (SC) (associated with the Southland Front) along the southern rise. These eastward currents eventually meet the cold northern limb of the 
ACC and flow eastward, forming a boundary between subtropical waters (STW) and subantarctic waters (SAW) which extends across the South Pacific (Bryden and Heath, 1985).

This front is a transition between STW and SAW as shown in maps of Sea Surface Temperature (SST) and Sea Surface Salinity (SSS) (Fig. 1.3). For example, the STF east of New Zealand is delineated by the surface isotherm of $12-13^{\circ} \mathrm{C}$ (Uddstrom and Oien, 1999) whereas the SAF follows the isotherm of $8^{\circ} \mathrm{C}$ (Emery, 1977) (Fig. 1.3a). Bryden and Heath (1985) describe this confluence front as the region where the isotherms of $6^{\circ} \mathrm{C}$ and $4^{\circ} \mathrm{C}$ reach its maximum depth in the South Pacific, and where the isohaline of 34.5 at the surface separates STW to the north from SAW to the south (Fig. 1.3b).

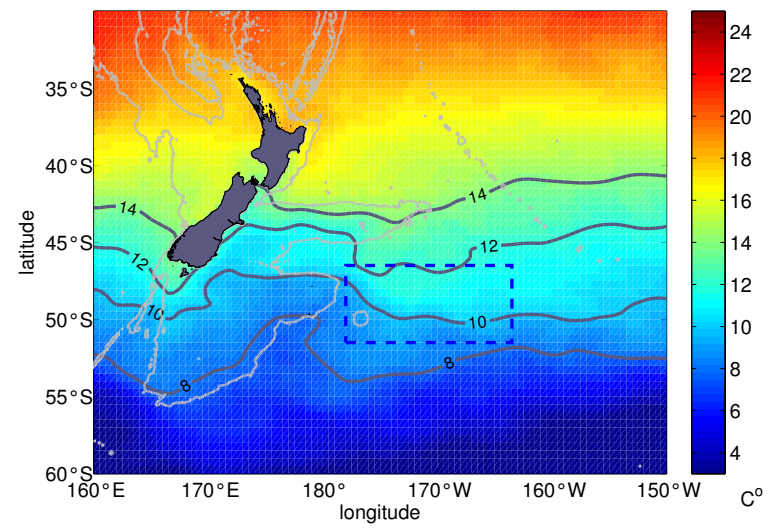

(a) Sea Surface Temperature (SST).

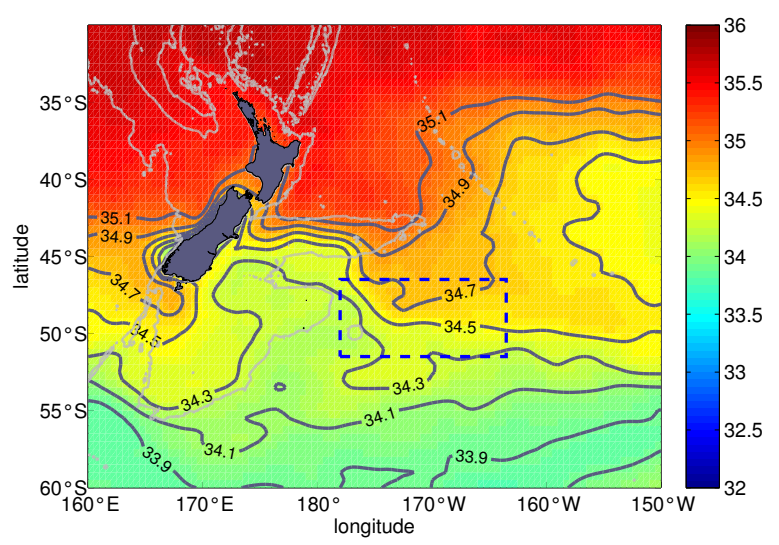

(b) Sea Surface Salinity (SSS).

Figure 1.3: SST and SSS maps indicating the confluence region (dashed blue area), light grey contour is 2000 metres isobath. (a) Isotherms of $12-13^{\circ} \mathrm{C}$ represent STW, whereas the isotherm of $8^{\circ} \mathrm{C}$ represents SAW. (b) Isohaline of 34.5 shows boundary for STW (to the north) and SAW (to the south) (SST and SSS maps were created using climatology data from CSIRO Atlas of Regional Seas (CARS2009)).

Sokolov and Rintoul (2007) show that locations and intensities of oceanic fronts along the circumpolar path can be derived from SSH data giving similar results to methods using water mass properties. For instance, Figure 1.4 shows 
a temporal mean of SSH fronts for the period January 1993 to December 2010 (from the analysis of altimeter data which will be discussed in next chapter). Farther north the Chatham Rise extends to the east and Bollons Seamount is located at approximately $50^{\circ} \mathrm{S}-177^{\circ} \mathrm{W}$. South and east of New Zealand, there are three areas where the SSH fronts reach maxima. These areas are enclosed by boxes $\mathbf{A}, \mathbf{B}$ and $\mathbf{C}$. It is common practise when analysing SSH fields and EKE signals to select regions of interest as boxes enclosing the prominent variability of these signals (Chen and Qiu, 2010; Yoshida et al., 2010; Thompson and Richards, 2011).

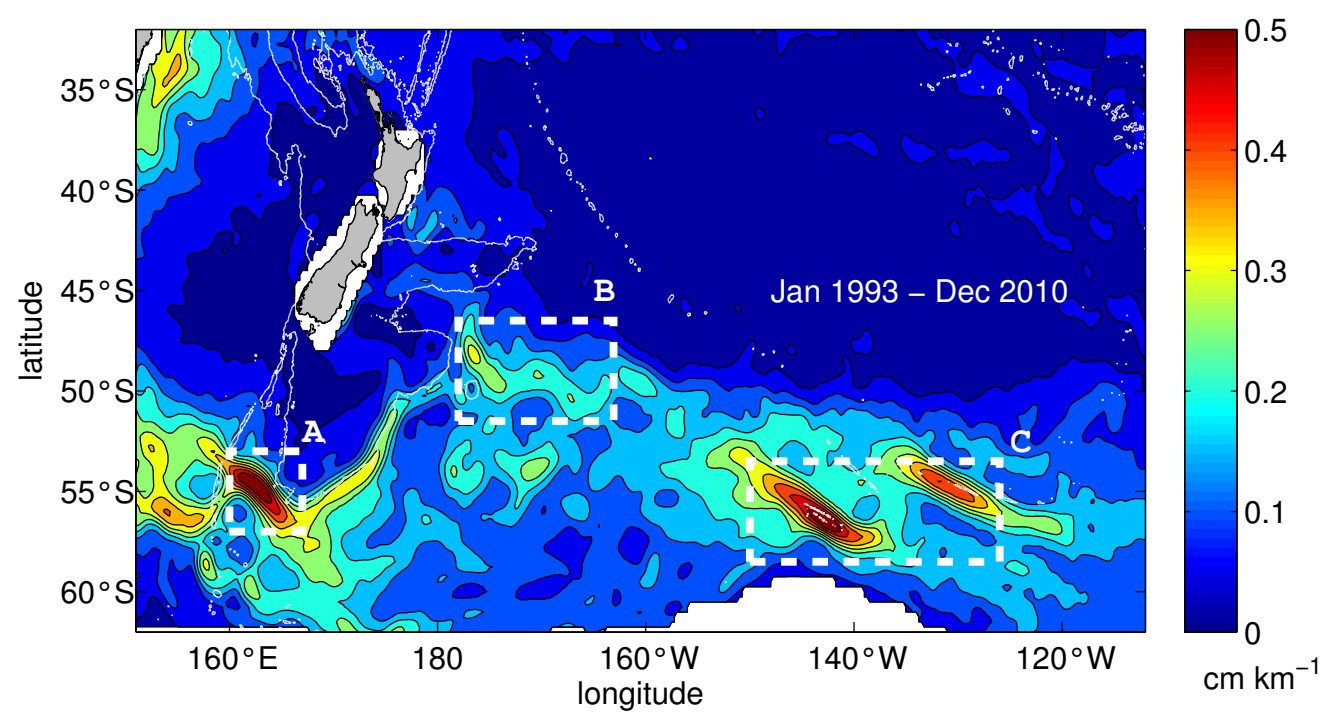

Figure 1.4: Mean SSH fronts from January 1993 to December 2010 (data from AVISO). The white contour is the 2000 metres isobath locating the outer edge of Campbell Plateau and Bounty Plateau offshore the South Island of New Zealand. Boxes $\mathbf{A}, \mathbf{B}$, and $\mathbf{C}$ enclose regions with strong SSH fronts.

The strong fronts in box $\mathbf{A}$ and $\mathbf{C}$ are associated with the ACC flowing over and around topography and discussed in detail by Morris et al. (2001) and more recently by Thompson and Richards (2011). In box A, the southern edge of Campbell Plateau acts as a bathymetric constraint for the northern branch of the ACC. In box $\mathbf{C}$, the topography of the Pacific-Antarctic Ridge affects the 
passage of the ACC over the ridge. This thesis focuses on the confluence, i.e., box B, where STW meets SAW, southeast of the Chatham Rise.

\subsection{Wind forcing of the South Pacific Ocean}

In each ocean basin, the clockwise ACC abuts the subtropical gyres, basinscale flows that rotate anticlockwise in the Southern Hemisphere. This largescale rotation is generated by the torque of the wind stress, or wind stress curl, that supplies relative vorticity to the ocean. In the Southern Hemisphere the gyre motion is generated by the easterly Trade Winds along the equator band, and the westerly winds over mid-latitudes (Colling, 2001). Figure 1.5 shows a schematic of the South Pacific circulation and its relationship to the wind stress curl. East of New Zealand, where the strong flow of the ACC meets the southern limb of the SPSG, the wind stress curl shows a relative maximum. Western boundary currents (WBCs), such as the East Australian Current (EAC), transfer warmer and saltier water from tropical areas to higher latitudes, balancing the northward transport of colder water in the central and eastern Pacific. The gyre circulation is responsible for much of the poleward advection of heat on the ocean from tropical regions that make subpolar climates more temperate (Trenberth and Caron, 2001).

It is expected that changes in the winds have an impact on the patterns of global ocean circulation. For example, during the 1990s, a spin-up of the SPSG has been observed and correlated to an increase in the regional wind stress curl (Roemmich et al., 2007). In the Southwest Pacific, using a long time series (from 1944 to 2006), Hill et al. (2008) show that decadal changes in the coastal temperature and salinity of the EAC reflect an intensification in the SPSG and poleward extension of the EAC in response to changes in the South Pacific winds. The trend is an intensification of the circumpolar westerly winds, which 


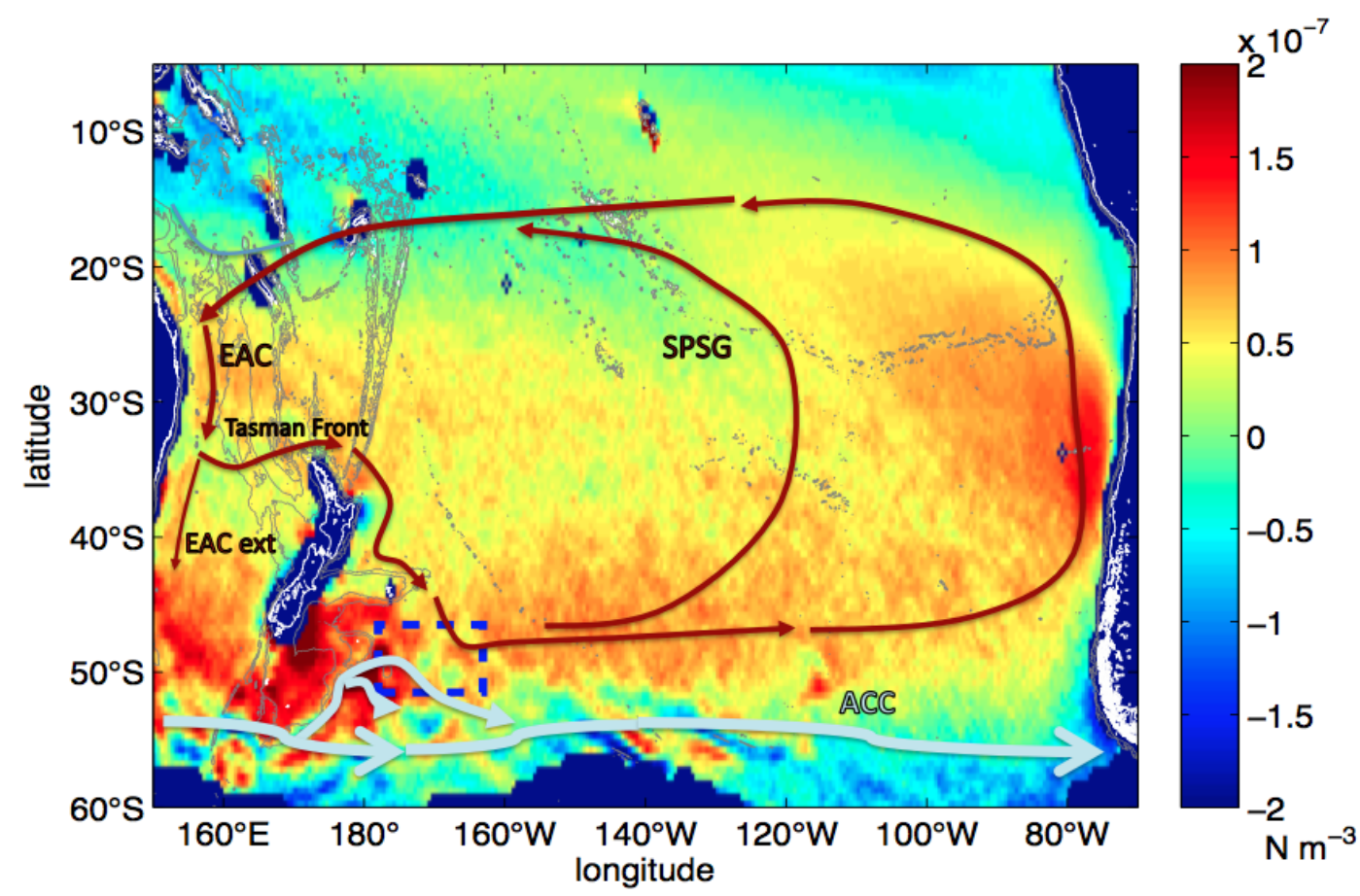

Figure 1.5: Schematic of subtropical (dark red) and subantarctic (light blue) inflows in the South Pacific Ocean. The background is wind stress curl $\left(\mathrm{N} \mathrm{m}^{-3}\right)$ averaged from January 1993 to October 2009 (data from IFREMER). The dashed rectangle east of New Zealand shows the confluence region, where the subtropical and subantarctic flows meet in the Southwestern Pacific basin.

spin-up and force the gyre circulation southward advecting warm water to the south (Cai, 2006). Figure 1.6 shows the time series of the area average wind stress curl from east of New Zealand to the west coast of South America (from the analysis of satellite data which will be described in next chapter). In this region $\left(172^{\circ} \mathrm{E}-80^{\circ} \mathrm{W}, 32^{\circ} \mathrm{S}-52^{\circ} \mathrm{S}\right)$, the wind stress curl has a positive trend over the last two decades. The variability of the wind stress has been affecting the extent, intensity and location of frontal regions of the Southern Ocean (Sallée et al., 2008b; Sokolov and Rintoul, 2009a).

Large-scale winds over the South Pacific have been related to the patterns of the gyre circulation and the transport of the WBCs via the Island Rule (Godfrey, 1989; Pedlosky et al., 1997). The Island Rule is a dynamic balance 


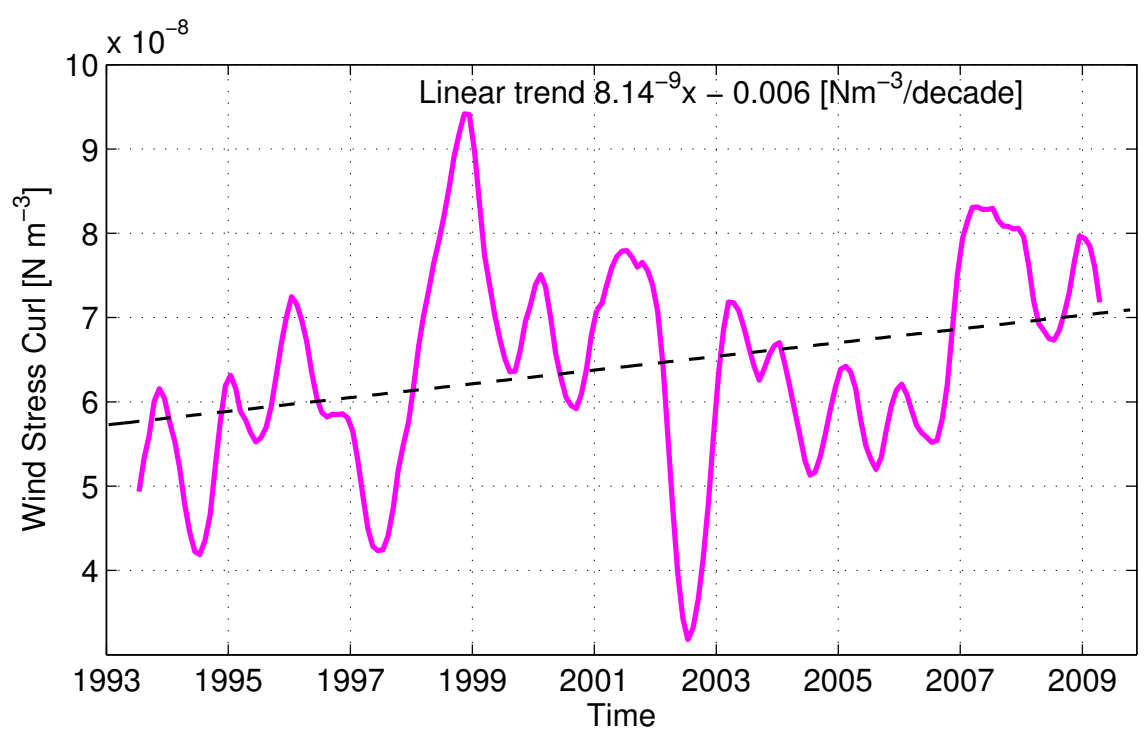

Figure 1.6: Time series of the area average wind stress curl of the South Pacific region (data from IFREMER), from New Zealand to Chile $\left(172^{\circ} \mathrm{E}-80^{\circ} \mathrm{W}, 32^{\circ} \mathrm{S}-52^{\circ} \mathrm{S}\right)$.

between winds and the Coriolis force that provides a measure of the flow around an island. It was first applied by Godfrey (1989) to determine the Indonesian Throughflow (ITF), but has also been applied to observations off Hawaii (Firing et al., 1999), Australia (Hill et al., 2008) and New Zealand (Stanton, 2001). In the Southwest Pacific, the Island Rule has been used to predict the strengthening of the SPSG gyre due to changes in the South Pacific winds (Cai, 2006; Hill et al., 2008).

Model and observational studies in other confluence regions have also shown that the location of the confluence changes due to variations in the transport of the confluent currents driven by variations in the wind stress patterns (Wainer et al., 2000; Lumpkin and Garzoli, 2011). For example, Lumpkin and Garzoli (2011) found, using along-track satellite sea level anomalies, that the BrazilMalvinas confluence in the Atlantic sector is moving southward at a rate of $-0.6^{\circ}$ to $-0.9^{\circ}$ per decade. They attribute this southward shift to the basinaveraged wind stress curl in the South Atlantic, whose maximum intensity has also a negative trend in location. Cai (2006) shows a small southward shift of 
the wind stress curl at midlatitudes in the Southern Hemisphere. He infers a southward intensification and extension of the subtropical gyre circulation. In the Southwest Pacific, the warming of the Tasman Sea and an intensification of the poleward extension of the EAC are related to these trends in location and intensity of the South Pacific winds (Cai, 2006; Hill et al., 2011).

Recent studies provide more evidence of a movement of the main fronts of the ACC in response to changes in the wind field. Sokolov and Rintoul (2009b) use SSH data to show that, in the circumpolar average, the fronts of the ACC migrated southwards by about $60 \mathrm{~km}$ between 1992 and 2007. This southward shift has been associated with the phases of the two main atmospheric climate modes of the Southern Hemisphere: the Southern Annular Mode (SAM), and El Niño Southern Oscillation (ENSO) (Sallée et al., 2008b). While the strong core of the zonal westerly winds sits above the ACC, their influence on the current system has yet to be resolved. Toggweiler et al. (2006) suggest a strengthening of the ACC, whereas Böning et al. (2008) do not see a strengthening of the ACC flow, suggesting that wind energy is taken up by increased eddy activity.

The confluence region contains flows from the subtropical gyre and from the ACC and should therefore be expected to show some of the wind-driven influences found in other studies.

\subsection{Role of mesoscale eddies in oceanic frontal regions}

Eddy activity is another important characteristic of the confluence region (Bryden and Heath, 1985). Eddies are turbulent flows that form as a result of the horizontal or vertical current shear (Colling, 2001), but also can be created by the wind stress at the surface which transfers momentum downwards mixing 
water masses by transferring heat and diffusing salts and carbon across frontal boundaries (Sallée et al., 2008a). Eddies have been found to modulate the intensity of frontal regions. For instance, Qui and Chen (2010), found in the Kuroshio Extension current (KE) east of Japan that whereas the locations of the KE fronts are set by decadal signals propagating from the North Pacific gyre, eddies modulate the strength of the fronts.

Some studies suggest a direct relation between wind forcing and eddy activity. Hogg and Blundell (2006) use model simulations of the Southern Ocean to show that an intensification of the westerly winds leads to an increase of the potential energy of the upper layers of the ACC that is eventually transferred to an increase in Eddy Kinetic Energy (EKE). Morrow et al. (2010) suggest that when positive phases of SAM and La Niña occur, the EKE increases due to the strengthening of the meridional winds in the South Pacific. However, the response of the EKE to wind forcing is not immediate: they found a 2-3 year delay between wind forcing and the increase in EKE. The delay in the eddy activity response to the wind stimulus could be due to the time taken by the winds to influence the deep circulation of the ACC (Meredith and Hogg, 2006).

Near the confluence, eddies have been observed from shipboard and satellite data (Morris et al., 2001; Williams, 2004; Stanton and Morris, 2004). Southeast of New Zealand, eddies propagate southeastward with the SAF, and have been found to be very energetic, with amplitudes at $1000 \mathrm{~m}$ depth of $20 \mathrm{~cm} \mathrm{~s}^{-1}$ (Bryden and Heath, 1985). Figure 1.7 shows the mean eddy activity from January 1993 to December 2010 (derived from the analysis of altimeter data which will be discussed in the next chapter). Three distinctive regions with high eddy signals can be observed: regions $\mathbf{a}, \mathbf{b}$ and $\mathbf{c}$.

In region a, the ACC funneling through the Macquarie Ridge, creates an area of permanent eddy activity (Gordon, 1972). There are not significant eddy signals on the Campbell Plateau where velocities have been found to be less 
than $10 \mathrm{~cm} \mathrm{~s}^{-1}$ (Stanton and Morris, 2004), nor over the Chatham Rise.

In region $\mathbf{c}$, the seabed topography affects the passage of the ACC through the Pacific-Antarctic Ridge, which generates instabilities of the mean flow creating large eddies as discussed by Thompson and Richards (2011).

A deep isolated cold-core eddy in mid-1996, north of the confluence, was studied by Chiswell and Sutton (1998). They suggest that this eddy could have originated in the separation of the flows off the eastern edge of the Chatham Rise and then advected away from its location of formation. Another isolated, but warm-core eddy in 2001 that formed south of Chatham Rise was documented by Williams (2004), who describes this eddy as being a mixture of $60 \%$ STW and $40 \%$ SAW. The signature of mesoscale eddies can be seen in regional sea surface temperature analyses (Uddstrom and Oien, 1999). In the time average, the confluence shows significant EKE northeast of Bollons Seamount (region $\mathbf{b}$ in Figure 1.7). Whether this is a preferential location for the eddy activity is one of the subjects of analysis of this thesis.

\subsection{Additional potential controls on the con- fluence region}

The seabed topography and local winds may also alter the position and variability of fronts and EKE (Sallée et al., 2008b; Yoshida et al., 2010). South of New Zealand, the pass of the ACC across the Macquarie Ridge and along the Campbell Plateau is known to shed large eddies (Gordon, 1972; Morrow et al., 1992; Stanton and Morris, 2004) capable of propagating momentum away from the circumpolar domain (Bryden and Heath, 1985; Carter and Wilkin, 1999). In the confluence region, the Bounty Plateau, Bollons Seamount and the Chatham Rise may play a role in the variability of fronts and the development of eddies. 


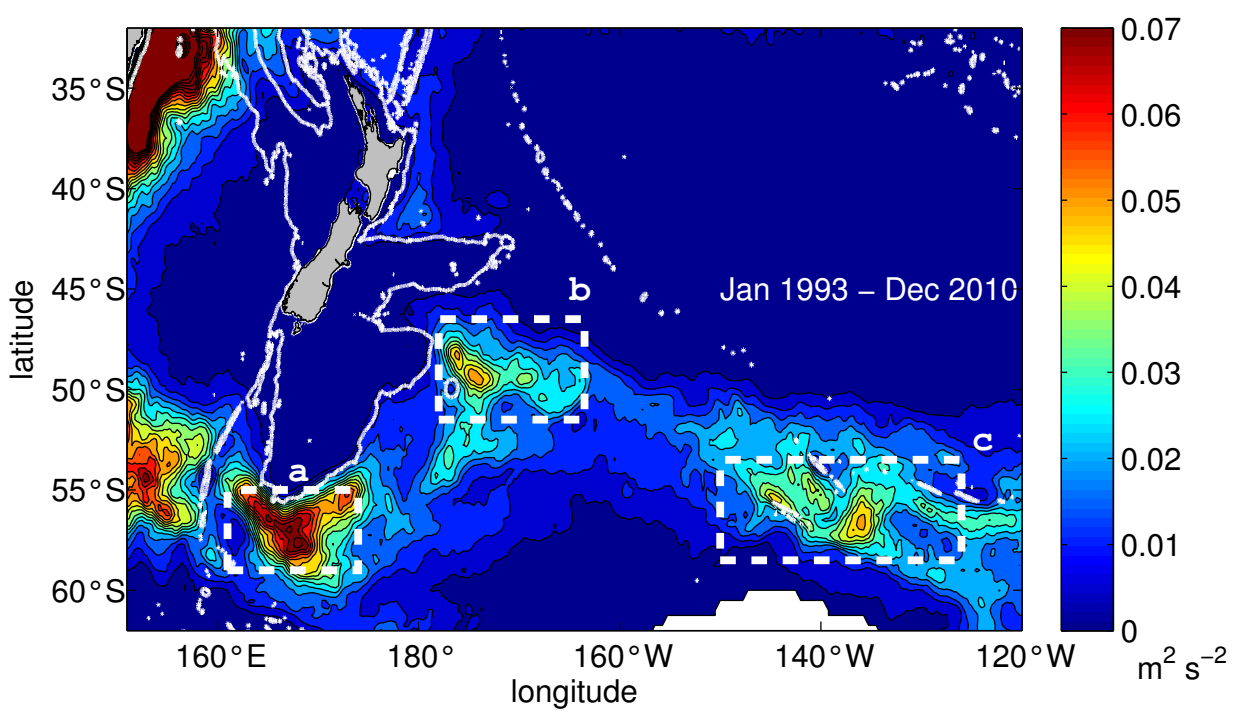

Figure 1.7: Mean EKE from January 1993 to December 2010 (data from AVISO). White contour indicates $2000 \mathrm{~m}$ isobath. Boxes a, b, and $\mathbf{c}$ enclose regions with higher mean EKE.

Orographic influences on the local wind field can create wind jets which in turn can drive a mesoscale response in the ocean. For example, Yoshida et al. (2010) find from an analysis of wind stress and SSH data between 1992 and 2008 that wind stress curl created by the topography of the islands of Hawaii induces the formation of eddies in the lee of the islands at 60-day periodicity. They suggest that basin-scale currents forced by large-scale winds may modulate the local winds and the 60-day eddy signals. In the South Pacific, the region southeast of New Zealand has many areas of high wind stress curl some near or in the confluence region (Fig. 1.5). Thus, local winds may be quite influential in the spatial and temporal variability of the confluence.

Hence, in addition to the direct influence of the winds over the South Pacific, there are other factors such as eddies, local winds and the local bathymetry that may affect the intensity and extent of ocean currents and associated fronts that form the confluence. The relative importance of these influences is unclear and will be evaluated in this thesis. 


\subsection{Thesis goals and outline}

This study aims to answer the following set of questions:

1) What is the temporal and spatial variability of the ocean fronts and eddy activity east of New Zealand?

2) What is the response of the confluence to winds? Is it dominated by basin-scale or local winds?

3) Are there any other influences in determining position of fronts, such as bathymetry?

4) What is the relationship of the eddy activity to the strength of fronts in the confluence region?

Underpinning this research is an extensive, high quality collection of oceanic and atmospheric data. The SSH data from satellite altimeters, collected between January 1993 and December 2010, were used to identify fronts and to calculate the EKE in the confluence. The wind data were analysed to test global and local influences of the wind stress curl. Climate indices were also included and correlated with the variations of the SSH and EKE signals to evaluate connections to larger-scale climate events. In addition, SST data covering the same time period provide an independent approach to describe temporal changes in STW and SAW across the confluence.

A description of the data and methods used to calculate gradients of SSH, EKE, and the curl of the wind stress for basin-scale (Island Rule) and local influences, are in Chapter 2.

Chapter 3 outlines the analysis and results of the data sets. A description of the spatial and temporal variation of the confluence is provided in terms of the area average of front intensity and EKE. This is followed by comparisons 
of the fronts and EKE with large-scale winds, local winds, climate indices, and SST difference across the confluence.

A discussion of results is in Chapter 4 .

Chapter 5 presents the conclusion of this study and a summary of principal findings. This final chapter also looks at the implications of this research with respect to New Zealand climate response to global warming, ramifications for paleo research in providing a physical background to understand change and future lines of research. 


\section{Chapter 2}

\section{Data and Methods}

\subsection{Sea Surface Height (SSH) data}

Satellite altimetry has become one of the most important tools to monitor mesoscale ocean dynamics, especially in the Southern Ocean, where in situ observations were sparse until the implementation of the Argo program during the last decade (Roemmich et al., 2009). The combination of data from various altimeters resolves ocean mesoscale features such as fronts and eddies with approximate spatial and temporal scales ranging between 50-500 km and 20-300 days respectively (Ducet et al., 2000). Remotely sensed data provide global coverage, which results in high spatial resolution maps of the sea surface with accuracy in individual measurements of $\pm 4 \mathrm{~cm}$ (Chelton et al., 2001).

Archiving, Validation, and Interpretation of Satellite Oceanographic Data (AVISO) provided SSH global data sets for this study (http://www.aviso . oceanobs.com). The SSH data consist of weekly Mapped Sea Level Anomalies (MSLA) for the period January 1993 to December 2010, resampled at quarter of a degree in both latitude and longitude. The data have been merged from the European Remote Sensing Satellite altimeters missions 1 and 2 (ERS-1; 
ERS-2), Jason 1 and 2, the TOPEX/Poseidon satellite (T/P), and from other altimeters where available.

Sea Level Anomalies (SLA) show changes in surface pressure gradients and the associated geostrophic flow (Stewart and Texas, 2005). MSLA were added to the CNES-CLS09 Mean Dynamic Topography (MDT) (Rio et al., 2011), an estimate of the mean sea surface height, to compute maps of absolute SSH for the calculation of the total $|\nabla S S H|$ (i.e., fronts). MSLA also were used to calculate the EKE.

\subsection{Sea Surface Temperature (SST) data}

SSTs were used to calculate temperature changes along the path of subtropical and subantarctic inflows near the confluence. The Optimum Interpolation Sea Surface Temperature field (OI SST) from the National Oceanic and Atmospheric Administration (NOAA) produces weekly analysis of in situ and satellite data (http://www.emc.ncep.noaa.gov/research/cmb/sst_analysis/). The data used here are monthly means between January 1993 and December 2010 at one degree resolution in latitude and longitude. This set is the second version of the SSTs field (OI.v2) computed using a linear interpolation from the weekly OI analysis (Reynolds et al., 2002).

\section{$2.3 \quad$ Wind stress data}

Two merged data sets of the sea surface wind stress were retrieved from the Institut Français de Recherche pour L'exploitation de la MER (IFREMER) (http://cersat.ifremer.fr). The first set was gathered by the SeaWinds scatterometer on the Quikscat satellite operated by the U.S. National Aeronau- 
tics and Space Administration (NASA). The second data set is from the ERS-1 and ERS-2 altimeters. SeaWinds scatterometer on the QuikSCAT satellite is a microwave which samples more than $90 \%$ of the global ocean every 24 hours (Chelton et al., 2004). The monthly wind stress data cover January 1993 to October 2009 (when the QuikSCAT mission was discontinued) and are mapped to a grid at every 0.5 of a degree in latitude and longitude.

In order to complete the analysis for the full 18-years period, the wind stress data from the National Centre for Environmental Prediction/ National Center for Atmospheric Research (NCEP/NCAR) Reanalysis project were included. NCEP/NCAR combines in situ and remote sensed observations assimilated to a complete database at 1 degree in latitude and longitude (Kalnay et al., 1996). The monthly means of wind stress at the surface were interpolated to the scatterometer grid from January 1993 to December 2010. Both data sets produce highly correlated (a correlation coefficient $r=0.87$ significant at $99 \%$ confidence level) time series of the wind stress curl of the total averages over the whole South Pacific.

NCEP/NCAR reanalysis wind stress data were used for the basin-scale wind forcing because of its longer time span. The finer-scale scatterometer wind stress data were used to calculate the local wind forcing in the confluence.

\subsection{Climate indices}

\subsubsection{Global indices}

The Southern Annular Mode (SAM) is the principal mode of climate variability in the Southern Hemisphere. The SAM describes approximately 35\% of the total variability of the surface pressure field. The main pattern is a synchronous 
pressure anomaly band that extends zonally around the Southern Hemisphere, and meridionally from Antarctica to mid latitudes (Marshall, 2007). The SAM index is defined as the difference in observations of mean sea level pressure (MSLP) at several stations located approximately at $40^{\circ} \mathrm{S}$ and $65^{\circ} \mathrm{S}$ :

$$
\mathrm{SAM}=P_{40^{\circ} S}^{*}-P_{65^{\circ} S}^{*}
$$

where $P_{40^{\circ} S}^{*}$ and $P_{65^{\circ} \mathrm{S}}^{*}$ are the normalised MSLP at $40^{\circ} \mathrm{S}$ and $65^{\circ} \mathrm{S}$ respectively (after Gong and Wang (1999) and Marshall (2003)). Phases of SAM are positive (negative) when atmospheric pressures are below (above) average over Antarctica and above (below) average over mid latitudes. These opposite-signed anomalies in mid and high latitudes are used to describe the strength and meridional oscillations of the midlatitude jet, which affects the windiness and storm activity between mid and high latitudes and over the Southern Ocean (Renwick and Thompson, 2006). The frequency of positive phases of SAM has been increasing since late 1950s (Marshall, 2003), resulting in a strengthening of the circumpolar westerly winds (Thompson and Solomon, 2002), a major driver of the ACC (Orsi et al., 1995).

The SAM index used in this study corresponds to monthly data from January 1993 to December 2010, retrieved from the British Antarctic Survey (BAS) database (http: //www . antarctica . ac . uk/met/gjma/sam . html), an observationbased SAM index compiled by Marshall (2003).

The Southern Oscillation Index (SOI) describes the oscillatory nature of ENSO. The SOI index is a measure of the air pressure fluctuations between the eastern and western Pacific during ENSO events. The negative phase of the SOI is associated with the development of El Niño, when weaker Trade Winds inhibit upwelling of cold, nutrient-rich water off the coast of South America leading to a rise in SSTs over the eastern Pacific Ocean. Conversely, a positive SOI is 
related to La Niña episodes, when stronger Trade Winds enhance upwelling of cold water extending along the equatorial Pacific (Philander, 1983). The SOI index is a useful tool that describes atmosphere-ocean interactions linked to the strength of the winds.

The University Corporation for Atmospheric Research (UCAR) provided the SOI data for this study (http://www.cgd.ucar.edu/cas/catalog/climind/ soi.html). The SOI data set covers January 1993 to December 2010, the same period of the SAM, and consists of the difference between monthly, MSLP anomalies at two south Pacific stations, Tahiti (T) and Darwin (D). Then, the SOI index is the difference of MSLP anomalies at Tahiti and Darwin [T-D] divided by the standard deviation and multiplied by 10 (Troup, 1965). Figure 2.1 shows time series of SAM and SOI indices from January 1993 to December 2010 filtered using a 13-month cosine filter to retain time-scales greater than one year.

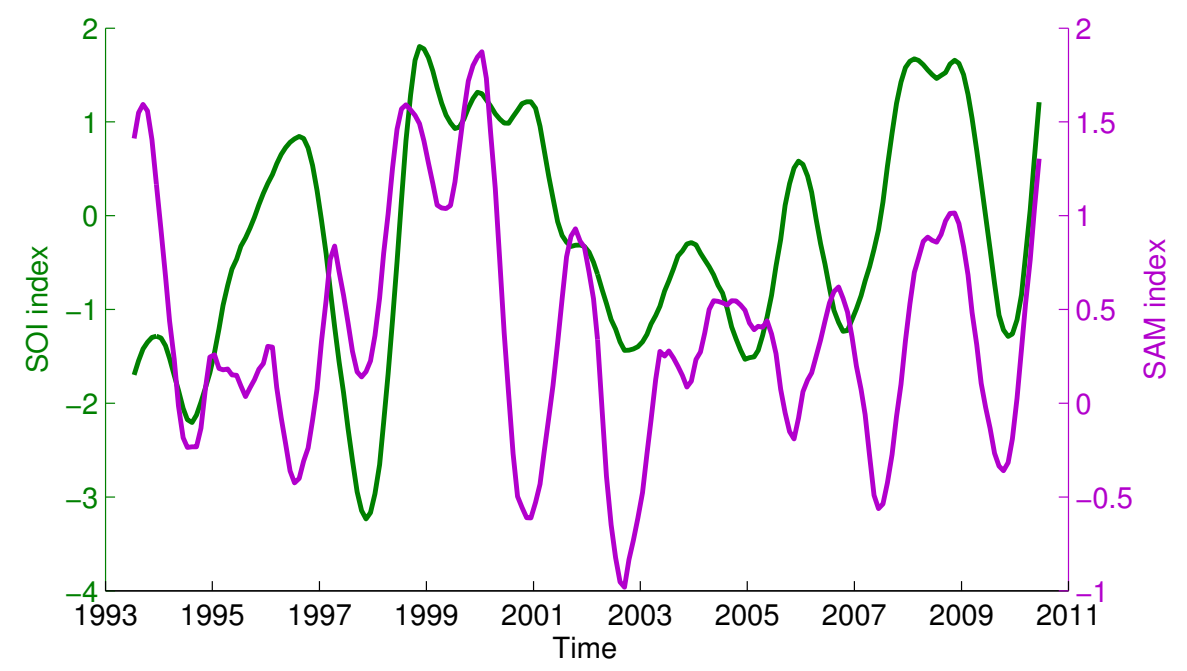

Figure 2.1: Climate indices SAM and SOI from January 1993 to December 2010. Time series have been smoothed to retain frequencies with periods longer than annual. 


\subsubsection{Local indices}

The Trenberth index Z2 (Trenberth, 1976) was analysed to further test the influence of local winds in the confluence. The National Institute of Water and Atmospheric Research (NIWA) provided this data set. Z2 is a measure of the anomalous pressure difference between Christchurch $(\mathrm{CH})$ and Campbell Island (CAI), approximately at $43.5^{\circ} \mathrm{S}$ and $52.5^{\circ} \mathrm{S}$ respectively. The $\mathrm{Z} 2$ index $(\mathrm{CH}-$ CAI) is in units of $0.1 \mathrm{hPa}$, local to New Zealand and covers the period January 1993 to December 2010. Trenberth finds that a positive trend in Z2 since the 1940s indicates an increase in the westerlies across the Tasman Sea south of $45^{\circ} \mathrm{S}$. 


\subsection{Methods and analysis}

The boundaries of the confluence region are defined by the dimension of the box enclosing the maximum mean values of the SSH fronts from January 1993 to December 2010 as shown in the previous chapter (box $\mathbf{B}$ in Figure 1.4). The box extends zonally from $178^{\circ} \mathrm{W}$ to $164.5^{\circ} \mathrm{W}$ and meridionally from $51.5^{\circ} \mathrm{S}$ to $46.5^{\circ} \mathrm{S}$. The size of the confluence region is the same for analysing front intensity, eddy activity and for the calculation of the local wind stress curl.

\subsubsection{Spectra of Sea Level Anomalies}

The dominant frequencies of the SLA record for the area of the confluence were analysed by computing the power spectra at each grid point. A power spectrum for the region was then found by averaging together all the spectra from the locations in the confluence area.

Confidence levels for the area average power spectrum were estimated by finding the degrees of freedom (DOF). The DOF represent the number of independent data points that determine the statistical significance of the record. The power spectrum at each location is modelled as a $\chi^{2}$ variable and has two DOF, however, SLA at each grid point are not independent due to spatial correlation scales in the optimal interpolation. To determine the number of DOF it is necessary to calculate the space correlation scales for SLA in the confluence region. Poleward of $14^{\circ}$ latitude the correlation spatial scales used in the optimal interpolation of the SLA are:

$$
\text { meridional }=\text { zonal }=50+250\left(\frac{900}{L a t^{2}+900}\right) \mathrm{km}
$$

where Lat represents latitude in degrees and distances are in kilometres (after Ducet et al. 2000). 
For $L a t=49^{\circ} \mathrm{S}$, which is the latitude of the midpoint of the confluence box (an average between $46.5^{\circ} \mathrm{S}$ and $51.5^{\circ} \mathrm{S}$, the northern and southern latitudes respectively), Eq. 2.2 gives a space correlation scale of about $118 \mathrm{~km}$. Points separated by less distance than this are not statistically independent. Therefore there is approximately 1 DOF per 1 degree of latitude (Fig. 2.2). This allowed use of:

$$
D O F=n / 16
$$

where $n$ is the number of data points present in the confluence box, and 16 represents the number of independent points in each $1^{\circ} \times 1^{\circ}$ square grid (as the sample resolution of the SLA data is a quarter of a degree in latitude and longitude). This method shows that $\mathrm{DOF}=75$.

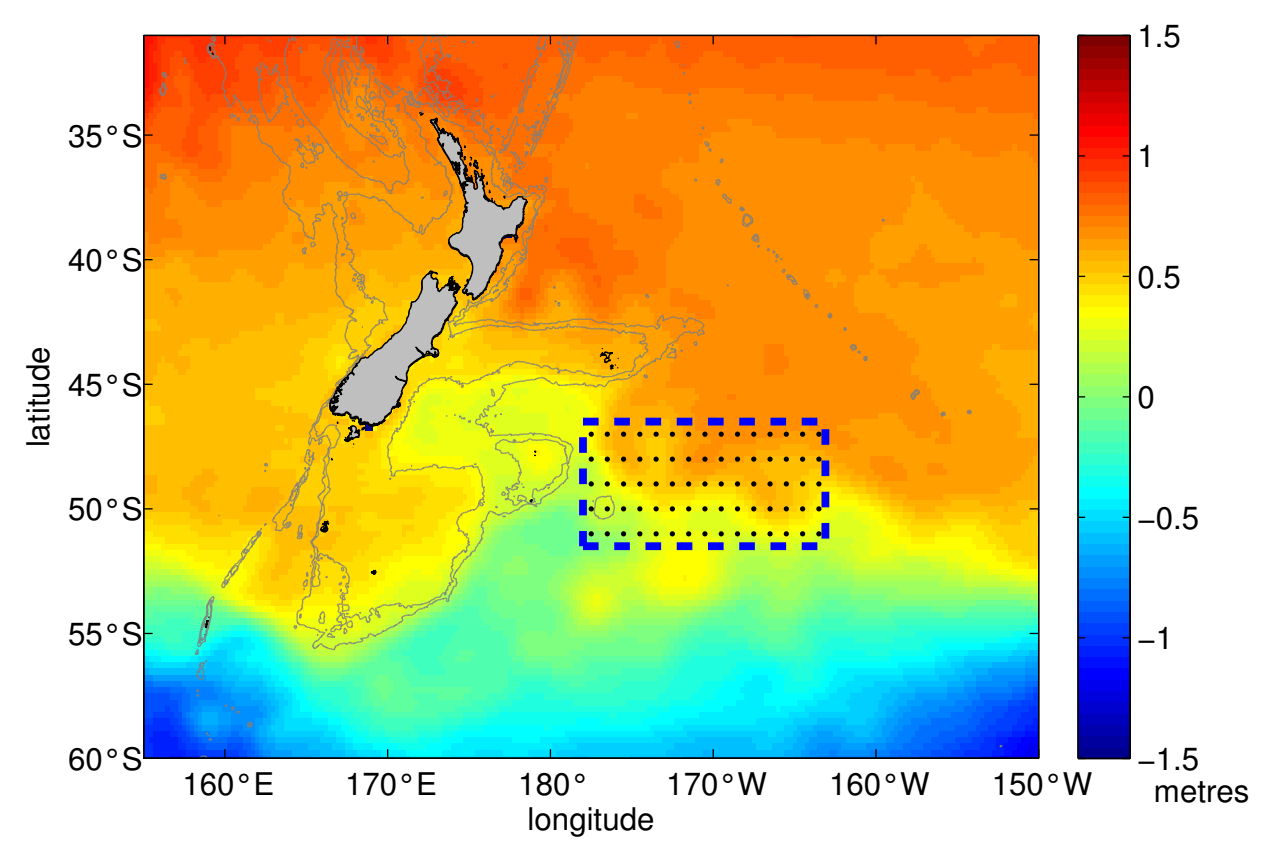

Figure 2.2: Number of DOF (75) are represented by dots enclosed by rectangle (confluence region) on top of mean SSH from January 1993 to December 2010.

The approach used to further smooth the spectra consists of firstly increasing the number of DOF and secondly applying a window to the data (Emery and Thomson, 2001). To achieve that, the time series were split into three over- 
lapping segments and a Hanning window with $50 \%$ overlap was applied to each segment. The power spectrum was calculated over each of the three segments and then averaged together (Emery and Thomson, 2001). A confidence interval can be defined where the value of the true spectrum $G_{y y}$ is expected to be within an interval with $(1-\alpha) 100 \%$ confidence:

$$
\frac{\nu \quad \bar{G}_{y y}}{\chi_{1-\alpha / 2, \nu}^{2}}<G_{y y}<\frac{\nu \quad \bar{G}_{y y}}{\chi_{\alpha / 2, \nu}^{2}}
$$

In Eq. $2.4 \nu$ is the number of DOF, $\alpha$ is 0.05 for a $95 \%$ confidence level and $\quad \bar{G}_{y y}$ represents the spectral estimate of the true spectrum. Here I used equivalent degrees of freedom which are different for windowed and nonwindowed time series. For an overlapping Hanning window the equivalent DOF are calculated as:

$$
\frac{8}{3} \frac{N}{M}
$$

where $N=939$ is the total number of data points in the time (939 weeks from January 1993 to December 2010) and $M=470$ represents the half width of the window in the time domain (half of the total period) (Emery and Thomson, 2001). The number of DOF used in the calculations according to Eq. 2.5 are 421, more than five times the number of DOF using Eq. 2.3.

The variance-preserved spectra of SLA were calculated by multiplying the power of the signal by the frequency. Displaying the spectra in variancepreserved form is useful to compare the energy in different frequencies.

\subsubsection{Calculating gradients of SSH}

One of the goals of this thesis is to describe the frontal structure east of New Zealand from SSH data. The approach consists in calculating the gradient of the SSH $(\nabla S S H)$.

In the confluence zone, fronts form the boundary that separates warmer and 
saltier subtropical waters from colder and fresher subantarctic waters (Deacon, 1937; Orsi et al., 1995). The first step towards finding the location of the fronts in the confluence is to obtain the full SSH field.

To produce maps of absolute SSH the MSLA maps were added to the CNESCLS09 Mean Dynamic Topography (MDT) (Rio et al., 2011), which is the part of the mean sea surface height due to mean currents (the mean height minus the geoid) (Altimetry, 2006). By convention all AVISO products are referenced to the six year period 1993-1999. In instances when the MDT is displayed alone it has been re-referenced to the 1993-2010 period by adding the 1993-2010 mean of the SLA referenced to 1993-1999:

$$
M D T_{P}=M D T_{[93-99]}+<S L A_{[93-99]}>_{P}
$$

where P indicates a reference period over the entire 1993-2010 period and $<>$ indicates a time average.

Gradients of SSH were calculated in its meridional and zonal components for each of the 939 weeks covering the time period. A 5-point cosine window was used to smooth the SSH data in both the meridional and zonal directions before differencing. This 5-point smoothing of the signal corresponds to spatial distances of about $111 \mathrm{~km}$ in the meridional direction and approximately between $70 \mathrm{~km}$ and $76 \mathrm{~km}$ in the zonal direction, the range reflecting the convergence of meridians at higher latitudes. This spatial difference ensured that mesoscale eddies with spatial scales of less than $100 \mathrm{~km}$ are not present in the $\nabla S S H$ signal. Spatial gradients of SSH with latitude and longitude were then computed for each grid point using the method of centred finite differences over every 5 data points. This smoothing scale has been used in previous studies to separate eddy signals from fronts (Sokolov and Rintoul, 2007, 2009a, 2009b), but results were examined for sensitivity to changes in the smoothing and differencing length scale (smoothed over $150 \mathrm{~km}$ and $200 \mathrm{~km}$ produced similar 
time series). In addition, yearly means also were calculated in order to show interannual variations of the frontal region with time.

The intensity of the fronts is calculated as the absolute value of the SSH gradients, i.e., as the square root of the zonal and meridional components squared $(|\nabla S S H|)$, for each week of the total period. A time series of the confluence intensity was created by calculating the area average of $|\nabla S S H|$.

\subsubsection{Eddy Kinetic Energy (EKE)}

EKE was derived from the maps of SLA. After removal of the mean of the SLA data set, I used centred finite differences over 3 data points (in the spatial range of 50-80 km) to find the zonal and meridional gradients of the SLA at the eddy scale. The zonal and meridional geostrophic velocity anomalies, $u^{\prime}$ and $v^{\prime}$, were calculated using the slope of the SLA $(h)$ :

$$
u^{\prime}=-\frac{g}{f} \frac{\partial h}{\partial y} \quad v^{\prime}=\frac{g}{f} \frac{\partial h}{\partial x}
$$

where $\frac{\partial h}{\partial x}$ and $\frac{\partial h}{\partial y}$ are the zonal and meridional gradients of the SLA respectively, $g$ is the gravity force, and $f$ is the local Coriolis factor calculated at each grid point.

The EKE per unit mass is then calculated at each grid point and time:

$$
E K E=\frac{u^{\prime 2}+v^{\prime 2}}{2}
$$

to examine interannual changes in the location and intensity of the eddy activity in the confluence. A time series of the EKE for the whole region was created by calculating the area average of the time series. 


\subsubsection{SST variability across the confluence}

The climatological seasonal cycle for the 1993-2010 period was removed by calculating the mean for all Januaries, all Februaries, and so on, and then each mean was removed from the corresponding month in the time series. From now on the temperature signal (with the annual cycle removed) will be referred to as SST.

Two methods were used to find the SST gradient across the region. The first method consists in selecting two boxes of 8 degrees in latitude and 12 degrees in longitude, one located north and one south of the confluence, to capture the signature of STW and SAW respectively. Figure 2.3 illustrates the location of the subtropical and subantarctic boxes with respect to the confluence. On top of the mean SST field for 1993-2010, the map shows isotherms of $8^{\circ} \mathrm{C}, 10^{\circ} \mathrm{C}$, $12^{\circ} \mathrm{C}$ and $14^{\circ} \mathrm{C}$, used to differentiate STW from SAW. Belkin (1988) associates STW with temperatures $>14^{\circ} \mathrm{C}$ in winter and $>18^{\circ} \mathrm{C}$ in summer (and salinities $>35.1$ ) and SAW to have temperatures $<10^{\circ} \mathrm{C}$ in winter and $<14^{\circ} \mathrm{C}$ in summer (and salinities <34.6). Other criteria describing the confluence in terms of temperature and salinity have been discussed in Section 1.2.

The area average of the SST was computed in each box and the difference across the confluence (subtropical box - subantarctic box) was calculated for each time and compared to the time series of front intensity.

The second method employed is based on observing SST changes along a transect $\mathrm{AB}$ in a skew angle parallel to the edge of Campbell Plateau and Bounty Plateau in the path of the main inflows of STW and SAW into the confluence (Fig. 2.3). Changes of SSTs across the confluence region were examined by calculating a time series of the SST along the transect AB. 


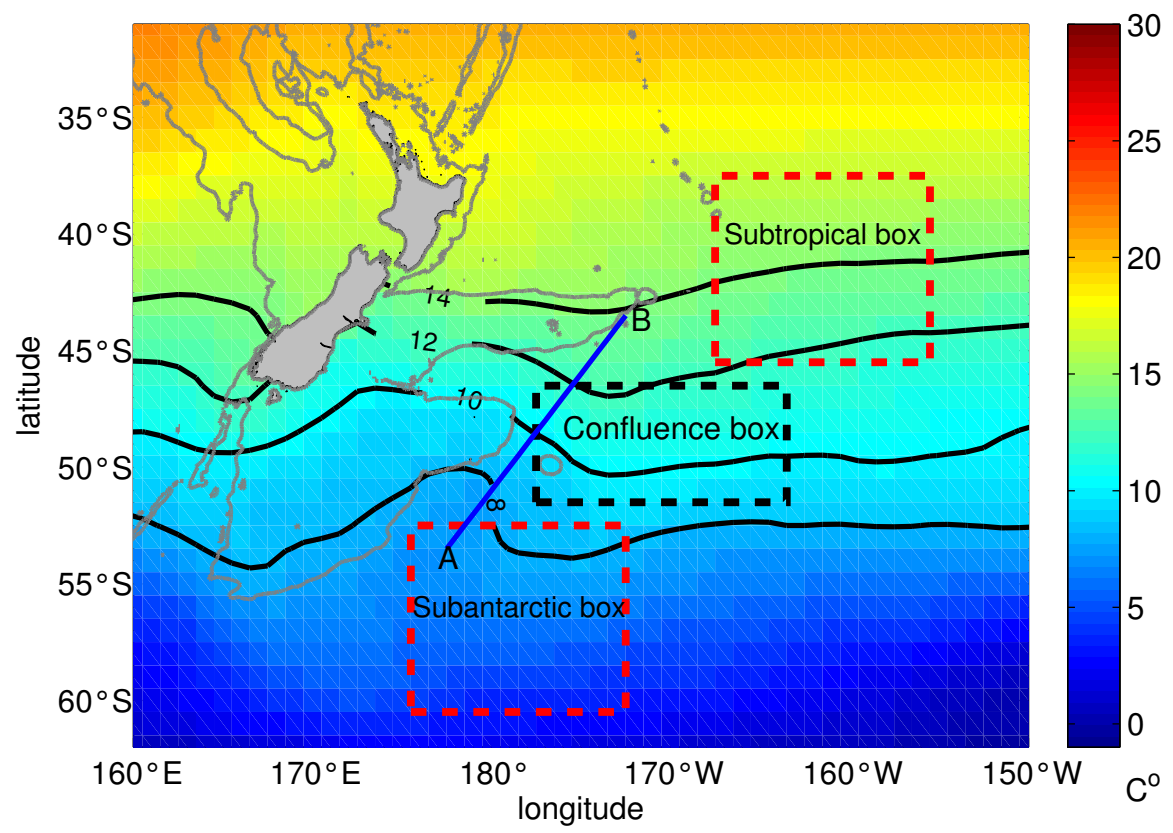

Figure 2.3: Map of the SST (OI.v2 data). Subtropical box and subantarctic box were used to compute SST differences across the confluence. In addition, SST variations were analysed along the transect $\mathrm{AB}$, intersecting the pathways of subtropical and subantarctic inflows, from 1993 to 2010. 


\subsubsection{South Pacific wind forcing of the confluence}

The confluence region is where the WBCs meet, separate from the western boundary and turn eastward into the open ocean. This separation can be explained by many mechanisms including inertial forces, abrupt changes in topography, interaction of two opposing boundary currents and large-scale wind control (e.g., see Agra and Nof (1993) for a discussion). In this study I will focus on the last mechanism, the connection to the large-scale winds, although local winds and topography will also be discussed.

The response of the confluence can be linked to South Pacific winds by finding the flow along the western boundary required to balance the wind-driven transport in the gyre using the Island Rule (Godfrey, 1989; Pedlosky et al., 1997). For the Island Rule, the dynamical balance is assumed to be linear, in steady-state, for a flat-bottomed ocean and friction is ignored everywhere except in the boundary region. Pedlosky et al. (1997) find that the transport in the western boundary current from the Island Rule is "surprisingly robust" and usually within $75 \%$ of the western boundary transport calculated from numerical simulations.

The Island Rule can be derived from the horizontal momentum equation for a thin layer of homogeneous fluid in a rotating frame of reference:

$$
\frac{\partial \mathbf{u}}{\partial t}+(\zeta+f) \hat{k} \times \mathbf{u}=-\nabla\left(\frac{p}{\rho}+\frac{|\mathbf{u}|^{2}}{2}\right)+\operatorname{Diss}(\mathbf{u})+\tau
$$

where the $\mathbf{u}$ is the velocity of the flow, $\zeta$ and $f$ are the relative vorticity and the Coriolis factor respectively representing the vortex force, and $\hat{k}$ is a unit vector in the vertical direction. The first term in the right hand side of Eq. 2.9 refers to the tangential component of the gradient of the Bernoulli function, where $\rho$ and $p$ are the density and the pressure of the fluid respectively. Diss $(\mathbf{u})$ is the dissipation term that depends on the velocity $\mathbf{u}$ and $\tau$ is an external forcing, which in this case is the wind stress (Pedlosky et al., 1997). 
In the steady-state balance, the depth-integrated transport between the northern and southern tip of an island is constant. Mathematically, this constant mass flux can be described by a streamfunction $\psi$ which represents the pressure (Stewart and Texas, 2005) between an island and the eastern boundary of a basin. Since the motion is horizontally nondivergent, the velocity $\mathbf{u}$ can be written in terms of a streamfunction $\psi$ :

$$
\mathbf{u}=\hat{k} \times \nabla \psi
$$

The integration of the tangential component of the momentum equation around an island gives a solution to the equation for the circulation around the island (Pedlosky et al., 1997):

$$
\frac{\partial}{\partial t} \oint_{C_{i}} \mathbf{u} \cdot \hat{t} d s=\oint_{C_{i}} \operatorname{Diss}(\mathbf{u}) \cdot \hat{t} d s+\oint_{C_{i}} \tau \cdot \hat{t} d s
$$

where $\hat{t}$ is a unit vector tangent to the path of integration $C_{i}$, and $d s$ is the differential length $s$ along $C_{i}$ (Fig. 2.4). The Bernoulli term in Eq. 2.9 vanishes in the integration since it is a perfect differential. The vortex force (second term in Eq. 2.9) also vanishes because the velocity component normal to the island is zero. A portion of the integral along $C_{i}$ runs along the eastern side of the island where dissipation is not negligible.

Godfrey (1989) proposed to include a contour $C_{R}$ enclosing a region $\mathrm{R}$ to the east of the island and running zonally from $x_{w}$ to $x_{e}$ (the longitudes of the western and eastern boundaries of the basin respectively) and meridionally from $y_{s}$ to $y_{n}$ (the latitudes of the southern and northern tip of the island respectively). $C_{R}$ runs along the eastern side of the island (Fig. 2.4). The momentum equation integrated along $C_{R}$ is: 


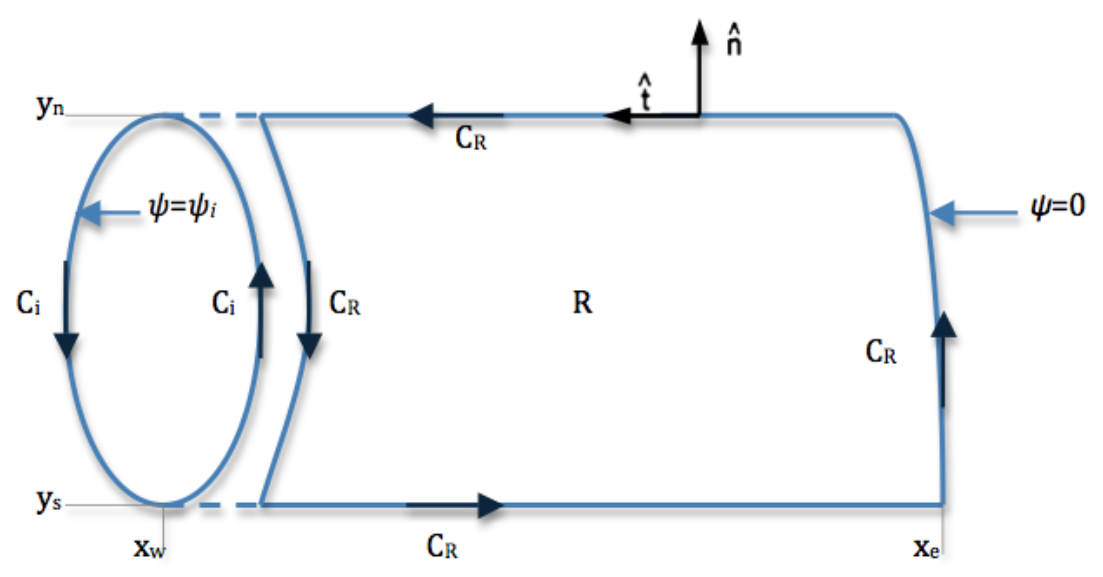

Figure 2.4: Schematic of the integration contours for Island Rule. $C_{i}$ encloses the island and $C_{R}$ the interior region $\mathrm{R}$ of a basin to the east of the island. The contour $C$ encompasses $C_{i}$ and $C_{R}$, unit vectors $\hat{t}$ and $\hat{n}$ (tangential and normal to contour) are also shown. The integration is performed counter-clockwise along the contours zonally from $x_{w}$ to $x_{e}$ and meridionally from $y_{s}$ to $y_{n}$. The streamfunction $\psi$ is chosen to be zero at the eastern portion of the contour $C_{R}$ and is a constant $\psi_{i}$ around the island. Diagram modified from Figure 2, Pedlosky (1997).

$$
\frac{\partial}{\partial t} \oint_{C_{R}} \mathbf{u} \cdot \hat{t} d s+\oint_{C_{R}}(\zeta+f) \mathbf{u} \cdot \hat{n} d s=\oint_{C_{R}} \operatorname{Diss}(\mathbf{u}) \cdot \hat{t} d s+\oint_{C_{R}} \tau \cdot \hat{t} d s
$$

The Bernoulli term also vanishes along $C_{R}$, however, the vortex force tangent to the contours at the latitudes of $y_{s}$ and $y_{n}$ is not zero. The sum of $C_{i}$ and $C_{R}$ (Eq. $2.11+$ Eq. 2.12) gives the contour $C$, which avoids dealing with friction terms since, at the eastern side of the island, the integrals of the momentum equation along $C_{i}$ and $C_{R}$ have equal magnitudes but with opposite signs and cancel each other. The flow is zero through the western side of the island and the eastern coast of the basin so the streamfunction is constant along these boundaries. The integral of the planetary vorticity along $C$ reduces to:

$$
\oint_{C} f \mathbf{u} \cdot \hat{n} d s=-\left(f_{n}-f_{s}\right) \psi_{i}
$$


where $\psi_{i}$ is the streamfunction describing the transport between the island and the eastern boundary, $f_{n}$ and $f_{s}$ are the Coriolis factors at the northern and southern latitudes of the island, and $\rho$ is the density of the water.

If dynamics are assumed to be linear, in a steady state and friction is negligible (negligible dissipation), $\psi_{i}$ can be calculated by using Eq. 2.13 and the sum of Eq. 2.11 and Eq. 2.12:

$$
\psi_{i}=\frac{1}{\left(f_{n}-f_{s}\right)} \oint_{C} \frac{\tau \cdot \hat{t} d s}{\rho}
$$

Eq. 2.14 is the Island Rule that determines the transport $\psi_{i}$ around an island.

In the interior of the basin, the Sverdrup balance, the same balance between winds and the Coriolis force, describes the meridional transport $\psi_{s}$, between the eastern side of the basin and the outer edge of the WBCs east of the island. The integration of the wind stress $\tau$ along $C_{R}$ is equivalent, by the Stokes Theorem, to the surface integral of the wind stress $\operatorname{curl}(\nabla \times \tau)$ over the area enclosed by $C_{R}$ :

$$
\psi_{s}=\frac{1}{\rho\left(f_{n}-f_{s}\right)} \int_{x_{w}}^{x_{e}} \nabla \times \tau d x
$$

The difference between the $\psi_{i}$ and $\psi_{s}$ provides an estimate of the transport of the western boundary currents $\left(\psi_{w b c}\right)$ on the east side of the island (Pedlosky et al., 1997):

$$
\psi_{w b c}=\psi_{i}-\psi_{s}
$$

For the case of New Zealand and the South Pacific, the streamfunction $\psi_{i}$ is calculated by performing an integration of the wind stress around a closed 
contour $C$ that avoids the western boundary (Fig. 2.5). The path extends westwards following the latitude of the northern tip of New Zealand along the segment $C 1$, enclosing the island on its western side along C2 and returning eastward along the latitude of the southern tip of New Zealand through C3. The contour is closed when it goes back to the starting point following the offshore coast of South America along the segment $C_{4}\left(C=C 1 \cup C 2 \cup C 3 \cup C_{4}\right)$. The contour enclosing the South Pacific Basin to the east of New Zealand is $C^{\prime}=C 1 \cup C 2 b \cup C 3 \cup C 4$ (Fig. 2.5). $C 2 b$ runs along the the eastern side of the Campbell Plateau, treated as the edge of the island as its steep side rises to within a few hundred metres from the surface and flows across it are weak (Morris et al., 2001; Stanton and Morris, 2004). Slight E-W shifts of contour $C 2 b$ produced similar results.

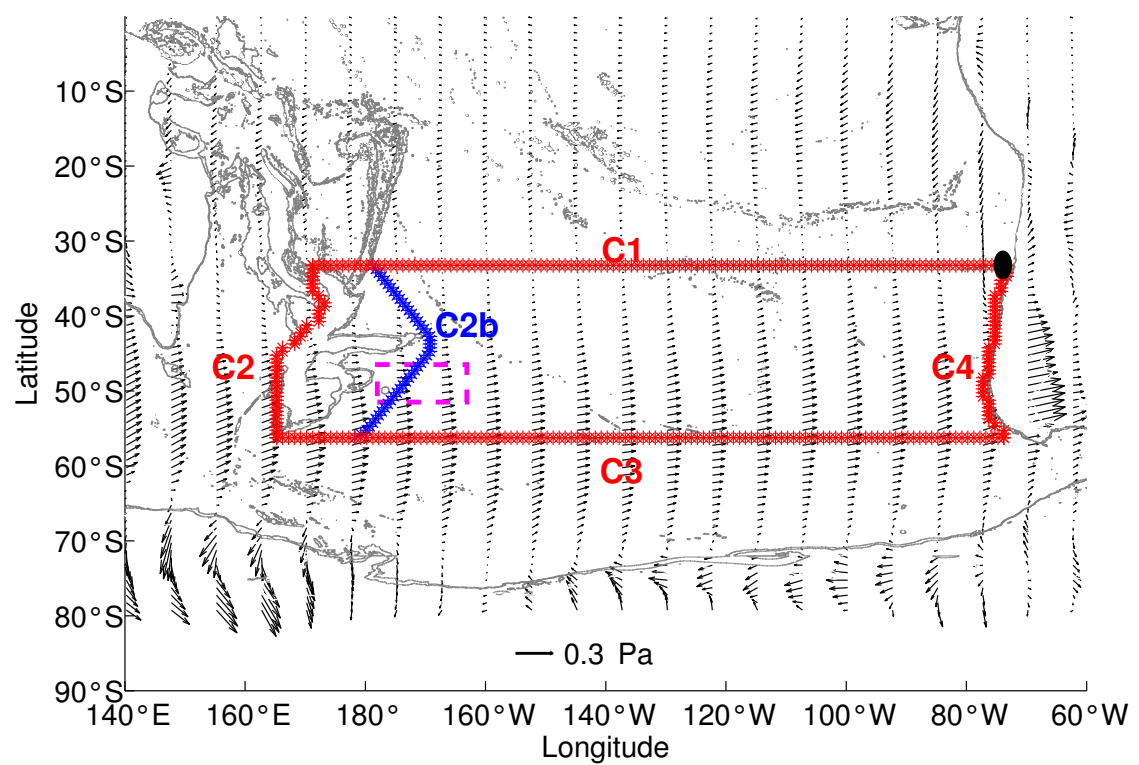

Figure 2.5: Island Rule integration contour. The dotted red path represents the Island Rule contour $C=C 1 \cup C 2 \cup C 3 \cup C 4$ enclosing New Zealand. Sverdrup balance holds inside contour $C^{\prime}=C 1 \cup C 2 b \cup C 3 \cup C 4$. Arrows show the mean NCEP wind stress at the surface for the period January 1993 to December 2010. Dashed magenta rectangle shows the confluence region. 
This thesis uses the Island Rule with the NCEP wind stress data to estimate the transport of the WBCs in the confluence east of New Zealand. The original Island Rule was applied to a steady state only; I will also be applying the Island Rule to the time-varying transport which requires consideration of adjustment processes, namely the planetary waves, that bring signals from the winds to the western boundary. In the New Zealand region, Stanton (2001) used the Island Rule with model winds to estimate the annual mean EAUC transport from 1986 to 1998. He finds interannual variations were not consistent with observations for the same time period, and he attributes the discrepancy in part to the failure to reach a steady state in the time scale considered in the study. The Island Rule seems to have worked well for other studies in the Australasian region. For example, Hill et al. (2008) used this method with the NCEP winds to estimate the transport through the Tasman Sea as the difference between the transports for Australia and New Zealand. They find that interannual variability of the temperature and salinity of the poleward extension of the EAC are well correlated with basin-scale wind forcing.

If the confluence is responding directly to the flow into the region and if these currents are responding according to the dynamic balance in the Island Rule, then changes in the strength and location of the fronts should be related to the South Pacific wind stress curl. 


\section{Chapter 3}

\section{Results}

\subsection{Sea surface height anomaly}

The time series of the area average of the SLA for 1993-2010 (after removal of the mean of the data set) is shown in Figure 3.1. A 13-month cosine window was applied to the signal to remove fluctuations with periods shorter than annual.

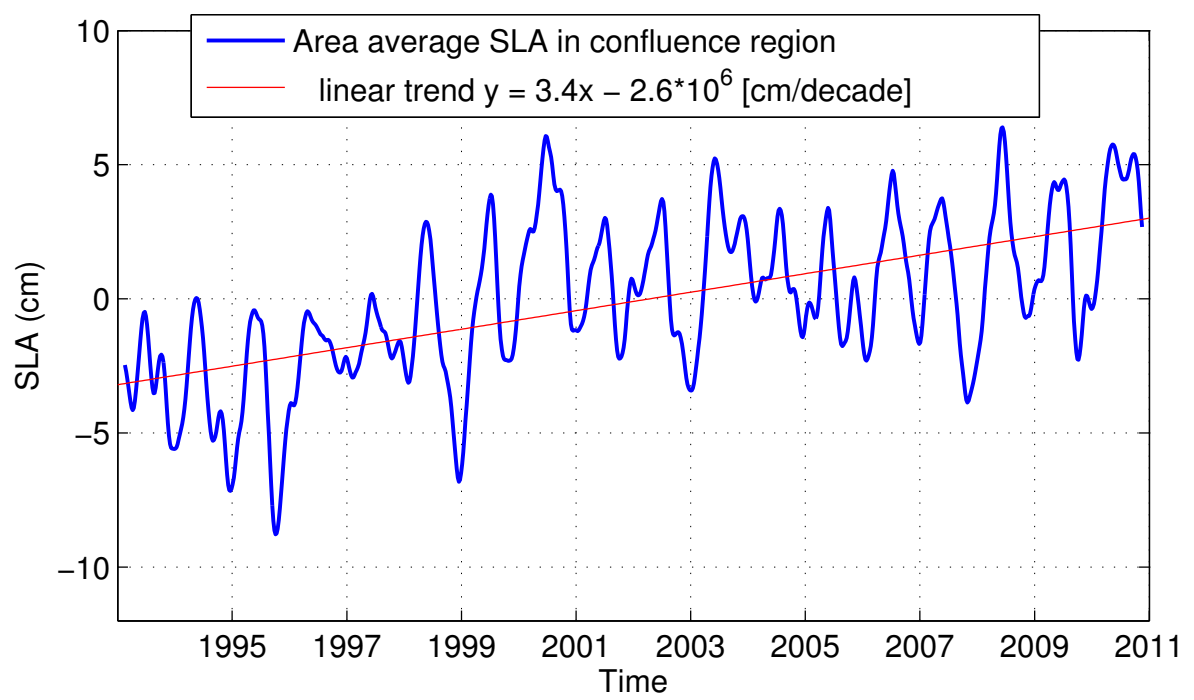

Figure 3.1: Time series of the area average Sea Level Anomaly (SLA) smoothed with a 13-month running cosine window. 
The time series of the SLA varies annually and interannually and has a positive trend of $3.4 \mathrm{~cm}$ per decade (Fig. 3.1). A maximum amplitude change was registered during the first half of 1999 and 2008, where SLA increased from $-7 \mathrm{~cm}$ to $4 \mathrm{~cm}$, and from $-4 \mathrm{~cm}$ to $7 \mathrm{~cm}$, respectively.

The power spectrum of the SLA in the confluence region shows the time scales of the SLA variations (Fig. 3.2). The power spectrum in variancepreserving form (Fig. 3.3) shows that the SLA energy is mostly concentrated in typical mesoscale frequencies between annual and 120 day periods. The peak containing greatest energy is centred at 227 day periods, and is followed by another two distinct peaks at 153 days and at 124 days. Higher frequencies found in the power spectrum are most likely tidal aliasing for altimeter measurements. For example, the peak observed at approximately 64 days is likely associated with the M2 tide, measured in the 10-day repeat of the $\mathrm{T} / \mathrm{P}$ orbit configuration (Fu and Cazenave, 2001). Lower frequencies in the spectrum (346 days and 286 days) show periods related to annual and close to annual cycles, that could be related to waves propagating energy in response to a combination of seasonal surface buoyancy and seasonal wind stress forcing (Vivier et al., 1999; Stammer, 1997).

SSH signals analysed throughout this thesis were smoothed with a 13-month and a 25-month cosine windows to separate long-term variability of frontal motion and eddy activity from the mesoscale signals. In each case, the length of the running window is specified. 


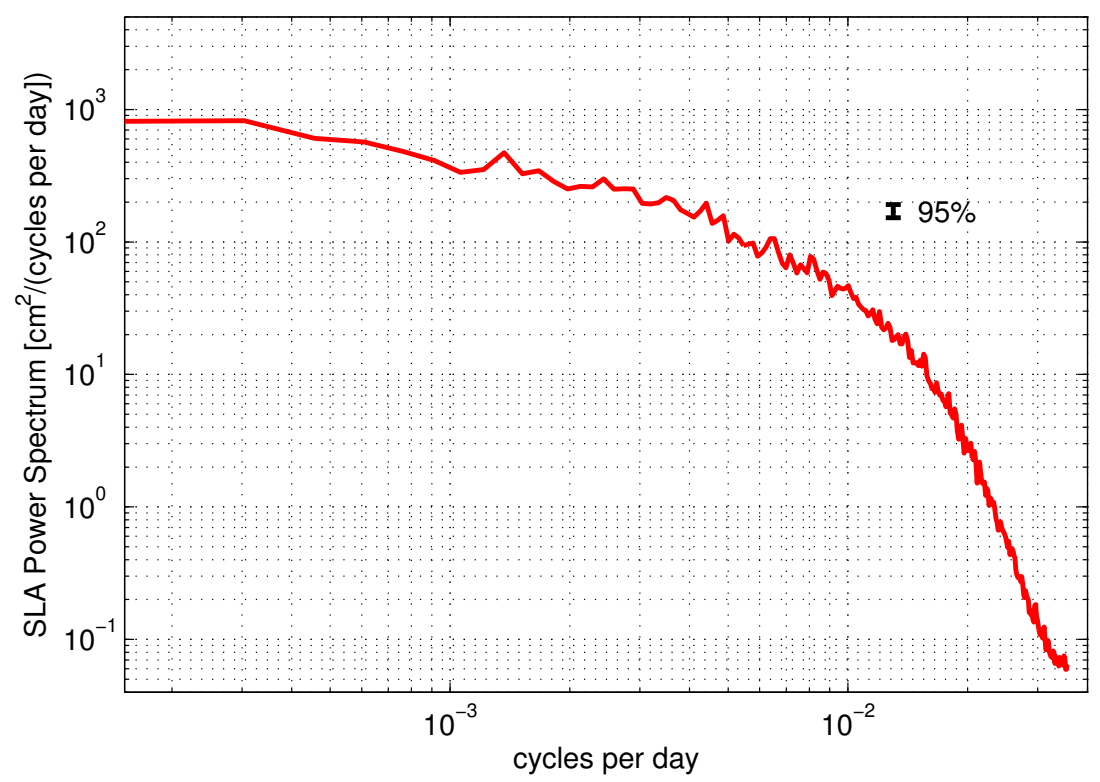

Figure 3.2: Power spectrum of area average SLA, at 95\% confidence level, after smoothing the signal using a Hanning window as explained in Section 2.5.1.

\subsection{Variability of the Confluence}

\subsubsection{Intensity of fronts}

Absolute values of the $\nabla S S H$ were calculated to identify frontal regions within the confluence zone. Figure 3.4 shows the mean $|\nabla S S H|$ for the 1993-2010 period. The maximum magnitude of the mean $|\nabla S S H|$ is $0.33 \mathrm{~cm} \mathrm{~km}^{-1}$.

To better observe the spatial and temporal variability of the $|\nabla S S H|$, snapshots of the annually averaged $|\nabla S S H|$ were plotted as shown in Figure 3.5. Large gradients of SSH were defined when $|\nabla S S H|$ greatly exceed the maximum magnitude of the average for the entire period $\left(0.33 \mathrm{~cm} \mathrm{~km}^{-1}\right)$. Following this criterion, fronts in the confluence were more intense during 1993, 1998, 2002 and 2008, when values of $|\nabla S S H|$ reached over $0.42 \mathrm{~cm} \mathrm{~km}^{-1}$. This represents approximately 30\% increase in intensity compared to the average for 1993-2010.

A persistent feature observed in Figure 3.5 is an elongated diagonal maxi- 


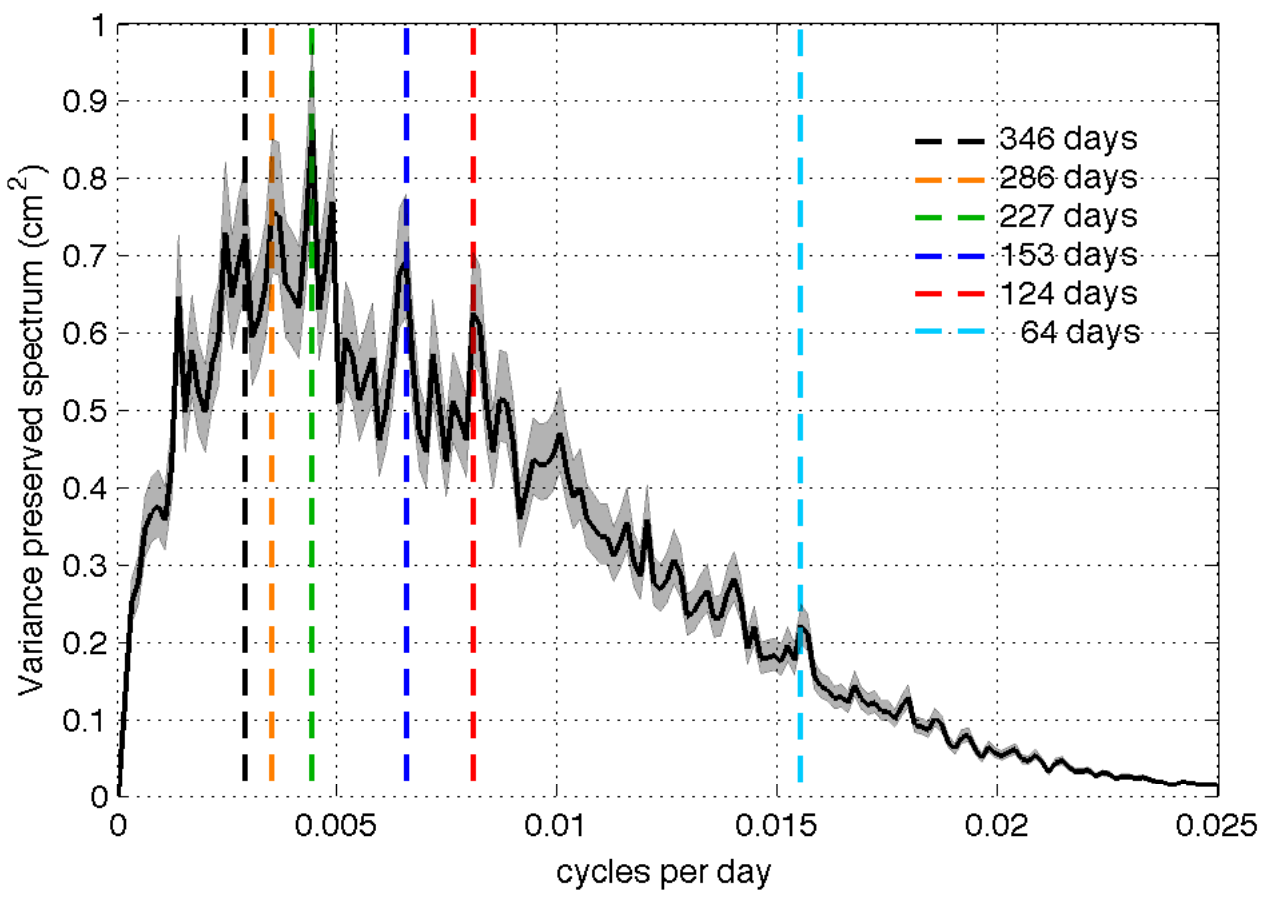

Figure 3.3: Variance preserved spectrum of area average SLA computed as the power of the signal multiplied by the frequency. The grey shaded profile reflects $95 \%$ confidence intervals. Vertical lines are drawn through the peaks to show annual and higher frequency mesoscale signals.

mum, north of Bollons Seamount that turns eastward as a prominent tongue. SSH gradients appear to spread along the $49^{\circ}-50^{\circ} \mathrm{S}$ latitude band, however, in most years there is a region at the southern boundary of the confluence box where gradients of SSH are very small.

To analyse temporal variations of the zonal extent of the confluence, maxima of $|\nabla S S H|$ were averaged over a year and plotted as a function of longitude (Fig. 3.6). Most intense gradients are found at the western edge of the confluence, from about $177^{\circ} \mathrm{W}$ and $175^{\circ} \mathrm{W}$ near Bollons Seamount, however, they show little temporal variation. In mid longitudes of the confluence, from about $174^{\circ} \mathrm{W}$ to $168^{\circ} \mathrm{W}$, there seems to be an overall increase of the magnitude of the more intense fronts with time (except for 2006). At the eastern edge of the box there are variations in the intensity of $|\nabla S S H|$, however there is no clear trend in 


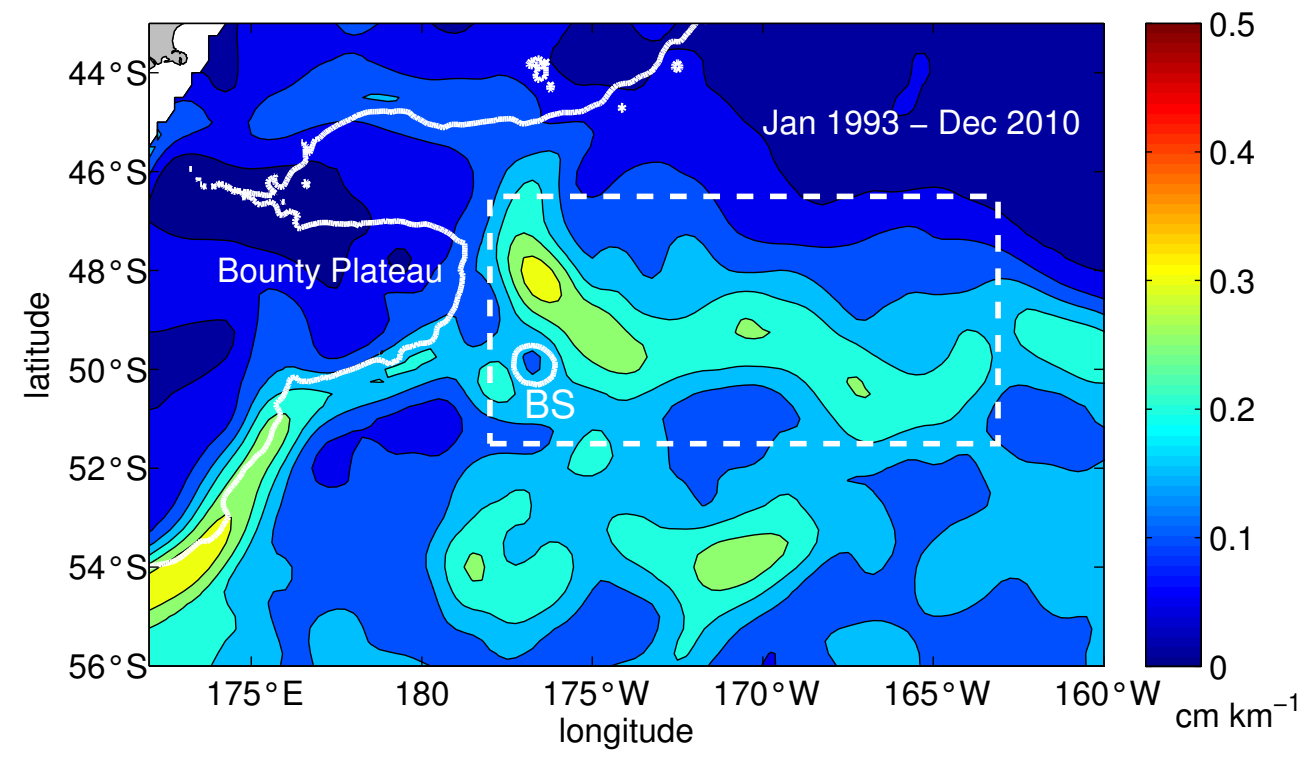

Figure 3.4: Mean $|\nabla S S H|$ from January 1993 to December 2010 in confluence region (BS=Bollons Seamount).

time.

Figure 3.7 shows annual means of the latitude associated with the maximum $\mathrm{SSH}$ gradient in the confluence. There is an apparent oscillatory behaviour of the latitude of the maximum $|\nabla S S H|$ through the years and an apparent increase in the intensity towards the end of 2010. While in 1993 and 1994 there is little shift in latitude, the change in intensity is quite sharp; it increases about 0.08 $\mathrm{cm} \mathrm{km}^{-1}$ in only one year. Between 1995 and 2010 there is an apparent shift in the confluence northwards at a rate of about $0.45^{\circ}$ per decade. More precisely, after 2002, when the confluence is more intense, its location remains north of $48^{\circ} \mathrm{S}$. However, as observed in Figure 3.6 maxima seem to be found north of Bollons Seamount, therefore this meridional shift of the maxima could only be a reflection of the front and eddy activity immediate north of Bollons Seamount, but not of the average.

Meridional variations in the location of the confluence can be better analysed in Figure 3.8, which shows yearly snapshots of the maximum SSH gradients as a 


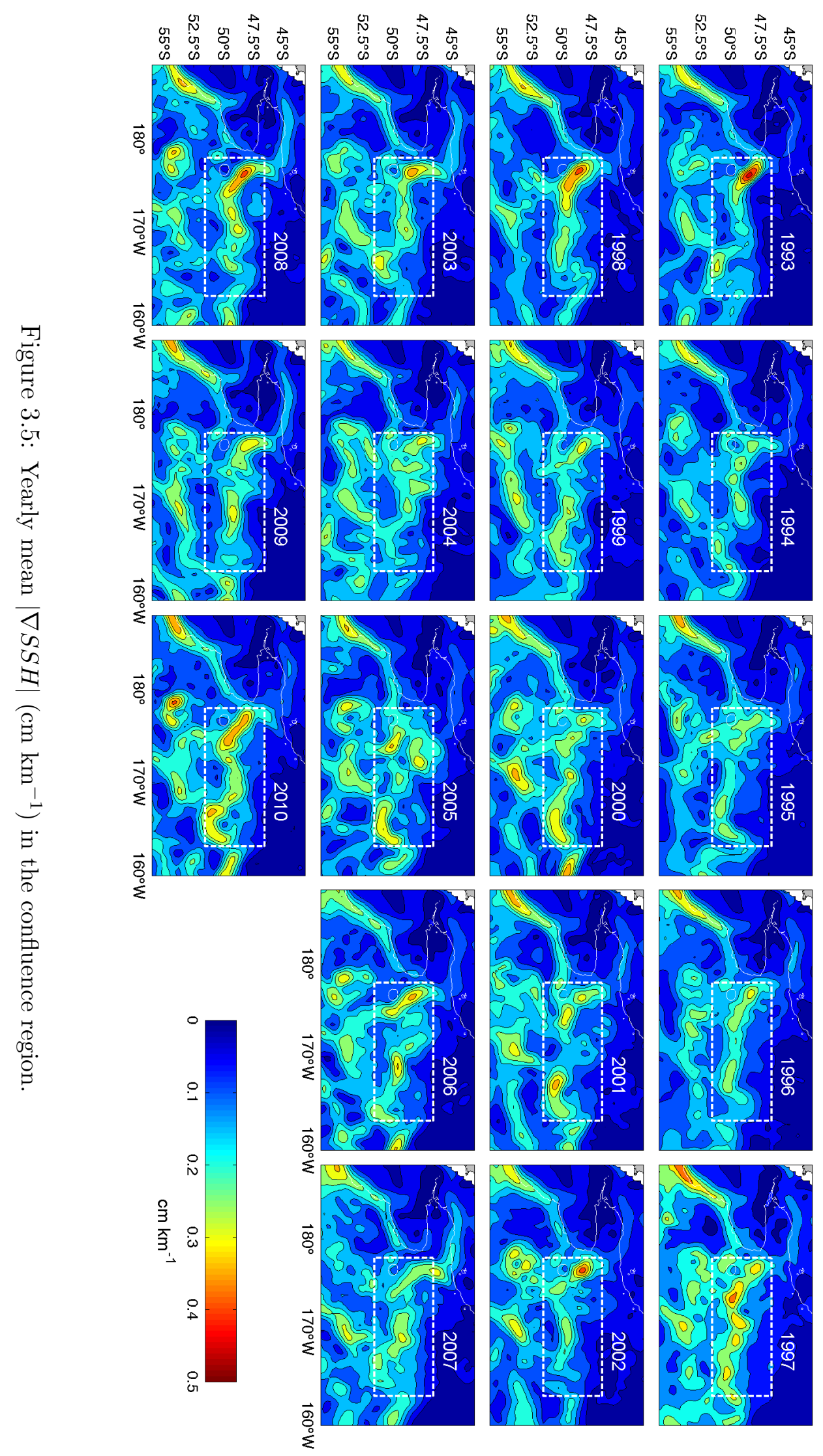




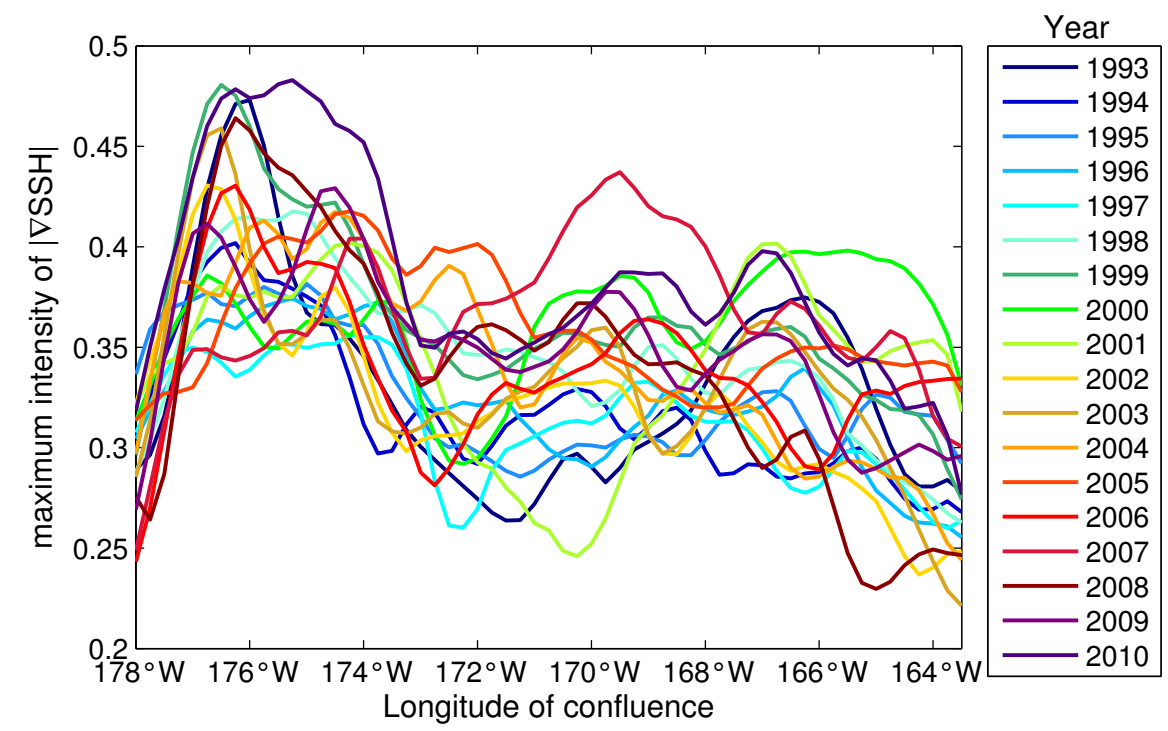

Figure 3.6: Maximum intensity of $|\nabla S S H|$ at the confluence plotted as function of longitude. Each contour represents a yearly average in $\mathrm{cm} \mathrm{km}^{-1}$.

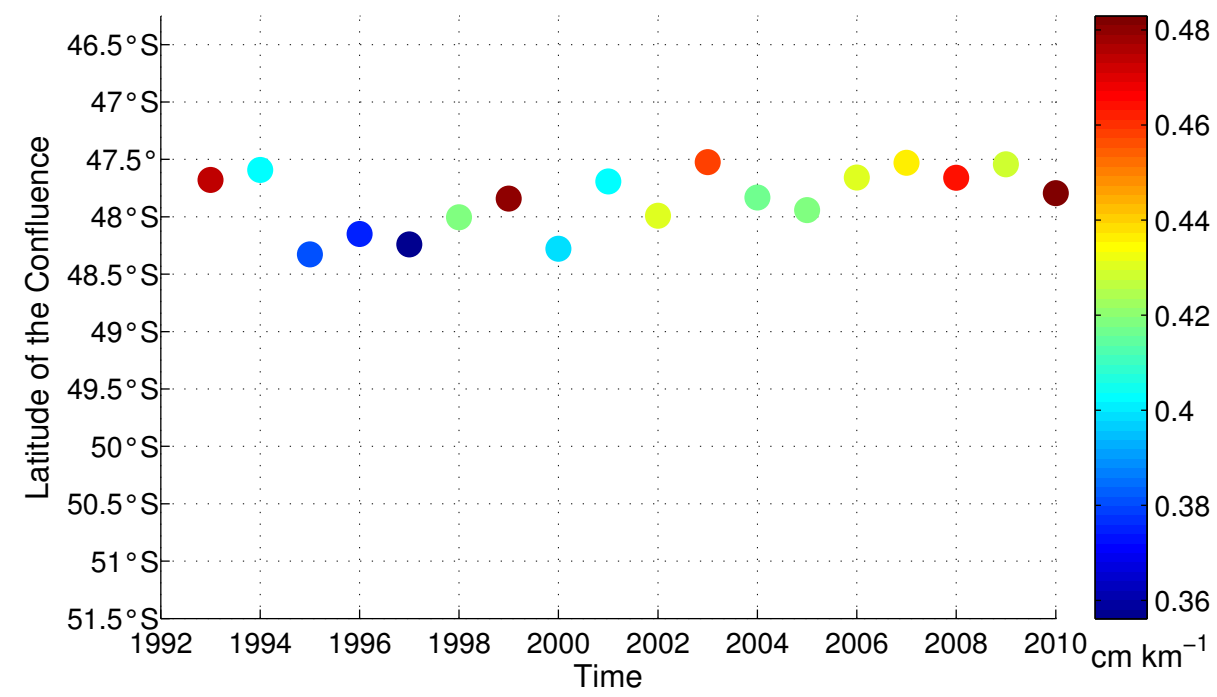

Figure 3.7: Latitude of maximum intensity of the confluence plotted as a function of time. Colour indicates strength of $|\nabla S S H|$ in $\mathrm{cm} \mathrm{km}^{-1}$.

function of latitude and longitude. The more intense fronts are concentrated in the western side of the confluence, except for 2000, 2001 and 2007 when stronger gradients were located farther east, at about $170-168^{\circ} \mathrm{W}$. Between $170^{\circ} \mathrm{W}$ and 
$165^{\circ} \mathrm{W}$, where there is not obvious bathymetric constraint, there is a southward dip of the fronts regardless of the intensity. At these longitudes, for most years, fronts sit at about $50^{\circ} \mathrm{S}$, and no significant temporal trend in the latitude of the fronts is observed. Fronts are less intense on the eastern side of the confluence. 


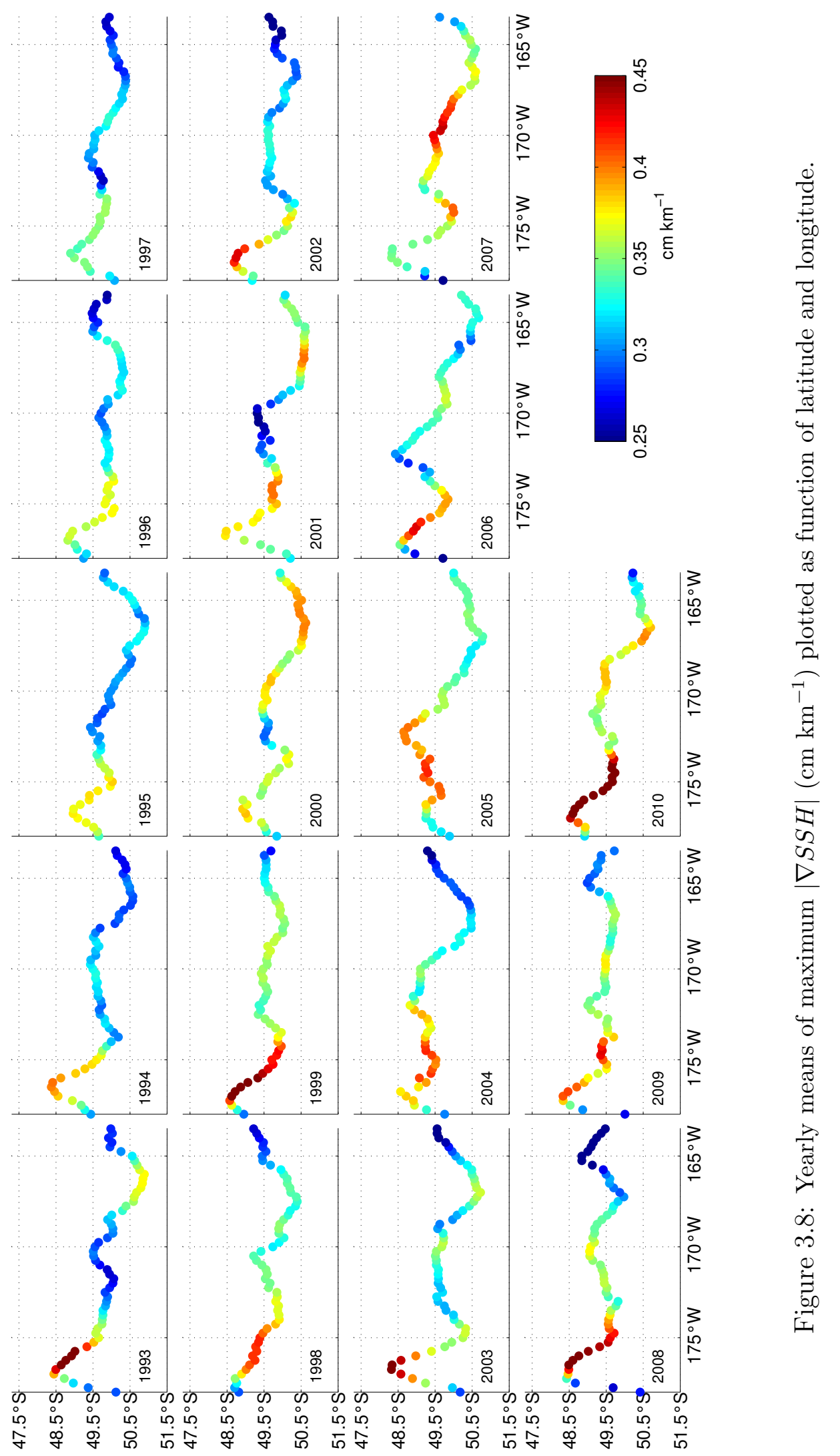




\subsubsection{EKE variability}

Using geostrophic velocity anomalies derived from maps of SLA the mean EKE from January 1993 to December 2010 was calculated for each grid point (Fig. 3.9). To investigate the spatial variability of the EKE in the confluence I used the same domain as for the analysis of the gradient of SSH, given that in the time average, maximum values of $|\nabla S S H|$ and EKE have similar spatial extent (cf. Fig. 3.4 and 3.9). The maximum value of the time average of the EKE in the confluence is $0.054 \mathrm{~m}^{2} \mathrm{~s}^{-2}$, corresponding to geostrophic velocity anomalies of nearly $33 \mathrm{~cm} \mathrm{~s}^{-1}$.

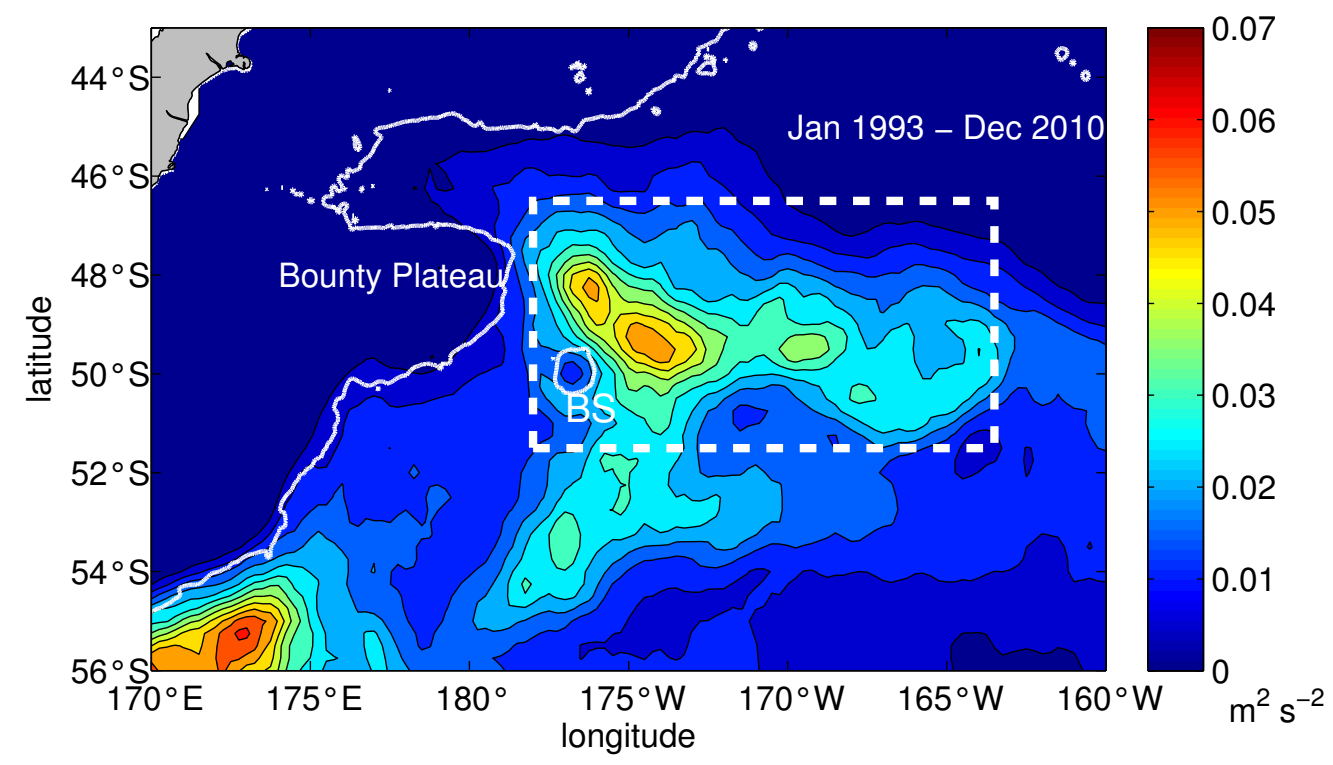

Figure 3.9: Mean EKE from January 1993 to December 2010 in the confluence region (BS=Bollons Seamount).

Figure 3.10 shows snapshots of the yearly averaged EKE field. For most years, the EKE peaks are concentrated northeast of Bollons Seamount within the confluence zone. Comparing snapshots of $|\nabla S S H|$ and EKE (cf. Fig. 3.5 and 3.10), the EKE does not extend as far eastwards as the gradients of SSH. 
Most years the EKE is concentrated within the E-W limits of the box. However, during 2002 the EKE signal spreads southwest, south of Bollons Seamount and outside the confluence domain, reaching amplitudes of up to $0.085 \mathrm{~m}^{2} \mathrm{~s}^{-2}$. This observation will be analysed in more detail in the next section.

The temporal and zonal variability of the EKE show that maxima are observed at the western edge of the confluence along the longitudes of Bollons Seamount (Fig. 3.11) in a similar location found for maxima of front intensity (Fig. 3.6). From $177^{\circ} \mathrm{W}$ to $174^{\circ} \mathrm{W}$, maximum EKE values oscillate between 0.07 $\mathrm{m}^{2} \mathrm{~s}^{-2}$ in 1993 and nearly $0.15 \mathrm{~m}^{2} \mathrm{~s}^{-2}$ in 2010, corresponding to geostrophic velocities between $37 \mathrm{~cm} \mathrm{~s}^{-1}$ to $55 \mathrm{~cm} \mathrm{~s}^{-1}$ respectively. Although the EKE decreases towards mid longitudes of the confluence, there appears to be an increase in EKE levels with time, particularly from 2006 to 2010. The zonal and temporal variability of the EKE is similar to that of the SSH fronts. 


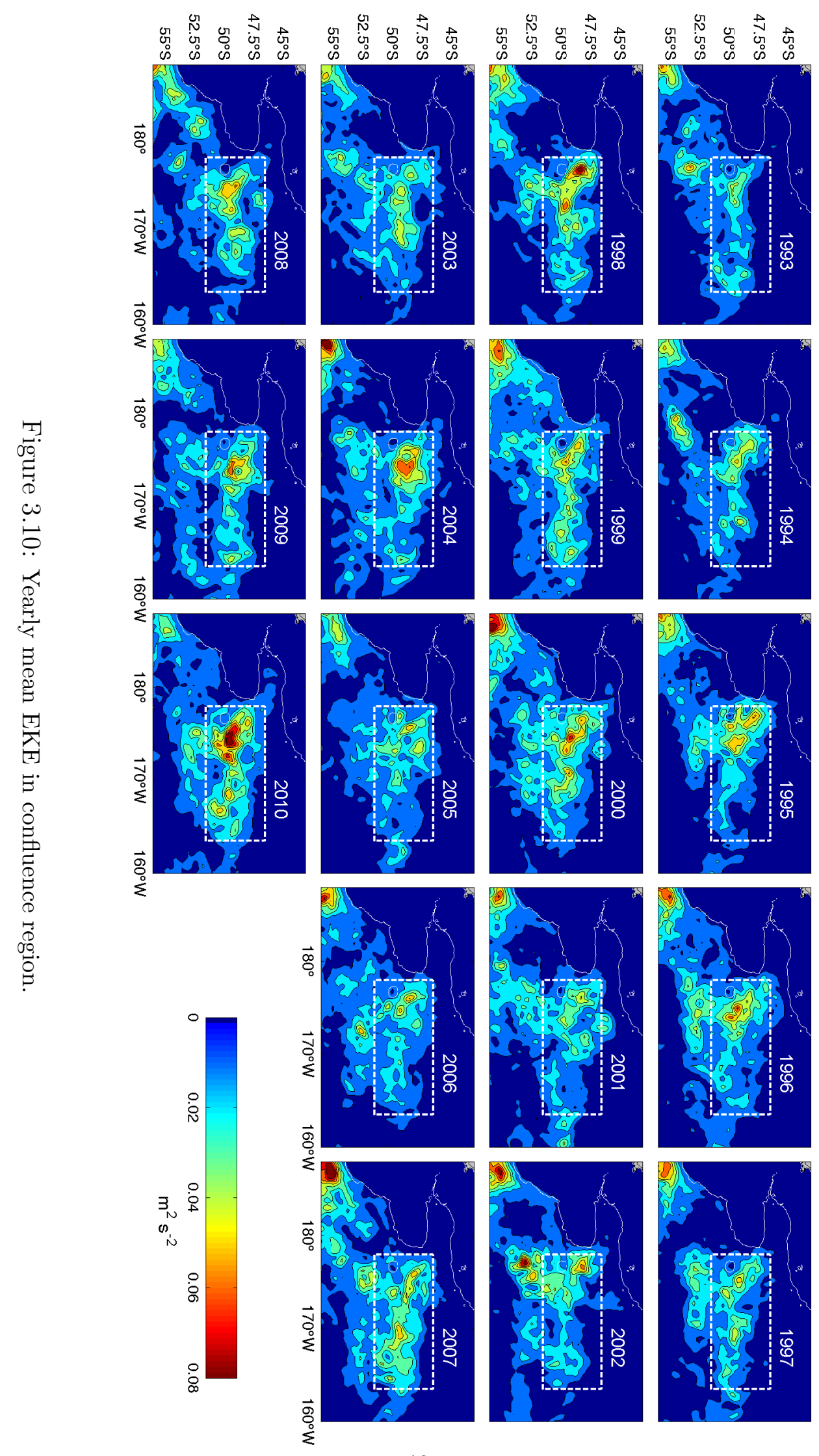




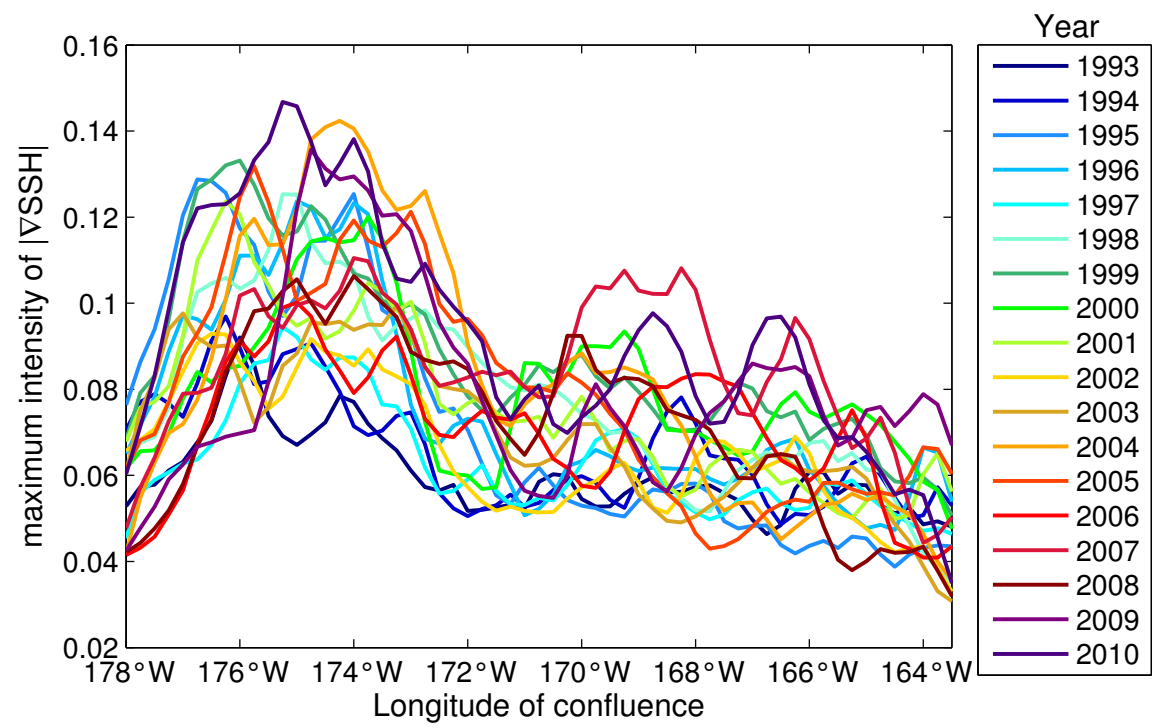

Figure 3.11: Maximum EKE levels plotted as function of longitude. Each contour represents a yearly mean in $\mathrm{m}^{2} \mathrm{~s}^{-2}$. 


\subsection{Area average of fronts and EKE time series}

To investigate the relationship between the intensity of the fronts and the EKE in the confluence, time series were created for the area averages of $|\nabla S S H|$ and EKE (Fig. 3.12). The time series was smoothed with a 13-month cosine window. Both signals show an interannual variability and are highly correlated with a correlation coefficient $r=0.84$ and exhibit an overall increasing trend into recent time. This correlation coefficient is significant at the $99 \%$ confidence level with 6 DOF, calculated as the number of oscillations (or fluctuations) observed in the time series (Emery and Thomson, 2001). The intensity of the area average SSH gradients increased by $0.01 \mathrm{~cm} \mathrm{~km}^{-1}$ per decade and the EKE $0.0023 \mathrm{~m}^{2} \mathrm{~s}^{-2}$ per decade (equivalent to $23 \mathrm{~cm}^{2} \mathrm{~s}^{-2}$ per decade). An analysis of the de-trended data gives a correlation $r=0.75$ (significant at $95 \%$ confidence level).

A substantial increase in the amplitude of both signals is observed during 1998 and from 2003 until 2005 when the area average magnitude of the SSH fronts reach its maximum of $0.195 \mathrm{~cm} \mathrm{~km}^{-1}$. Both SSH and EKE continue to rise in 2010 reaching approximately $0.19 \mathrm{~cm} \mathrm{~km}^{-1}$ and $0.03 \mathrm{~m}^{2} \mathrm{~s}^{-2}$ respectively. These observations are expected to show some differences from those observed in the yearly snapshots (Fig 3.5 and 3.10) since here the analysis encompasses an area average, which smooths out maximum amplitudes observed at particular locations.

The relationship between the EKE in the confluence and the EKE south of Bollons Seamount was also examined. This analysis is motivated by the anomalous high eddy activity observed in 2002 outside the confluence domain (Fig. 3.10). The area average of the EKE was calculated in a box south of the confluence (Fig. 3.13) and compared with the EKE in the confluence (Fig. 3.14) to observe the contribution of this region; i.e., whether the variability in 


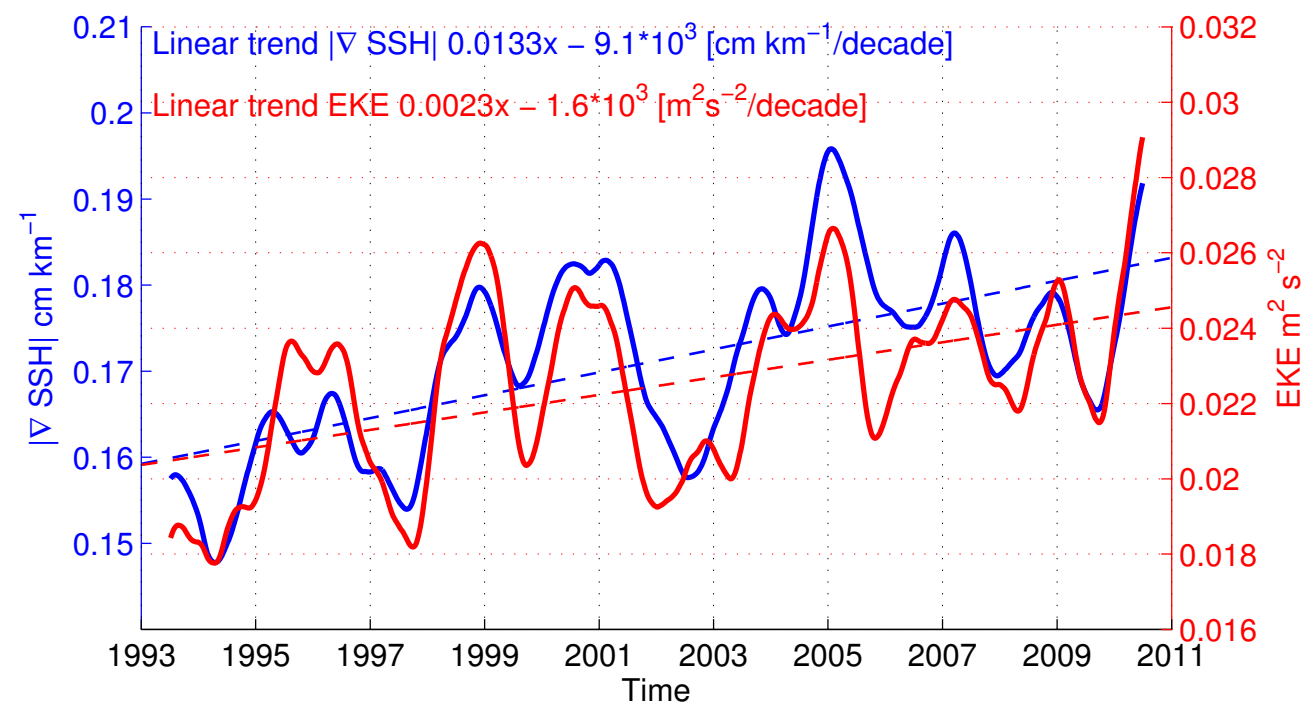

Figure 3.12: Area average of $|\nabla S S H|$ and EKE time series smoothed with a 13month cosine window.

this region is similar or not to that observed in the confluence. Average EKE south of the confluence was scaled by the ratio of the areas of the two regions to show time series proportional to the total EKE in each region.

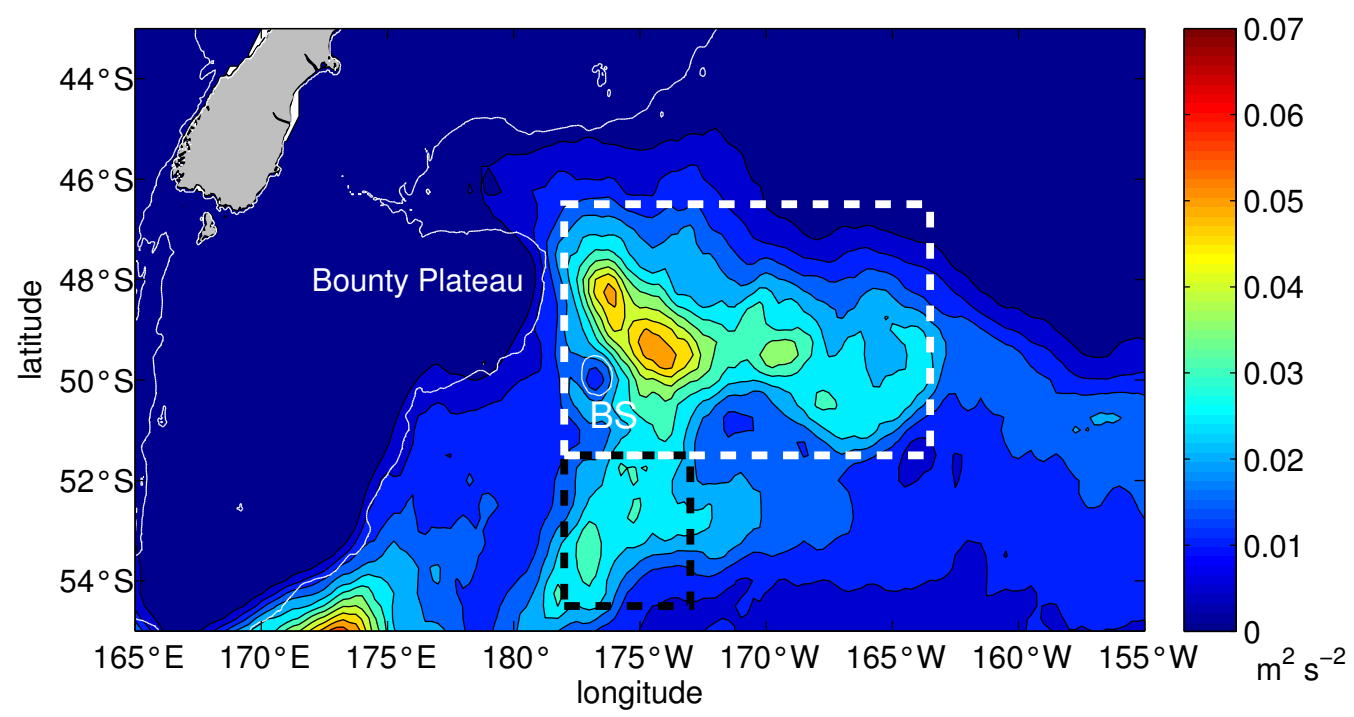

Figure 3.13: Eddy activity south of the confluence. Dashed white box delineate the confluence domain, to the south the black dashed box indicates the region where significant eddy activity is observed in 2002 . 
The EKE south of the confluence does not show an obvious trend, and is uncorrelated to the EKE in the confluence region when time scales shorter than annual are removed and weakly anticorrelated when time scales longer than 2 years are retained $(r=-0.07$ and $r=-0.3$ respectively at $95 \%$ confidence level), particularly during 2002, which is the year of anomalous eddy activity outside the confluence. The total EKE in this region is much less than the EKE in the confluence.

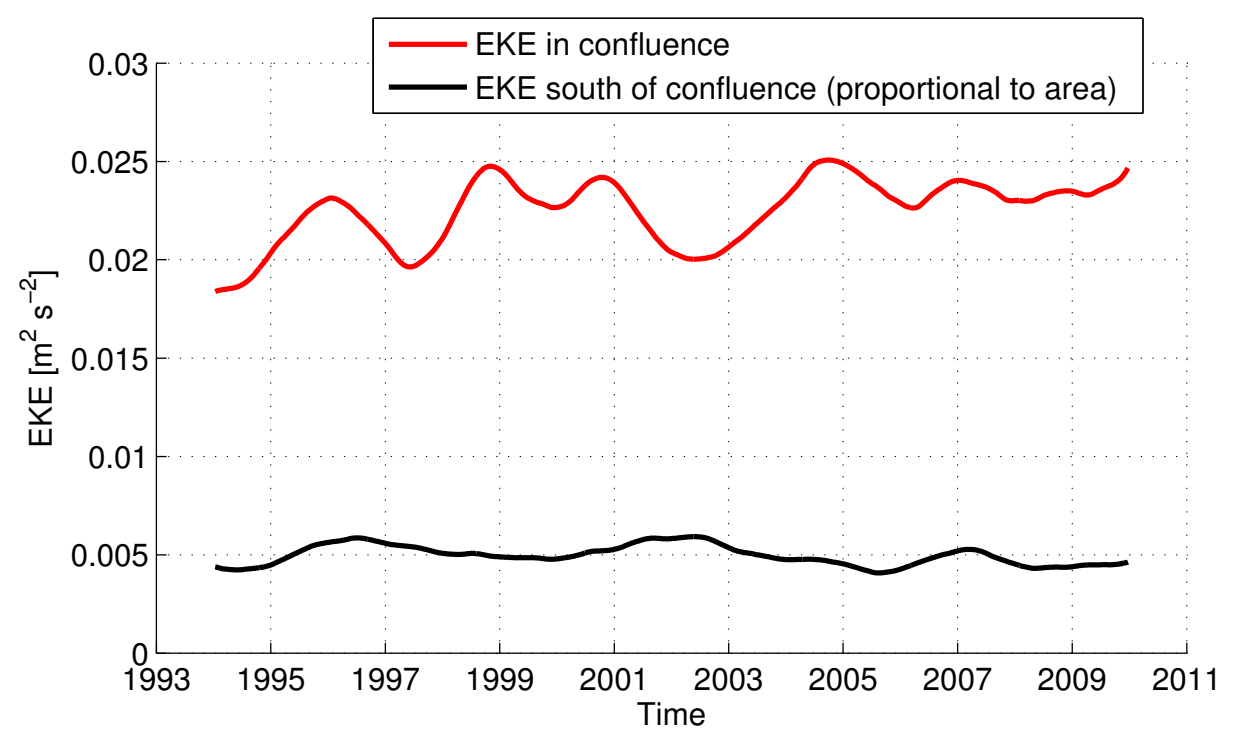

Figure 3.14: Time series of area weighted EKE in the confluence compared to time series of EKE immediate south of the confluence. Figure ahows times series smoothed using a 25-month cosine filter to retain periods with time scales longer than 2 years. There is little correspondence between the time series. 


\subsection{Sensitivity tests: changing the shape of the confluence}

In this study, the selected area of the confluence box is based on the extent and location of the most significant values of the time averaged $|\nabla S S H|$ and EKE signals and where STW meets SAW. The purpose of the experiments carried out in this section is to observe the sensitivity of the results to changes in the domain. In other words, whether the $|\nabla S S H|$ and EKE signals are still well correlated in time, as shown by Fig. 3.12, when the size and shape of the confluence area are changed.

Based on the time average of the EKE map, two regions were selected. The first region is delimited by the contour with EKE values $\geq 0.026 \mathrm{~m}^{2} \mathrm{~s}^{-2}$ corresponding to velocity anomalies $\geq 23 \mathrm{~cm} \mathrm{~s}^{-1}$ (Fig. 3.15a). The second region encloses all the points with EKE values $\geq 0.032 \mathrm{~m}^{2} \mathrm{~s}^{-2}$, associated with velocities $\geq 25 \mathrm{~cm} \mathrm{~s}^{-1}$ (Fig. 3.16a). Therefore, the higher the EKE the higher the velocity anomalies and the smaller the contour. In each case, these boundaries were kept fixed for each time step. Time series of the area average of $|\nabla S S H|$ and EKE were calculated within these two different contours (Fig. 3.15b and 3.16b) using the same methodology explained in Sections 2.5.2 and 2.5.3. The signals were smoothed with a 13-month running cosine window to retain periods longer than annual.

EKE levels greater than $0.032 \mathrm{~m}^{2} \mathrm{~s}^{-2}$ are concentrated in a smaller area, resulting in fewer independent data points, which is reflected in the time series analysis (Fig. 3.16b). Selecting geostrophic velocity anomalies greater than 25 $\mathrm{cm} \mathrm{s}^{-1}$ instead of greater than $23 \mathrm{~cm} \mathrm{~s}^{-1}$, i.e., a change in contours, increases the frequency of the $|\nabla S S H|$ signal compared to the EKE, and reduces the correlation of both signals $(r=0.53$ for medium area and $r=0.18$ for the 


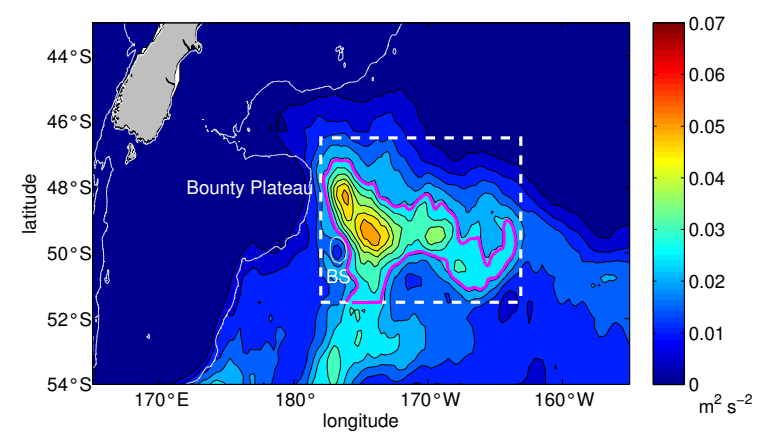

(a)

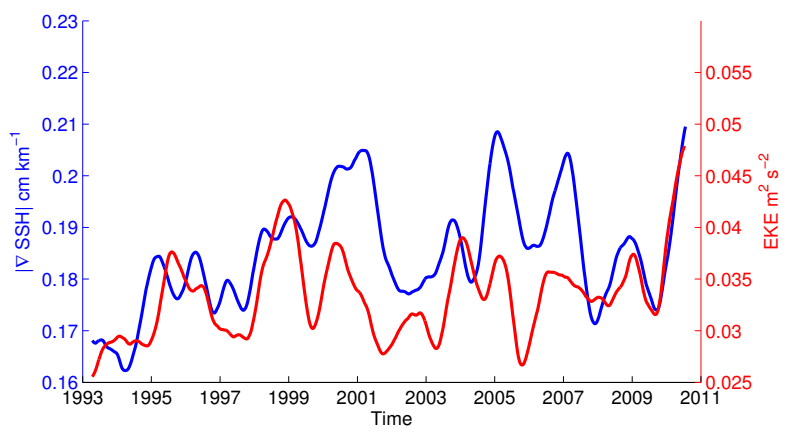

(b)

Figure 3.15: Sensitivity test 1: confluence domain determined by EKE levels associated with geostrophic velocities $\geq 23 \mathrm{~cm} \mathrm{~s}^{-1}$. a) Confluence enclosed by 0.026 $\mathrm{m}^{2} \mathrm{~s}^{-2}$ contour (magenta). b) Area average of $|\nabla S S H|$ and EKE time series. Time series were smoothed with a 13-month running cosine window and are correlated with $r=0.53$.

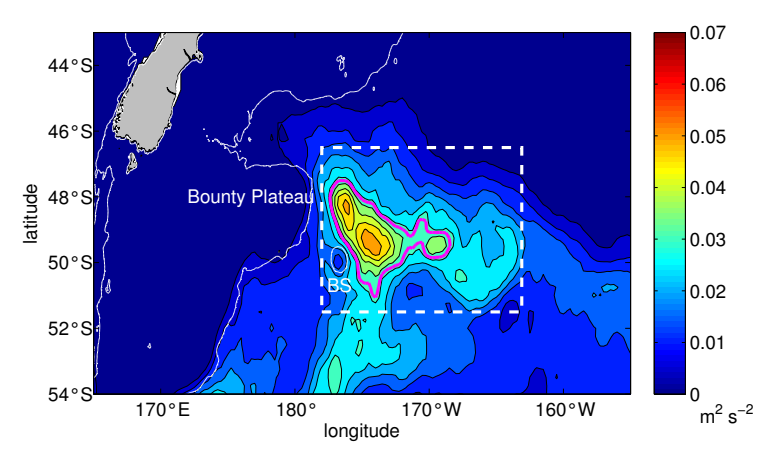

(a)

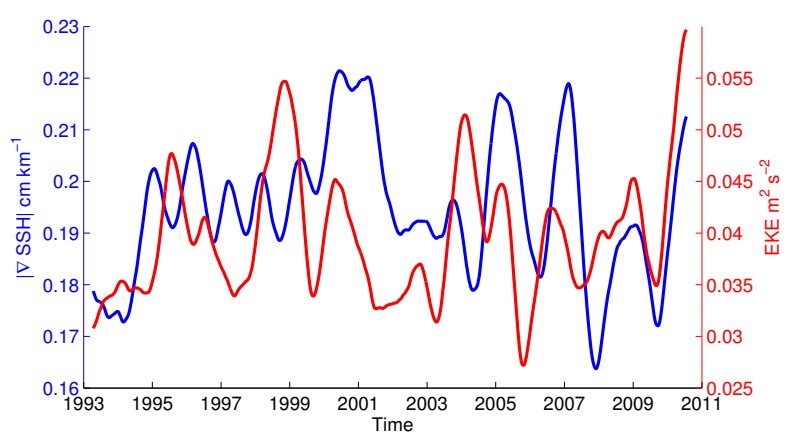

(b)

Figure 3.16: Sensitivity test 2: confluence domain determined by EKE levels associated with geostrophic velocities $\geq 25 \mathrm{~cm} \mathrm{~s}^{-1}$. a) Confluence enclosed by $0.032 \mathrm{~m}^{2} \mathrm{~s}^{-2}$ contour (magenta). b) Area average of $|\nabla S S H|$ and EKE time series. Time series were smoothed with a 13-month running cosine window are poorly correlated with $r=0.18$.

smaller one. Therefore, the correlation between the signals decreases as the confluence area is reduced and no temporal trend is seen in either the front or the EKE signal. 


\subsection{Temperature difference across the conflu- ence}

The SST variability across the confluence was calculated using two approaches as described in Section 2.5.4. The difference in $\operatorname{SST}(\Delta S S T)$ between boxes located northeast and southwest of the confluence shows an upward trend of about $0.42^{\circ} \mathrm{C}$ per decade in a nearly parallel direction to the trend of the area average $|\nabla S S H|$ (Fig. 3.17). A positive trend for $\triangle S S T$ indicates a greater temperature difference between STW and SAW, i.e., a greater temperature gradient across the confluence region. The $|\nabla S S H|$ and $\Delta S S T$ time series were low-pass filtered using a 25-month running cosine window and have a correlation coefficient $r=0.6$. However, the correlation is not significant since much of the correlation comes from the positive trend in both time series with clearly little correspondence at higher frequencies (the correlation of the residual time series (de-trended data) is $r=0.2$ ).

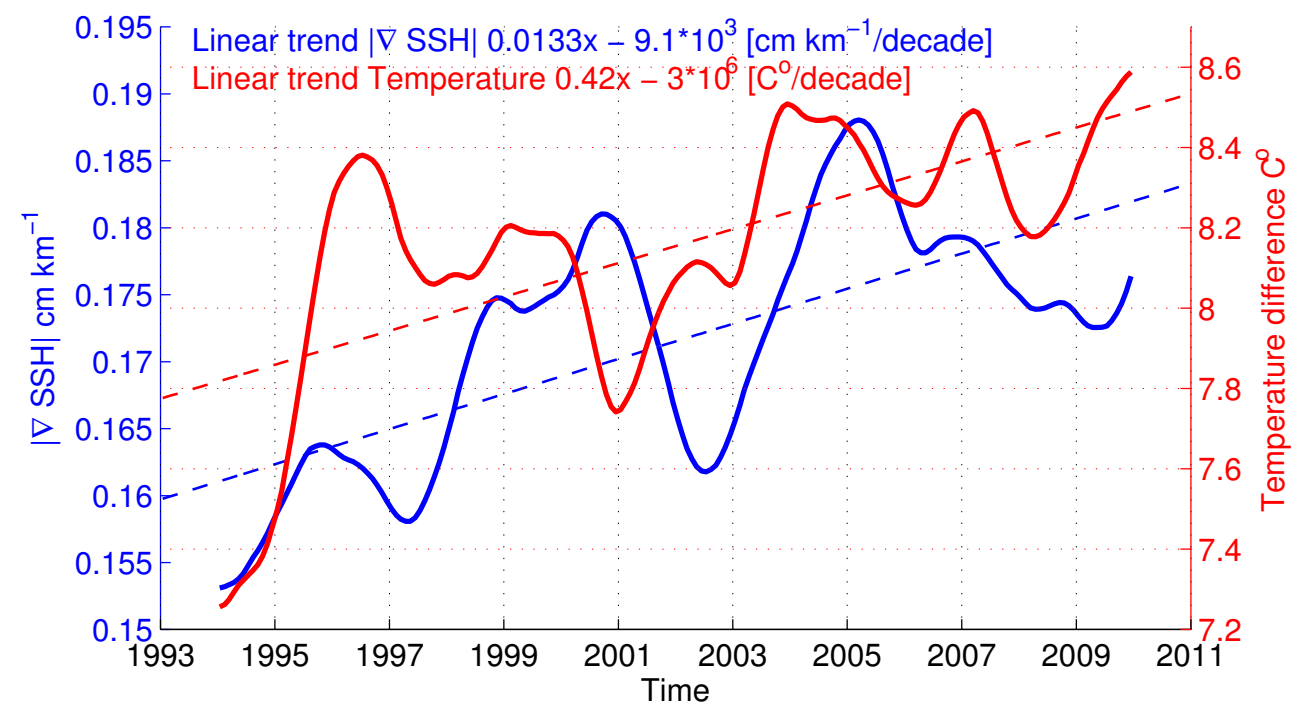

Figure 3.17: SST changes across the confluence compared to area average of $|\nabla S S H|$. The higher correlation of the signals $(r=0.6)$ comes from the positive trend in both time series, smoothed with a 25 -month running cosine window. 
The result of the second method employed to analyse SST variability in the western edge of the confluence is shown in a time latitude plot of the SST (Fig. 3.18). Between the latitudes of the confluence $\left(51.5^{\circ} \mathrm{S}-46.5^{\circ} \mathrm{S}\right)$ there is a tightening of the isotherms in the range of $8^{\circ} \mathrm{C}$ to $12^{\circ} \mathrm{C}$, indicating an increase in the SST gradient occurring across these latitudes.

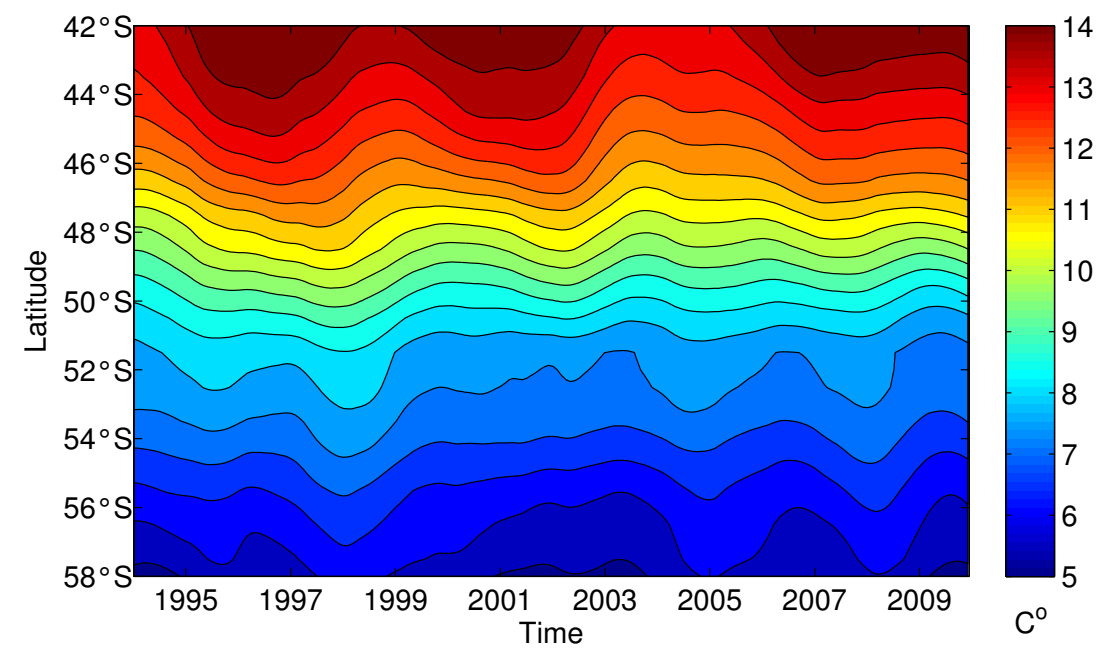

Figure 3.18: SST variability along southwest-northeast transect AB (see Fig. 2.3) at the western edge of confluence.

Temporal variations of $\triangle S S T$ are more obvious north and south of the confluence latitudes, where isotherms representing typical temperatures of STW and SAW spread more and show greater meridional oscillations than those in the confluence region. A southward shift of the isotherms started in mid-1996 (observed north of $46^{\circ} \mathrm{S}$ ) and ended in 1998 (observed south of $52^{\circ} \mathrm{S}$ ) implying warmer water entered the region during that period. A year later isotherms shifted northwards suggesting stronger influx from the south bringing colder water to the region. These south-to-north shifts of the isotherms occurred again in the period 2001-2003 and 2007-2009, although it was not as obvious as in 1997-1999. 


\subsection{Response of the confluence to wind forcing}

\subsubsection{South Pacific winds and the meridional transport of confluent Western Boundary Currents}

To test the hypothesis that basin-scale winds influence the intensity and extent of the confluence front, the wind-driven transport of the currents that feed the region was calculated using the Island Rule (Godfrey, 1989) with the NCEP reanalysis winds as described in Section 2.5.5. With the configuration chosen for the integration of the wind stress curl (Fig. 2.5), I ensure that the Island Rule will consider the wind-driven meridional transports at the boundary of the confluence. It is expected that changes in transports of the confluent currents will affect the extent and location of the SSH gradients due to the inflows of warm, STW from the northern side of the confluence and cold, SAW from the southern side.

The net meridional transport of the WBCs calculated using the Island Rule is portrayed in Figure 3.19. A positive (negative) transport indicates a northward (southward) transport. A meridional transport value of zero is equivalent to having purely zonal transport, indicating where the boundary currents turn eastward.

It is found that northward transports predicted by the Island Rule have greater magnitudes than poleward ones. Figure 3.19 shows two intrusions, greater than $20 \mathrm{~Sv}\left(1 \mathrm{~Sv}=10^{6} \mathrm{~m}^{3} \mathrm{~s}^{-1}\right)$ from the south into the confluence domain. The first northward intrusion was during 1998, and the second one during 2007.

The northern edge of the confluence appears to be dominated by inflows from the north, from 1999 to the end of 2010, reaching the most southerly lati- 


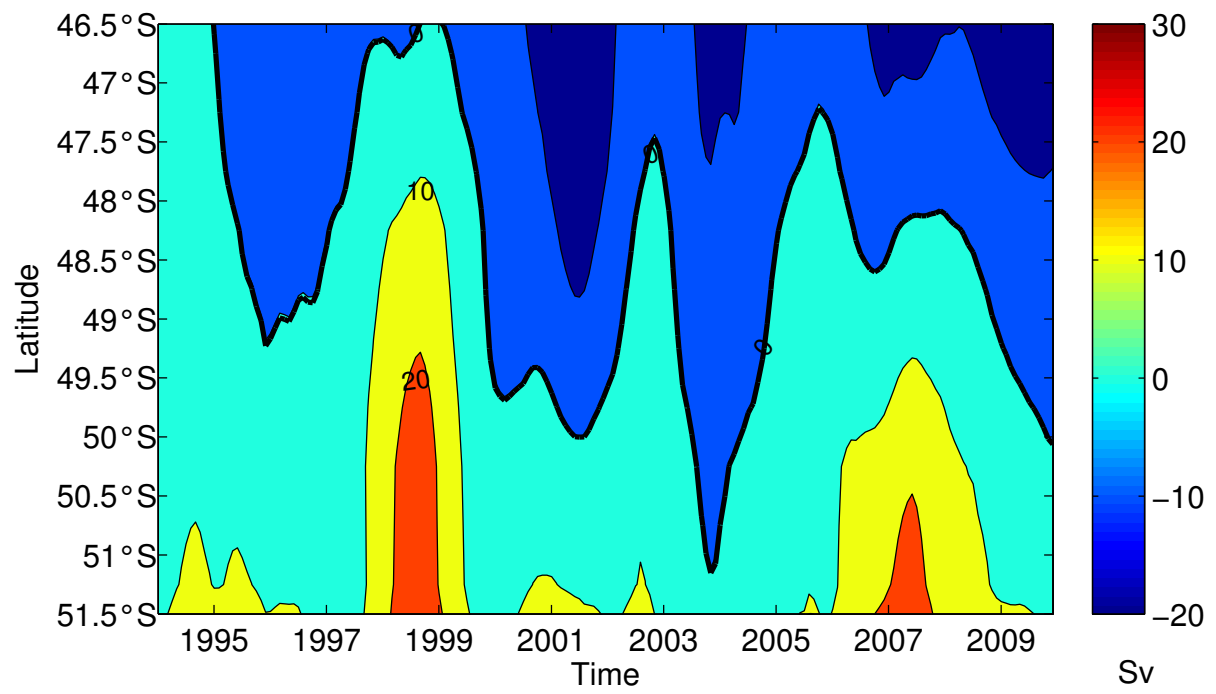

Figure 3.19: Meridional transport of WBCs east of New Zealand predicted by the Island Rule. Positive (negative) transport in Sv units $\left(1 \mathrm{~Sv}=10^{6} \mathrm{~m}^{3} \mathrm{~s}^{-1}\right)$ indicates a net northward (southward) transport. Zonal transport is highlighted in thick black contour. Time series have been smoothed with a 25 -month running cosine window.

tude (nearly going across the confluence) at the end of 2003. The apparent front indicating purely zonal transport (thick black curve corresponding to zero contour in Fig. 3.19) appears to migrate southward with time, despite interannual latitudinal oscillations.

The transport anomaly $(T A)$ into the confluence region was calculated by removing the temporal mean for each latitude. A large-scale meridional gradient $(\Delta T A)$ was computed by taking the difference in transport anomalies between $51.5^{\circ} \mathrm{S}$ and $46.5^{\circ} \mathrm{S}$, the southern and northern latitudes of the confluence domain respectively (an average for all longitudes). Fluctuations with periods shorter than 2 years were removed from the time series of $\Delta T A$ with a 25-month running cosine window. $\Delta T A$ is represented by the magenta curve in Figure 3.20.

These anomalies represent convergences and divergences of the transport driven exclusively by the basin-scale winds. When the transport into the region from either the north or the south is stronger than average there is a conver- 
gence (positive $\Delta T A$ ). Conversely, when the transport from either the north or south is weaker, there is a divergence (negative $\Delta T A$ ). Therefore, Figure 3.20 highlights convergences during 1998, from mid 2000 to 2002, and from mid 2006-2009 when $\Delta T A$ reached a maximum of about $20 \mathrm{~Sv}$.

To analyse the relationship between transport and strength of the SSH fronts I compare the wind-driven transport predicted by the Island Rule $(\Delta T A)$ with the time series of the area average $|\nabla S S H|$ (Fig. 3.20). A 25-month cosine window was applied to both time series in order to retain periods longer than 2 years. There is some correspondence between the fluctuations in $\Delta T A$ and $|\nabla S S H|$ from 1994 to 2003, and both show a positive trend. $\Delta T A$ has been increasing at a rate of $8.8 \mathrm{~Sv}$ per decade, however without 2006-2010 the trend would be much weaker. In addition, is important to point out that from 2003 to 2005 the intensity of the front increases while the difference in transport anomalies is weak, and in the last 4 years of the time series (2006-2010) front intensity decreases during the increase in $\Delta T A$. The overall correlation is not significant $(r=0.4)$.

The northward intrusions observed in 1998 and 2007, as mentioned earlier, coincide with years when altimetric observations show either an increase in the area average of gradients of SSH and high EKE or relatively high levels of these variables. This is especially the case for 1998, when this influx of SAW coincides with a northward shift of the SST isotherms (Fig. 3.18), a convergence of the transports and an increase in the confluence intensity (Fig. 3.20) and EKE. It appears that these connections do not hold over other time periods, for example, between 2003 and 2005 there is a significant increase of $|\nabla S S H|$, which is the maximum during this entire period; however it is uncorrelated with weak fluctuations in the transport during that period. 


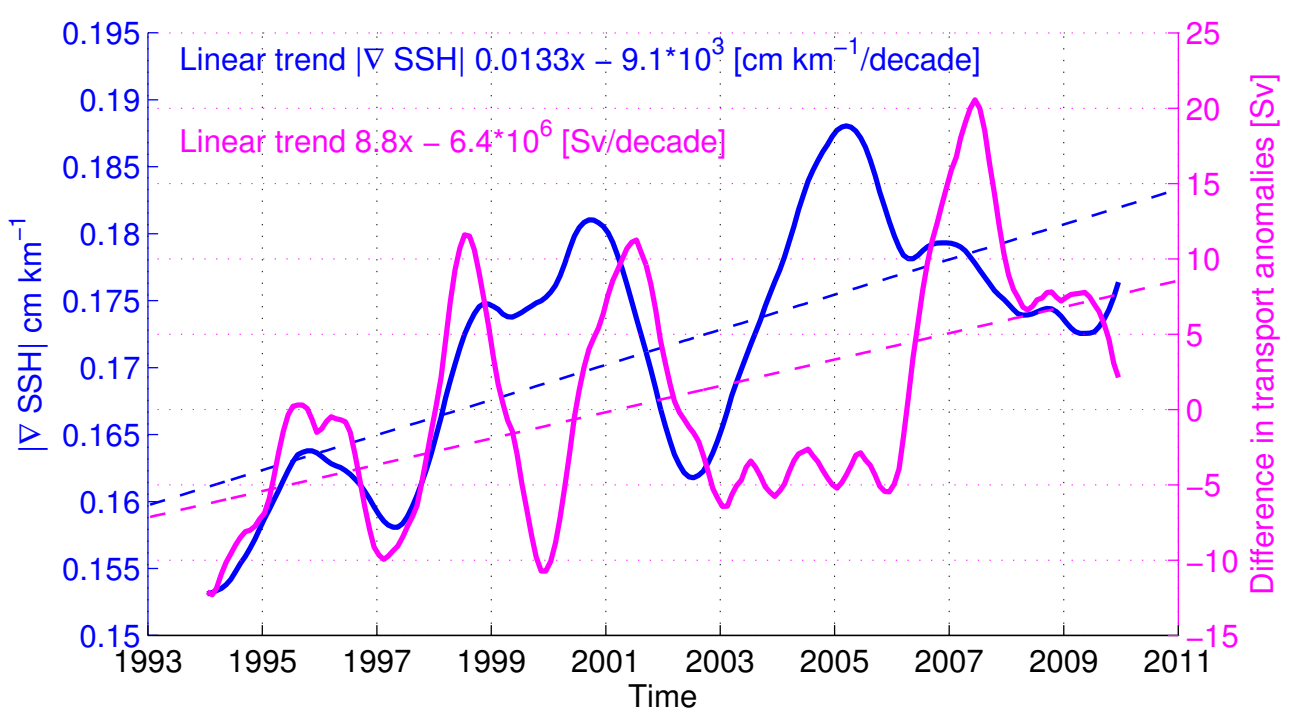

Figure 3.20: Time series of $\Delta T A$ and area average $|\nabla S S H|$ to compare intensity of SSH fronts with increasing convergences in the transport of WBCs. The positive trend for the transport anomalies $(\Delta T A)$ would be much weaker if the last years (2006-2010) of the transport time series were removed. Time series were smoothed with a 25-month running cosine window.

\subsubsection{Southern Hemisphere climate indices and variabil- ity of the confluence}

To further investigate the influence of the basin-scale winds on the intensity of the fronts in the confluence, the time series of the SAM and SOI indices were compared with the $|\nabla S S H|$ time series (Fig. 3.21).

The correlation between SAM and $|\nabla S S H|$ (smoothed with a 13-month cosine window) is very low and not significant $(r=0.1)$. Even retaining periods longer than 2 years, the signals remain poorly correlated $(r=0.2)$.

Comparing the time series of the SOI with the $|\nabla S S H|$ an upward trend of both signals can be observed. However, the signals do not show a significant correlation $(r=0.4)$. These correlations of SAM and SOI with $|\nabla S S H|$ are calculated at zero lag. 


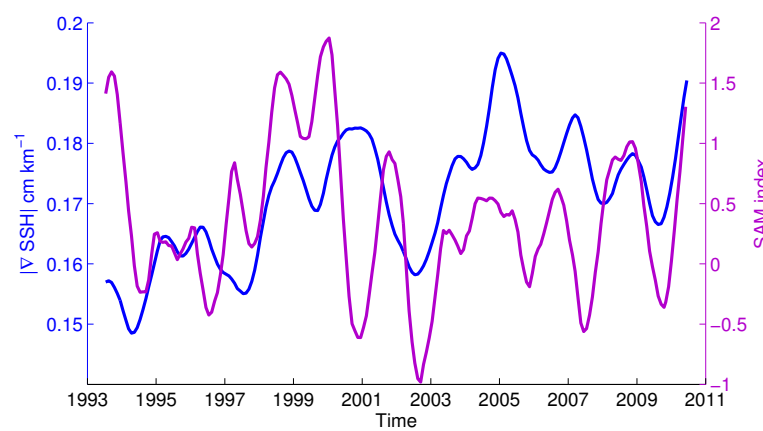

(a)

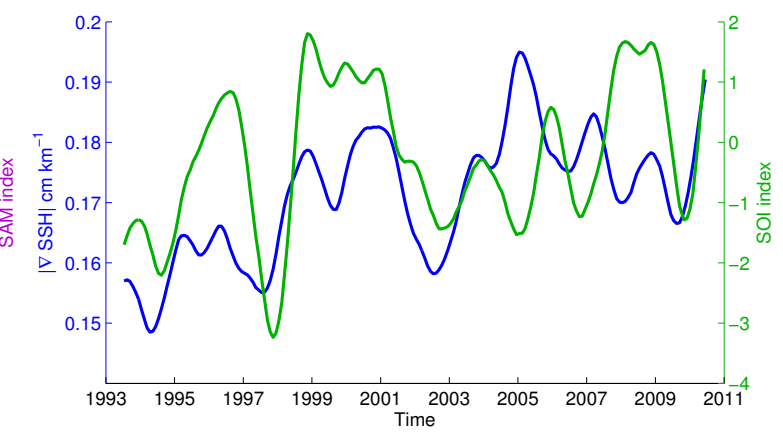

(b)

Figure 3.21: Global climate indices SAM and SOI compared with confluence front intensity. a) SAM index time series and area average of $|\nabla S S H|$. b) SOI index time series and area average of $|\nabla S S H|$. Both time series were smoothed with a 13-month running cosine window.

\subsubsection{Regional wind control on the confluence}

In this section, the influence of the local wind stress curl on the intensity of the confluence front is examined (Fig. 3.22). Both time series were low-pass filtered using a 25-month running cosine window. Over the entire period there is little correlation between the two signals is not significant $(r=0.2)$. Between 1994 and 2004 both signals have similar fluctuations. After 2004 the local wind stress curl and $|\nabla S S H|$ show opposite variability. The local wind forcing does not show the positive trend evident in the front signal $(|\nabla S S H|)$.

In addition, the connection between local wind forcing and EKE was explored by comparing the local wind stress curl anomaly with the EKE time series (Fig. 3.23). There is no clear correlation of the local wind forcing and the EKE on annual frequency bands. At longer periods than 2 years the correlations are similar to those calculated for the time series of $|\nabla S S H|$ and the local wind stress curl (Fig. 3.22), an expected result since the EKE and SSH gradients are well correlated (Fig. 3.12). 


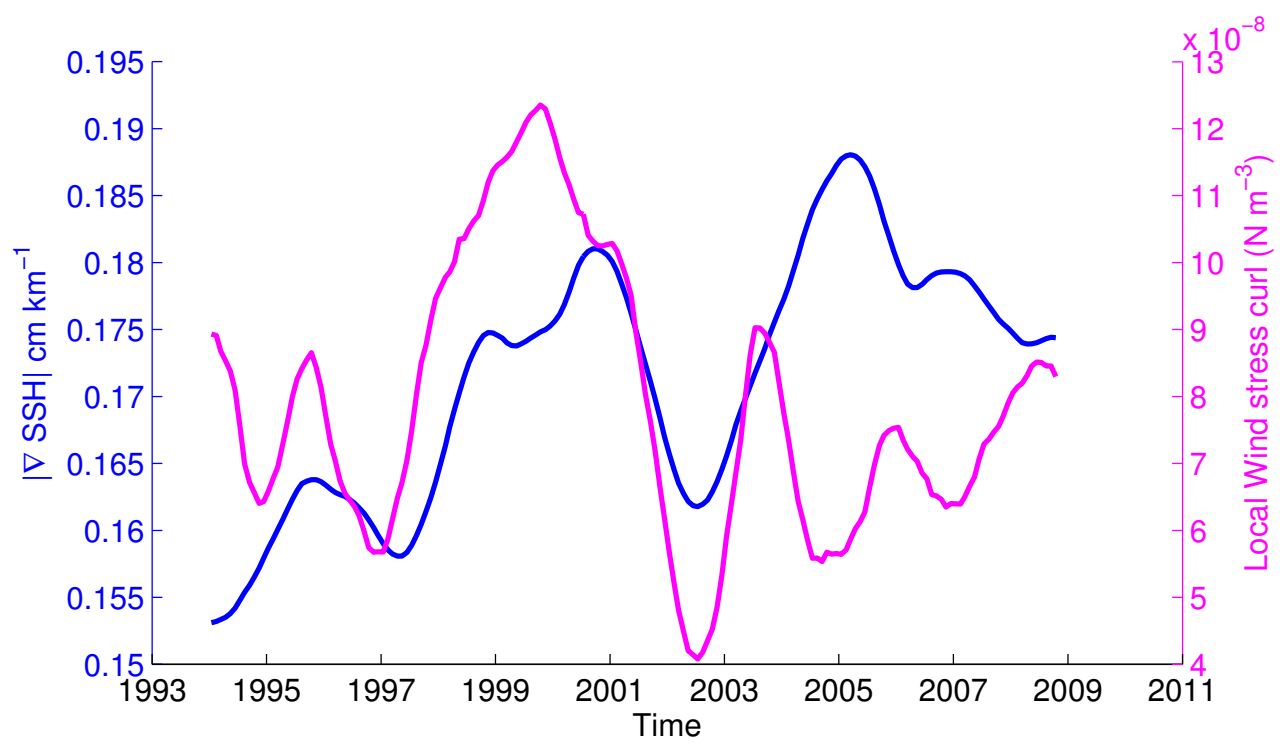

Figure 3.22: Time series of the area average local wind stress curl and $|\nabla S S H|$ highlighting the moderate correlation up to 2004, after which these parameters are anticorrelated. Both time series were smoothed with a 25-month running cosine window.

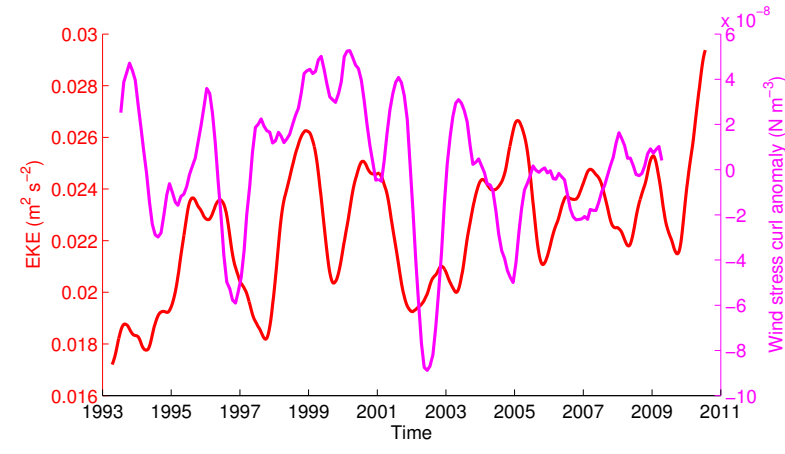

(a)

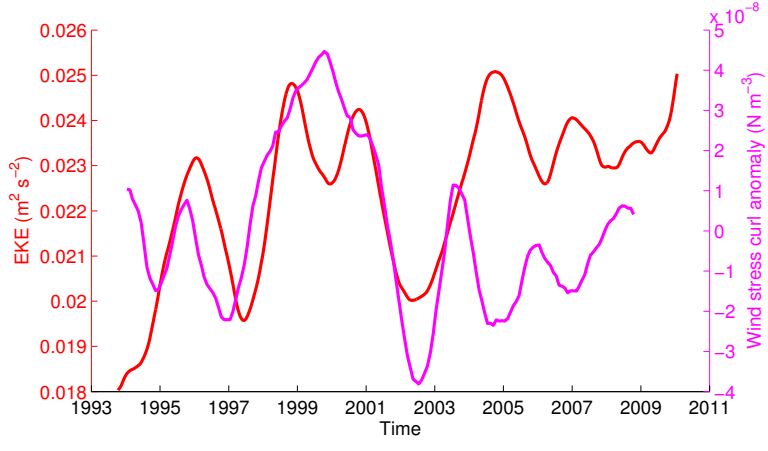

(b)

Figure 3.23: Time series of the area average local wind stress curl anomaly and EKE using a) a 13-month low-pass window and b) a 25-month low-pass window.

\subsubsection{Local indices}

Local climate indices are also examined to assess any influence of the local winds on the intensity of the confluence. Firstly, time series of the Z2 index is 
compared to the local wind stress curl to observe correlations between these local expressions of the wind forcing (Fig. 3.24). Both signals were smoothed with a 25-month running cosine window. Between 1997 and 2002, both signals show an increase in the anomalies, but outside of that period are anticorrelated, therefore the overall correlation is not significant $(r=0.4)$. However it is still worthwhile to further investigate the influence of the New Zealand local circulation and climate on the intensity of the confluence.

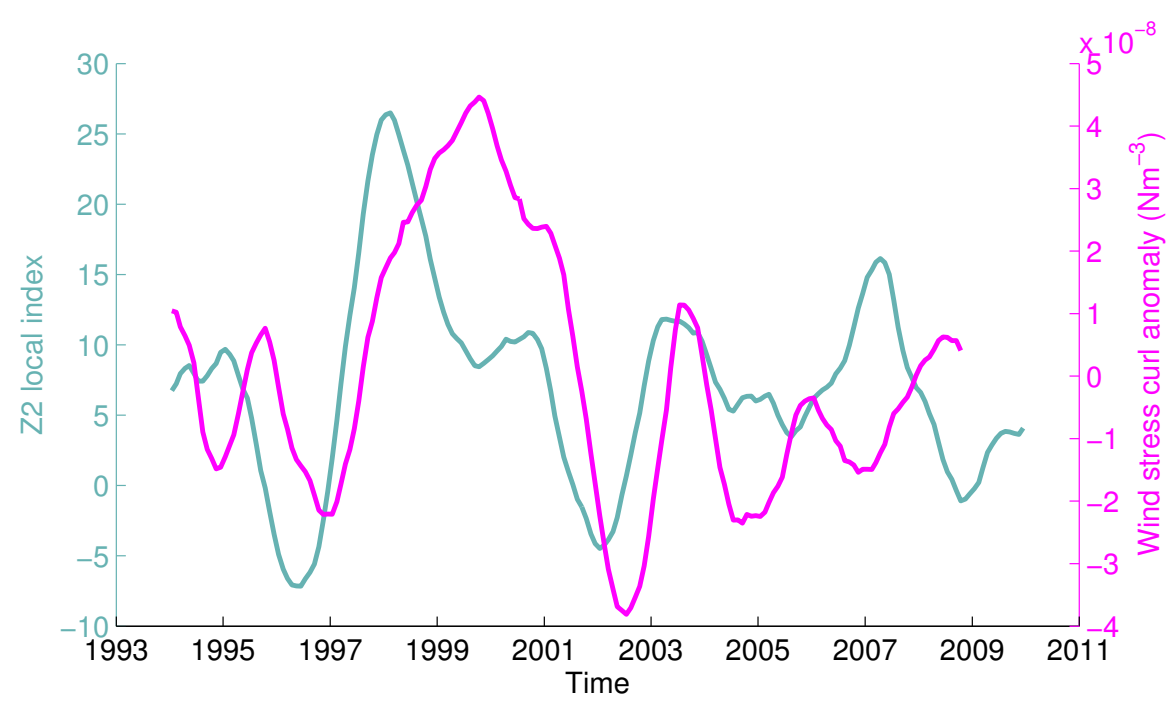

Figure 3.24: Local Z2 (in units $0.1 \mathrm{hPa}$ ) climate index compared to area average of local wind stress curl time series. Signals were smoothed to retain periods longer than 2 years.

The Z2 index is then compared to the time series of the $|\nabla S S H|$ (Fig. 3.25). Overall there is little correspondence between the two time series $(r=0.1$ and not significant) that were smoothed with a 25 -month running cosine window. The time series of the Z2 index does not show any obvious temporal trend either. 


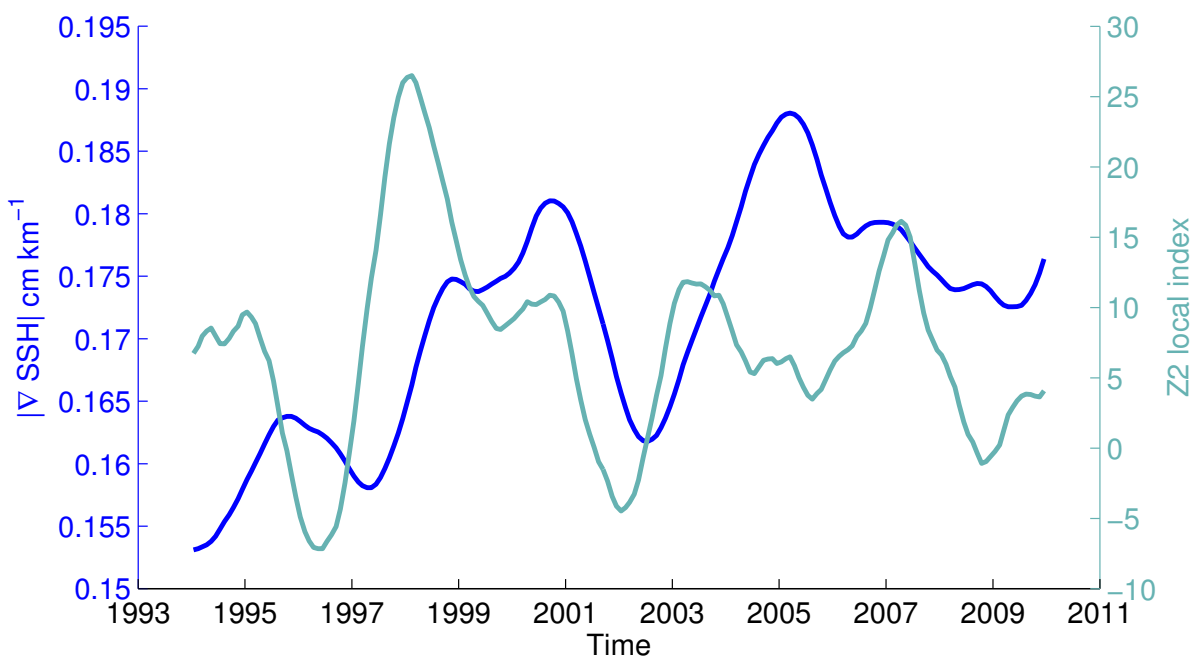

Figure 3.25: Local Z2 climate index and area average of $|\nabla S S H|$ time series. Periods shorter than 2 years were removed with a 25 -month cosine window. 


\section{Chapter 4}

\section{Discussion}

\subsection{Sea level anomalies}

The time series of the area average SLA in the confluence (Fig. 3.1) shows a positive trend of $3.4 \mathrm{~cm}$ per decade, from 1993 to 2010, in agreement with previous evidence of increasing SSH east of New Zealand during the last two decades (Qiu and Chen, 2006; Roemmich et al., 2007; Sokolov and Rintoul, 2009b). Roemmich et al. (2007) find more prominent signals of sea level rise at about $170^{\circ} \mathrm{W}$ and $40^{\circ} \mathrm{S}$, just north of the confluence. They attribute the rise in SSH of more than $12 \mathrm{~cm}$ between 1993 and 2004 to an increase in the wind stress curl east of New Zealand. Sokolov and Rintoul (2009b) also show increasing linear trends of over $6 \mathrm{~cm}$ from 1992 to 2007 in the SSH along the mean location of the fronts in the subantarctic zone, north of the SAF, for the longitudes of the confluence region east of New Zealand (their Figure 8).

A number of studies of SSH variability in the South Pacific estimate that a proportion of the Southern Hemisphere SSH rise is steric, i.e., an increase in water volume due to ocean warming (Vivier et al., 1999; Bowen et al., 2006; Morrow et al., 2008; Sutton and Roemmich, 2011). However, substantial in- 
creases in SSH immediately south of subtropical gyres and in WBC regions (Sokolov and Rintoul, 2009b) have been associated with an intensification of the wind stress curl (Qiu and Chen, 2006; Roemmich et al., 2007). Qiu and Chen (2006) show, just north of the confluence region, a positive trend in observed SSH anomalies of about $8.1 \mathrm{~mm} \mathrm{yr}^{-1}$ between 1997 and 2005 and about $4.9 \mathrm{~mm} \mathrm{yr}^{-1}$ in the same region from model simulations. They attribute these trends to large-scale wind forcing and propagation of baroclinic Rossby waves in the South Pacific. The results of the SLA variability described in this thesis show that trends in the confluence region are similar to trends previously found in larger-scale studies of the South Pacific and the ACC.

\subsection{Temporal and spatial variability of the con- fluence}

The variability of the confluence is described in terms of gradients of SSH (fronts) and EKE. The maximum mean value of $|\nabla S S H|$ is $0.33 \mathrm{~cm} \mathrm{~km}^{-1}$, which is in agreement with the mean SSH gradients of the ACC fronts, derived by Sokolov and Rintoul (2009b) in this region for a similar time period. Interannual variability of the confluence shows several years when SSH gradients exceeded $0.42 \mathrm{~cm} \mathrm{~km}^{-1}$, particularly northeast of Bollons Seamount. The spatial distribution and persistence of fronts over the western side of the confluence suggest that the topography may be playing a role in locating the fronts to the northeast of Bounty Plateau (Fig. 3.5). Furthermore, a sharp increase of the SSH gradients for all years observed between $177^{\circ} \mathrm{W}$ and $175^{\circ} \mathrm{W}$ suggests that Bollons Seamount affects the intensity of the fronts (Fig. 3.6). This interpretation is similar to that used by Moore et al. (1999) to explain the intensification

of the Polar Front within and downstream of large topographic features. Per- 
turbations generated in the SAF flow along the Bounty Plateau could also play a role in the eddy activity of the confluence region.

High eddy activity is observed northeast of Bollons Seamount for all years of the study. EKE in the confluence was previously described by Bryden and Heath (1985) in terms of historical hydrography, drifting buoys data and moored current meters and by Carter and Wilkin (1999) in model simulations. Bryden and Heath (1985) identify a deep reaching front (down to depths of $2000 \mathrm{~m}$ ) that marks the transition between SAW with salinities less than 34.5 and STW with salinities greater than 34.5. They report EKE at $1000 \mathrm{~m}$ of $0.0169 \mathrm{~m}^{2}$ $\mathrm{s}^{-2}$ comparable to levels in highly energetic regions at similar depth such as the Gulf Stream and Kuroshio extension in the Northern Hemisphere and the Drake Passage in the Southern Ocean. Carter and Wilkin (1999) estimate greater EKE levels at the same depth $\left(0.0193 \mathrm{~m}^{2} \mathrm{~s}^{-2}\right)$, and agree with Bryden and Heath (1985) that EKE is attenuated with increasing depth. A comparison with the results presented in this thesis requires some degree of caution; the mean EKE levels of $0.054 \mathrm{~m}^{2} \mathrm{~s}^{-2}$, are nearly three times the value found by these two previous studies. With respect to Bryden and Heath (1985), this may reflect that their values are from observations at $1000 \mathrm{~m}$ and extend over only 2 years (1978-1980) while those in this study are from stronger surface velocities and cover a longer time period. High EKE and intense SSH gradients east of the edge of Bounty Plateau and north of Bollons Seamount suggest that bathymetry in the western side of the confluence is an important factor in determining the location and extent of the fronts and the eddy activity.

Despite an overall decline of front intensity and eddy activity east of $174^{\circ} \mathrm{W}$ to about $168^{\circ} \mathrm{W}$, a temporal increase in the intensity of the SSH fronts and EKE levels persists, especially from 2006 to 2010 . East of $168^{\circ} \mathrm{W}$ there is no evident temporal pattern in SSH front and EKE variability. This is an interesting result since along these longitudes there are no direct bathymetric constraints for the 
flows. Therefore there must be some other mechanism explaining this trend in confluence intensity at this location. For example, an explanation for these zonal changes in confluence intensity and EKE may be an eastward migration of energy from generation near Bounty Plateau and Bollons Seamount to the eastern side of the confluence.

Latitudinal shifts of the confluence fronts were analysed by finding the latitude of the maxima SSH gradients (Fig. 3.7). There is an apparent shift of the more intense gradients to the north. However, this northward shift could be just a reflection of what is occurring in the western side of the confluence where the fronts and EKE are more intense, (as discussed above) due to the response of the currents to the edge of Bounty Plateau and Bollons Seamount.

The variability of the area average of SSH fronts and EKE are highly correlated suggesting that the eddy activity is directly related to the strength of the fronts. The correspondence is not because the gradients in SSH are predominantly associated with the eddies: the results are similar where the gradients across the fronts are calculated over much larger distances than those used for the EKE. An increase in the tilt of the isopycnals builds up potential energy that is converted to EKE through instabilities. The two signals tracking together reflects the generation of instabilities within the front as seen elsewhere in the ACC (Hogg and Blundell, 2006).

Experiments showing the sensitivity of the results to changes in the size and shape of the confluence area showed that the correlation between $|\nabla S S H|$ and EKE decreases from $r=0.86$ (Fig. 3.12) for the region enclosed by a box (Fig. 3.4) to $r=0.53$ and $r=0.18$ (Fig. 3.15 and 3.16) as the focus is on the region with higher EKE levels. Whereas northeast of Bollons Seamount there is a hotspot for front intensity and EKE, it appears that SSH gradients spread zonally towards the eastern edge of the confluence. The signals are clearly more variable than those for the confluence box as a whole, as the area over 
which they are calculated is reduced. It appears that the confluence box as a whole encompasses more of the total feature of the front and associated eddying including regions where the fronts and eddies are less prevalent.

The rise in SLA, plus an intensification of the area average of $|\nabla S S H|$ and EKE also coincide with an increasing trend in the temperature difference across the confluence (Fig. 3.17). Despite a slight decrease from 2006 to 2010 in the area average of $|\nabla S S H|$, a correspondence is observed between increasing trends in SST and SSH gradients in the region as well as an increase in EKE (since EKE is well correlated to $\mathrm{SSH})$.

In 1997-1998 SSH fronts experienced a significant increase in amplitude and southward shift of the isotherms (Fig. 3.18) implying that the confluence was more intense while the immediate region to the west was warmer than normal. Uddstrom and Oien (1999) observed a warming phase of the Tasman Sea starting in late 1996 and ending in early 1998, which coincided with the occurrence of a strong El Niño episode. They attribute this warming phase to an increased tropical inflow of the SPSG that warmed the Tasman Sea and northern New Zealand waters, and eventually flowed southeast of New Zealand. Because Uddstrom and Oien (1999) used a short time series (1993-1998), it cannot be established a longer time correspondence between the analysis of the SST anomalies difference across the confluence and their results of the SST variability east of New Zealand. Sutton et al. (2005), used expendable bathythermographs (XBTs) and a longer time series (1991-2005), to corroborate the warming of the Tasman Sea. However, the warming Sutton et al. (2005) detected occurred over a longer period from 1996 to 2002. After analysing the plausible sources of warming and dismissing local forcings, Sutton et al. (2005) conclude that this warming is likely forced from the South Pacific gyre. These studies suggest the warming of subtropical water in 1997-1998 and associated increase in temperature difference across the confluence region were part of a large-scale response 
in the South Pacific. 


\subsection{Confluence response to wind forcing}

To estimate the influence of South Pacific winds on confluence variability, I used the Island Rule and the climate indices SAM and SOI. Local wind forcing was investigated using local wind stress curl and the local index, Z2.

The Island Rule links the basin-scale wind forcing with transport of the WBCs that feed the confluence. Figure 3.20 shows that transport anomalies in the confluence have increased at a rate of $8.8 \mathrm{~Sv}$ per decade. A more qualitative analysis of the trend in transports indicates that the confluence is intensifying with time, i.e., increasing convergence of the flow, which coincides with the strengthening of the fronts. Toggweiler et al. (2006) suggest a strengthening of the ACC which could potentially be related to this increase in transport anomalies. However, the analysis of the temperature anomalies difference across the confluence (Fig. 3.18) shows no clear trend in temperature differences that would point to the ACC inflow increasing. An alternative explanation is provided by the Island Rule, bearing in mind its limitations, which indicates more southward flow increasing the intensity of the convergence.

Trends in the strength and location of the fronts and the EKE have been linked in this study to wind stress curl over the South Pacific and convergence of WBC transports from the Island Rule. Sokolov and Rintoul (2009b) showed that in the circumpolar average there is a southward migration of the SSH fronts explaining the overall warming of the Southern Ocean (Gille, 2002) and the rise of SSH. Lumpkin and Garzoli (2011) also found a southward shift of the BrazilMalvinas confluence in the South Atlantic in response to a southward shift of the wind stress curl. The location of the fronts, as indicated by the zero contour in meridional transports from the Island Rule, has an apparent southward trend (Fig. 3.19), in contrast to the observations which show a northward shift of the more intense fronts north of Bollons Seamount (Fig. 3.7). While the trend 
in front location appears to be poorly resolved by the Island Rule due to the limitations imposed by assuming linear dynamics, a steady-state and negligible friction (also outlined in Section 2.5.5), the intensification of the SSH fronts and EKE is supported by increasing transport at the confluence of WBCs.

The comparison of the climate indices, SAM and SOI, aimed to determine a relationship between the confluence intensity and eddy activity, and the principal modes of atmospheric variability of the South Pacific. The strength of the front and EKE have little correspondence with either SAM and SOI (Fig. 3.21). Previous studies indicate a combination of these two indices correlates with ocean variability. For example, Morrow et al. (2010) find EKE levels (in the Circumpolar average) peak 2-3 years after a positive SAM event coincides with La Niña and the South Pacific experiences stronger meridional winds. Between 1997 and 1999 the confluence registered relative maxima in SSH gradients and EKE (Fig. 3.12), coinciding with positive SAM and La Niña. However, this combination cannot explain the increased SSH gradients and EKE during 2003-2005, when positive SAM is in phase with El Niño.

Sallée et al. (2008b) also use a combination of SAM and SOI to characterise the response of the fronts of the ACC. For the Indo-Pacific sector they find the fronts shift polewards during positive SAM and El Niño. Observations show that the more intense fronts in the confluence shifted northwards. However, the signal representing this latitudinal migration of the fronts is too subtle to infer a direct influence of the climate modes on their location. The intensification of the fronts in the confluence, however, could be influenced by the increasing trend towards positive phases of SAM, as suggested by Marshall (2003), occurring during La Niña, which could enhance the transports of the ACC and the SAF flows into the confluence.

The effect of the local wind stress curl was also compared to the intensity of the confluence (Fig. 3.22). While there is close correspondence between 1994 


\section{Discussion}

and 2003 and strong anticorrelation between 2004 and 2010, the periods are short and contradictory and do not confirm a relationship between local winds and confluence intensity. The local index Z2 for New Zealand also appears to be unrelated to the confluence intensity. 


\section{Chapter 5}

\section{Conclusions}

\subsection{Summary of results}

The motivating question for this thesis is:

Do the South Pacific winds control the variability of the confluence region east of New Zealand?

To find the link between winds and ocean dynamics, the confluence was studied in terms of temporal and spatial variability of SSH fronts and EKE, these results were compared to winds and other forcing mechanisms that could explain the observed variability between 1993 and 2010 .

The presence of persistent SSH gradients east of Bounty Plateau and north of Bollons Seamount suggest there is a bathymetric preference for the front location on the western side of the confluence region. The eastern side, where deep relief does not impede the flow of the convergent currents, shows no obvious temporal or spatial trend.

A close correspondence between the area average of SSH fronts and EKE suggest a direct response of eddy activity to increasing frontal strength through 
the generation of baroclinic instabilities.

The key results are the increasing trends in the area average of SLA, SSH gradients and EKE, coinciding with an upward trend in the anomalies of the SST differences across the confluence. Increasing trends are also found in the South Pacific wind stress curl and the convergence in the WBCs derived from the Island Rule. These positive trends potentially establish a link between South Pacific winds and intensity of the confluence, indicating that large-scale winds may be the controlling influence of the convergence of STW and SAW.

Links between Southern Hemisphere climate indices and higher frequency variability in the time series of intensity of the confluence are not straightforward. For instance, the strong 1997-1998 ENSO event had an influence on the South Pacific region (Morrow et al., 2010), but neither SOI or SAM have much correspondence with the variability in the confluence over the time series as a whole. Combinations of the climate indices, such as positive SAM coincident with La Niña when wind forcing is enhanced (Sallée et al., 2008b), are not well correlated with increasing SSH gradients.

The analysis of local winds suggests little or no influence of the local wind stress curl and local climate indices in the position and intensity of the confluence. Despite some correspondence between front intensity and local winds between 1994 and 2003, there is no evident trend in local wind stress curl or climate indices that could support the positive trend of the SSH fronts and EKE.

In summary, variability in the confluence region east of New Zealand appears to be more connected to basin-scale winds than to local winds. This connection is through increasing trends in SLA, SSH gradients, EKE, and SST difference across the confluence that correlate with increasing trends in wind stress curl in the South Pacific and increasing transport at the confluence of WBCs estimated 
via the Island Rule. Although intensity of the fronts and eddy activity may be linked to the large-scale winds, bathymetry appears to locate the strongest SSH fronts and EKE to the edges of the Bounty Plateau and Bollons Seamount.

\subsection{Implications for the past and future oceanog- raphy of the region}

Assessing the connection between winds and the modern ocean is crucial to improving assessments of past ocean/climate change much of which has been based mainly on environmental proxies from widely scattered marine sediment cores. In the case of ocean fronts, paleooceangraphers have traditionally relied on proxies of sea surface temperatures as well as microfossil assemblages to identify approximate locations and extent of ocean fronts over G-I cycles, transitions between warmer and colder climates driven by orbital forcing (Milankovich, 1930), with little or no information on the role of winds affecting frontal position or dynamics (Howard and Prell, 1992; Crundwell et al., 2008; Hayward et al., 2008). Such interpretations have been hampered by widely spaced data points that fail to accurately capture the temperature and salinity gradients that characterise frontal systems (e.g., Gersonde et al. (2005)).

While this study did not find a clear correlation between meridional shifts of the confluence location and the wind stress curl, it did substantiate a link between increasing intensity of the large-scale wind stress curl and the intensity of the fronts. This link could potentially be used to infer changes in the volume of the transport of the WBCs east of New Zealand that feed the confluence and, moreover, the intensity of the confluence used as a proxy for the intensity of South Pacific winds. In that context, reconstruction of past frontal systems would allow assessment of changes in strength of westerly zonal winds in the re- 
gion over G-I cycles. Such reconstructions, especially for those warm interglacial periods when temperatures were $1^{\circ}-2^{\circ} \mathrm{C}$ warmer than present, would be valuable analogues for projecting the behaviour of these main flows that dominate the ocean and climate around New Zealand.

A better understanding of the connection between the winds and the fronts can also improve projections of the climate and ocean state around New Zealand. The results of this study suggest that if wind stress curl continues to increase, front intensity and EKE will increase, leading to more vigorous transport of heat, nutrients, and more intense mixing processes in this region. This is likely to have a significant impact on the local ecosystems, since the base of the marine food chain, phytoplankton, depends upon nutrient availability, temperature, light levels and oceanographic processes that affect the ocean upwelling and surface mixing (Longhurst, 1995). This is particularly relevant for the STF off eastern New Zealand, where the mixing of macro-nutrient rich SAW with micronutrient rich STW is the basis of a strongly productive region that supports significant fisheries of economical importance to New Zealand (Murphy et al., 2001).

\subsection{Future work}

Some results arising from this thesis leave some unanswered questions that could be subject of future work:

A limitation of this study is the inability to track confidently meridional shifts of the fronts in regions free of bathymetric influence. Defining a criterion for the latitude of the confluence may provide an alternative. For example, using along-track satellite SSH Lumpkin and Garzoli (2011) define the latitude of the Brazil-Malvinas confluence as the latitude of $3 / 4$ of the range between 
the Malvinas minimum and the Brazil maximum sea height. The next step would be to find correlations (and lagged correlations) between the time series of the confluence latitude and the latitude of the southern boundary of the SPSG circulation, i.e., the location of the zero wind stress curl (Cai, 2006). The comparison of these time series would allow meridional shifts of the confluence to be followed and related to shifts in the wind-driven SPSG circulation. It would be interesting to test the hypothesis that a southward intensification of the SPSG causes a southward shift of the fronts as is happening with the main ACC fronts.

A substantial contribution to the assessment of the variability of the confluence could result from a thorough modelling study. This approach would require simulations that permit removal of bathymetry and the ability to introduce stratification and friction, important parameters for resolving fronts and eddies in the region.

This study could be extended by analysing SST data, by resolving thermal fronts, as it has a longer time record and higher resolution than the SSH data, and could therefore provide more details of the frontal structure and eddies in the region.

\subsection{Concluding thoughts}

Currently, the availability of remote sensed data, in situ observations and numerical simulations provide numerous ways to gain an insight into oceanatmosphere interactions. Observational and model studies are showing that winds rather than buoyancy forcing drive the large-scale circulation of the oceans (Visbeck et al., 1998; Hall and Visbeck, 2002; Hill et al., 2008; Andres et al., 2011; Hill et al., 2011). As a result, physical oceanography is undergoing a 
fundamental re-evaluation of the role of winds in not only forcing the surface gyre circulation, but also in driving deep circulation through the transfer of momentum from the surface (Lozier, 2010). The results of this thesis could help to improve interpretations of the connection between large-scale winds and the ocean currents. 


\section{Bibliography}

Agra, C. and Nof, D. (1993). Collision and separation of boundary currents. Deep Sea Research Part I: Oceanographic Research Papers, 40(11-12):22592282.

Altimetry, A. (2006). Ssalto/Duacs user handbook:(M) SLA and (M) ADT near-real time and delayed time products. Report CLS-DOS-NT, 6 .

Andres, M., Kwon, Y., and Yang, J. (2011). Observations of the Kuroshio's barotropic and baroclinic responses to basin-wide wind forcing. Journal of Geophysical Research (Oceans), 116(C15):04011.

Belkin, I. and Gordon, A. (1996). Southern Ocean fronts from the Greenwich meridian to Tasmania. Journal of Geophysical Research, 101(C2):3675-3696.

Böning, C., Dispert, A., Visbeck, M., Rintoul, S., and Schwarzkopf, F. (2008). The response of the Antarctic Circumpolar Current to recent climate change. Nature Geoscience, 1(12):864-869.

Bowen, M., Sutton, P., and Roemmich, D. (2006). Wind-driven and steric fluctuations of sea surface height in the Southwest Pacific. Geophysical Research Letters, 33(14):L14617.

Bryden, H. and Heath, R. (1985). Energetic eddies at the northern edge of the Antarctic Circumpolar Current in the Southwest Pacific. Progress in Oceanography, 14:65-87. 
Cai, W. (2006). Antarctic ozone depletion causes an intensification of the Southern Ocean super-gyre circulation. Geophysical Research Letters, 33(3):L03712.

Carter, L. and Wilkin, J. (1999). Abyssal circulation around New Zealand A comparison between observations and a global circulation model. Marine Geology, 159(1):221-239.

Chelton, D., Ries, J., Haines, B., Fu, L., Callahan, P., Fu, L., and Cazanave, A. (2001). Satellite altimetry and earth sciences. Academic Press, International Geophysics Series, 69:1-1131.

Chelton, D., Schlax, M., Freilich, M., and Milliff, R. (2004). Satellite measurements reveal persistent small-scale features in ocean winds. Science, 303(5660):978.

Chen, S. and Qiu, B. (2010). Mesoscale eddies northeast of the Hawaiian archipelago from satellite altimeter observations. Journal of Geophysical Research, 115:C03016.

Chiswell, S. and Sutton, P. (1998). A deep eddy in the Antarctic Intermediate Water north of the Chatham Rise. Journal of Physical Oceanography, $28(3): 535-540$

Colling, A. (2001). Ocean circulation, volume 3. Butterworth-Heinemann, Oxford, 286pp.

Crundwell, M., Scott, G., Naish, T., and Carter, L. (2008). Glacial-interglacial ocean climate variability from planktonic foraminifera during the midpleistocene transition in the temperate Southwest Pacific, ODP Site 1123. Palaeogeography, Palaeoclimatology, Palaeoecology, 260(1):202-229.

Deacon, S. (1937). The hydrology of the Southern Ocean. Cambridge University Press, 124pp. 
Ducet, N., Le Traon, P., and Reverdin, G. (2000). Global high-resolution mapping of ocean circulation from TOPEX/Poseidon and ERS-1 and-2. Journal of Geophysical Research, 105(C8):19477.

Emery, W. (1977). Antarctic polar frontal zone from Australia to the Drake Passage. Journal of Physical Oceanography, 7:811-822.

Emery, W. and Thomson, R. (2001). Data analysis methods in physical oceanography. Elsevier Science, Amsterdam, 654pp.

Firing, E., Qiu, B., and Miao, W. (1999). Time-Dependent Island Rule and Its Application to the Time-Varying North Hawaiian Ridge Current. Journal of Physical Oceanography, 29(10):2671-2688.

Fu, L. and Cazenave, A. (2001). Satellite altimetry and earth sciences: a handbook of techniques and applications, volume 69. Academic Press, California.

Gersonde, R., Crosta, X., Abelmann, A., and Armand, L. (2005). Sea-surface temperature and sea ice distribution of the Southern Ocean at the EPILOG Last Glacial Maximum - a circum-Antarctic view based on siliceous microfossil records. Quaternary Science Reviews, 24(7-9):869-896.

Gille, S. (2002). Warming of the Southern Ocean since the 1950s. Science, 295(5558):1275.

Godfrey, J. (1989). A Sverdrup model of the depth-integrated flow for the world ocean allowing for island circulations. Geophysical \& Astrophysical Fluid Dynamics, 45(1):89-112.

Gong, D. and Wang, S. (1999). Definition of Antarctic oscillation index. Geophysical Research Letters, 26(4):459-462. 
Gordon, A. (1972). On the interaction of the Antarctic Circumpolar Current and the Macquarie Ridge. Antarctic Oceanology II: The Australian-New Zealand Sector, Antarctic Research Series, 19:71-78.

Hall, A. and Visbeck, M. (2002). Synchronous Variability in the Southern Hemisphere Atmosphere, Sea Ice, and Ocean Resulting from the Annular Mode . Journal of Climate, 15:3043-3057.

Hayward, B., Scott, G., Crundwell, M., Kennett, J., Carter, L., Neil, H., Sabaa, A., Wilson, K., Rodger, J., Schaefer, G., et al. (2008). The effect of submerged plateaux on pleistocene gyral circulation and sea-surface temperatures in the Southwest Pacific. Global and Planetary Change, 63(4):309-316.

Heath, R. (1985). A review of the physical oceanography of the seas around New Zealand -1982. New Zealand Journal of Marine and Freshwater Research, 19(1):79-124.

Hesse, P. (1994). The record of continental dust from Australia in Tasman Sea sediments. Quaternary Science Reviews, 13(3):257-272.

Hill, K., Rintoul, S., Coleman, R., and Ridgway, K. (2008). Wind forced low frequency variability of the East Australian Current. Geophysical Research Letters, 35(8):L08602.

Hill, K., Rintoul, S., Ridgway, K., and Oke, P. (2011). Decadal changes in the South Pacific Western Boundary Current system revealed in observations and ocean state estimates. Journal of Geophysical Research, 116(C1):C01009.

Hogg, A. and Blundell, J. (2006). Interdecadal variability of the Southern Ocean. Journal of Physical Oceanography, 36(8):1626-1645.

Howard, W. and Prell, W. (1992). Late quaternary surface circulation of the southern Indian Ocean and its relationship to orbital variations. Paleoceanography, $7(1): 79-117$. 
Kalnay, E., Kanamitsu, M., Kistler, R., Collins, W., Deaven, D., Gandin, L., Iredell, M., Saha, S., White, G., Woollen, J., et al. (1996). The NCEP/NCAR 40-year reanalysis project. Bulletin of the American Meteorological Society, $77(3): 437-471$.

Lamy, F., Hebbeln, D., and Wefer, G. (1999). High-Resolution Marine Record of Climatic Change in Mid-latitude Chile during the last 28,000 Years Based on Terrigenous Sediment Parameters. Quaternary Research, 51(1):83-93.

Longhurst, A. (1995). Seasonal cycles of pelagic production and consumption. Progress in Oceanography, 36(2):77-167.

Lozier, M. (2010). Deconstructing the conveyor belt. Science, 328(5985):1507.

Lumpkin, R. and Garzoli, S. (2011). Interannual to decadal changes in the western South Atlantics surface circulation. Journal of Geophysical Research, 116:C01014.

Marshall, G. (2003). Trends in the Southern Annular Mode from observations and reanalyses. Journal of Climate, 16(24):4134-4143.

Marshall, G. (2007). Half-century seasonal relationships between the Southern Annular mode and Antarctic temperatures. International Journal of Climatology, 27(3):373-383.

Meredith, M. and Hogg, A. (2006). Circumpolar response of Southern Ocean eddy activity to a change in the Southern Annular Mode. Geophysical Research Letters, 33(16):L16608.

Milankovich, M. (1930). Mathematische Klimalehre und astronomische. Theorie der Klimaschwankungen Handbuch der Klimatologie, Bd. I.: Berlin, Verlag. Borntrager. 
Moore, J., Abbott, M., and Richman, J. (1999). Location and dynamics of the Antarctic Polar Front from satellite sea surface temperature data. Journal of Geophysical Research, 104(C2):3059-3073.

Morris, M., Stanton, B., and Neil, H. (2001). Subantarctic oceanography around New Zealand: preliminary results from an ongoing survey. New Zealand Journal of Marine and Freshwater Research, 35(3):499-519.

Morrow, R., Church, J., Coleman, R., Chelton, D., and White, N. (1992). Eddy momentum flux and its contribution to the Southern Ocean momentum balance. Nature, 357(6378):482-484.

Morrow, R., Valladeau, G., and Sallee, J. (2008). Observed subsurface signature of Southern Ocean sea level rise. Progress in Oceanography, 77(4):351-366.

Morrow, R., Ward, M., Hogg, A., and Pasquet, S. (2010). Eddy response to Southern Ocean climate modes. Journal of Geophysical Research, 115(C10):C10030.

Murphy, R., Pinkerton, M., Richardson, K., Bradford-Grieve, J., and Boyd, P. (2001). Phytoplankton distributions around New Zealand derived from SeaWiFS remotely-sensed ocean colour data. New Zealand Journal of Marine and Freshwater Research, 35(2):343-362.

Orsi, A., Whitworth, T., et al. (1995). On the meridional extent and fronts of the Antarctic Circumpolar Current. Deep Sea Research Part I: Oceanographic Research Papers, 42(5):641-673.

Pedlosky, J., Pratt, L., Spall, M., and Helfrich, K. (1997). Circulation around islands and ridges. Journal of Marine Research, 55(6):1199-1251.

Philander, S. (1983). El Niño Southern Oscillation phenomena. Nature, 302:295301. 
Pond, S. and Pickard, G. (1983). Introductory dynamical oceanography. Bergamon, New York, 329pp.

Qiu, B. and Chen, S. (2006). Decadal variability in the large-scale sea surface height field of the South Pacific Ocean: Observations and causes. Journal of Physical Oceanography, 36(9):1751-1762.

Qiu, B. and Chen, S. (2010). Eddy-mean flow interaction in the decadally modulating Kuroshio Extension system. Deep Sea Research Part II: Topical Studies in Oceanography, 57(13-14):1098-1110.

Renwick, J. and Thompson, D. (2006). The Southern Annular Mode and New Zealand climate. Water and Atmosphere, 14(2):24-25.

Reynolds, R., Rayner, N., Smith, T., Stokes, D., and Wang, W. (2002). An improved in situ and satellite SST analysis for climate. Journal of Climate, 15(13):1609-1625.

Rio, M., Guinehut, S., and Larnicol, G. (2011). New CNES-CLS09 global mean dynamic topography computed from the combination of GRACE data, altimetry, and in situ measurements. Journal of Geophysical Research, 116(C7):C07018.

Roemmich, D., Gilson, J., Davis, R., Sutton, P., Wijffels, S., and Riser, S. (2007). Decadal spinup of the South Pacific subtropical gyre. Journal of Physical Oceanography, 37(2):162-173.

Roemmich, D., Johnson, G., Riser, S., Davis, R., Gilson, J., Owens, W., Garzoli, S., Schmid, C., and Ignaszewski, M. (2009). The Argo program: Observing the global ocean with profiling floats. Oceanography, 22(2):34-43.

Sallée, J., Morrow, R., and Speer, K. (2008a). Eddy heat diffusion and Subantarctic Mode Water formation. Geophysical Research Letters, 35:L05607. 
Sallée, J., Speer, K., and Morrow, R. (2008b). Response of the Antarctic Circumpolar Current to atmospheric variability. Journal of Climate, 21(12):3020-3039.

Sokolov, S. and Rintoul, S. (2007). Multiple Jets of the Antarctic Circumpolar Current South of Australia. Journal of Physical Oceanography, 37(5):13941412.

Sokolov, S. and Rintoul, S. (2009a). Circumpolar structure and distribution of the Antarctic Circumpolar Current fronts: 1. Mean circumpolar paths. Journal of Geophysical Research, 114(C11):C11018.

Sokolov, S. and Rintoul, S. (2009b). Circumpolar structure and distribution of the Antarctic Circumpolar Current fronts: 2. Variability and relationship to sea surface height. Journal of Geophysical Research, 114(C11):C11019.

Stammer, D. (1997). Global characteristics of ocean variability estimated from regional topex/poseidon altimeter measurements. Journal of Physical Oceanography, 27(8):1743-1769.

Stanton, B. (2001). Estimating the East Auckland Current transport from model winds and the Island Rule. New Zealand Journal of Marine and Freshwater Research, 35(3):531-540.

Stanton, B. and Morris, M. (2004). Direct velocity measurements in the Subantarctic Front and over Campbell Plateau, southeast of New Zealand. Journal of Geophysical Research, 109(C1):C01028.

Stewart, R. and Texas, A. (2005). Introduction to Physical Oceanography. Texas A \& M University, 353pp.

Sutton, P. and Roemmich, D. (2011). Decadal steric and sea surface height changes in the Southern Hemisphere. Geophysical Research Letters, 38(8):L08604. 
Thompson, A. and Richards, K. (2011). Low frequency variability of Southern Ocean jets. Journal of Geophysical Research, 116(C9):C09022.

Thompson, D. and Solomon, S. (2002). Interpretation of recent Southern Hemisphere climate change. Science, 296(5569):895.

Toggweiler, J., Russell, J., and Carson, S. (2006). Midlatitude westerlies, atmospheric $\mathrm{CO}_{2}$, and climate change during the ice ages. Paleoceanography, $21(2)$.

Trenberth, K. (1976). Fluctuations and trends in indices of the southern hemispheric circulation. Quarterly Journal of the Royal Meteorological Society, 102(431):65-75.

Trenberth, K. and Caron, J. (2001). Estimates of meridional atmosphere and ocean heat transports. Journal of Climate, 14(16):3433-3443.

Troup, A. (1965). The southern oscillation. Quarterly Journal of the Royal Meteorological Society, 91(390):490-506.

Uddstrom, M. and Oien, N. (1999). On the use of high-resolution satellite data to describe the spatial and temporal variability of sea surface temperatures in the New Zealand region. Journal of Geophysical Research, 104(C9):20729-20.

Visbeck, M., Cullen, H., Krahmann, G., and Naik, N. (1998). Ocean model's response to North Atlantic Oscillation-like wind forcing. Geophysical Research Letters, 25(24):4521-4524.

Vivier, F., Kelly, K., and Thompson, L. (1999). Contributions of wind forcing, waves, and surface heating to sea surface height observations in the Pacific Ocean. Journal of Geophysical Research, 104(C9):20767-20. 
Wainer, I., Gent, P., and Goni, G. (2000). Annual cycle of the Brazil-Malvinas Confluence region in the National Center for Atmospheric Research climate system model. Journal of Geophysical Research, 105(C11):26167-26.

Williams, M. (2004). Analysis of quasi-synoptic eddy observations in the New Zealand subantarctic. New Zealand Journal of Marine and Freshwater Research, 38(1):183-194.

Yoshida, S., Qiu, B., and Hacker, P. (2010). Wind-generated eddy characteristics in the lee of the island of Hawaii. Journal of Geophysical Research, 115(C3):C03019. 